\title{
Factors in the Successful Implementation of Six Sigma in Canadian Manufacturing Firms
}

$6 \sigma$

\section{MBA Thesis}

\author{
By: \\ David Tran
}

A Thesis submitted to the Faculty of Graduate Studies and Research in partial fulfiliment of the requirements for the degree of

Master of Business Administration

Eric Sprott School of Business

Carleton University

Ottawa, Ontario

May 23, 2006

(C) Copyright

2006, David Tran 


$\begin{array}{ll}\begin{array}{l}\text { Library and } \\ \text { Archives Canada }\end{array} & \begin{array}{l}\text { Bibliothèque et } \\ \text { Archives Canada }\end{array} \\ \begin{array}{l}\text { Published Heritage } \\ \text { Branch }\end{array} & \begin{array}{l}\text { Direction du } \\ \text { Patrimoine de l'édition }\end{array} \\ \begin{array}{l}\text { 395 Wellington Street } \\ \text { Ottawa ON K1A 0N4 } \\ \text { Canada }\end{array} & \begin{array}{l}\text { 395, rue Wellington } \\ \text { Ottawa ON K1A ON4 } \\ \text { Canada }\end{array}\end{array}$

Your file Votre référence ISBN: 978-0-494-16479-2 Our file Notre référence ISBN: 978-0-494-16479-2

NOTICE:

The author has granted a nonexclusive license allowing Library and Archives Canada to reproduce, publish, archive, preserve, conserve, communicate to the public by telecommunication or on the Internet, loan, distribute and sell theses worldwide, for commercial or noncommercial purposes, in microform, paper, electronic and/or any other formats.

The author retains copyright ownership and moral rights in this thesis. Neither the thesis nor substantial extracts from it may be printed or otherwise reproduced without the author's permission.
AVIS:

L'auteur a accordé une licence non exclusive permettant à la Bibliothèque et Archives Canada de reproduire, publier, archiver, sauvegarder, conserver, transmettre au public par télécommunication ou par l'Internet, prêter, distribuer et vendre des thèses partout dans le monde, à des fins commerciales ou autres, sur support microforme, papier, électronique et/ou autres formats.

L'auteur conserve la propriété du droit d'auteur et des droits moraux qui protège cette thèse. $\mathrm{Ni}$ la thèse ni des extraits substantiels de celle-ci ne doivent être imprimés ou autrement reproduits sans son autorisation.
In compliance with the Canadian

Privacy Act some supporting forms may have been removed from this thesis.

While these forms may be included in the document page count, their removal does not represent any loss of content from the thesis.
Conformément à la loi canadienne sur la protection de la vie privée, quelques formulaires secondaires ont été enlevés de cette thèse.

Bien que ces formulaires aient inclus dans la pagination, il n'y aura aucun contenu manquant.

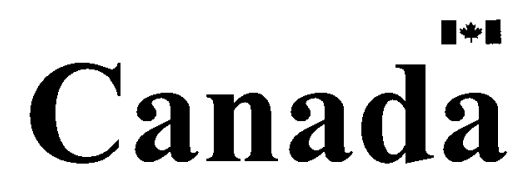




\section{FACTORS IN THE SUCCESSFUL IMPLEMENTATION OF SIX SIGMA IN CANADIAN MANUFACTURING FIRMS}

by

David Tran

\section{Abstract}

The objective of this research is to identify the factors that contribute to the successful implementation of Six Sigma. Surveys were forwarded to 230 potential respondents which resulted in a response of 35 . Potential respondents were obtained from the researcher's own compilation from the literature reviewed and from a listing on the iSixSigma.com website.

Sixteen variables (Financial Support; Integrating Six Sigma to Business Strategy; Management Involvement \& Commitment; Organizational Infrastructure; Integrating Six Sigma to Human Resources; Integrating Six Sigma to Suppliers; Training; Project Management Skills; Project Prioritization, Selection, Review \& Tracking; Understand Six Sigma Methodology, Tools \& Techniques; Statistical Tools; Rewards; Corporate Culture; Linking Six Sigma to the Customer; Communication; and Goal Setting) were considered as distinguishing factors. Further to these variables, four groups were established based on these variables' characteristics. These groups included Financing Six Sigma, Integration Strategy for Six Sigma, Managerial System for Six Sigma and Six Sigma Educational Underpinnings. 
These independent variables were gauged using five different measures of Six Sigma success (Financial, Defects Per Million Opportunities, Customer Satisfaction, Performance of Internal Work Processes, and Suppliers' Performance). The factors leading to success were hypothesized and tested using Stepwise Multiple Linear Regression Analysis. The analysis reveals that there was a specific grouping which affected each measure of Six Sigma success the most. For the Six Sigma successes of Financial and Performance of Internal Work Processes, Managerial System for Six Sigma affected them the most. For the Six Sigma success of Defects per Million Opportunities, Customer Satisfaction and Suppliers' Performance, Integration Strategy for Six Sigma turned out as the factors that lead to their success the most. 


\section{Acknowledgements}

I would like to thank a number of people for the completion of my thesis because without their support and encouragement this thesis would have never been completed. It was Professor Michael Armstrong who guided me towards the idea of putting together this thesis topic, and I am grateful to him for this. My thesis supervisor, Professor Vinod Kumar, assisted me in formalizing and putting into place my thoughts into a viable research topic and has been very helpful with resources for this research. Professor Kumar constantly guided me with his valuable comments and suggestions for improvement. Professor Aaron Nsakanda and Professor George Haines' input and guidance with respect to the formation of this research is greatly appreciated. I would also like to thank my significant other, Sara Wilson, for her motivation and encouragement to completing this thesis because without her constant support, I may still be trying to complete this study. Lastly, I'd like to thank the rest of my family for their support and patience throughout this period. 


\section{Table of Contents}

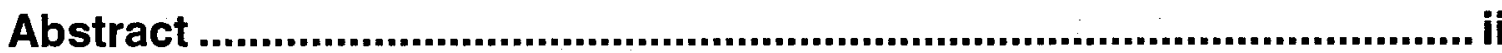

Acknowledgements .................................................................................. iv

List of Tables.............................................................................................. vii

List of Figures ............................................................................................. viii

List of Appendices................................................................................. viii

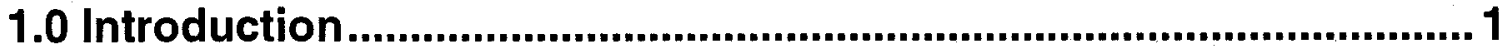

2.0 Literature Review............................................................................. 4

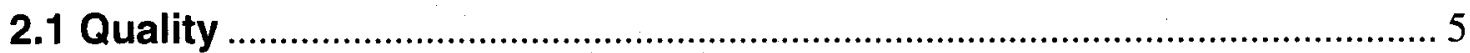

2.2 Costs of Poor Quality ...............................................................................

2.3 The History of Six Sigma....................................................................... 10

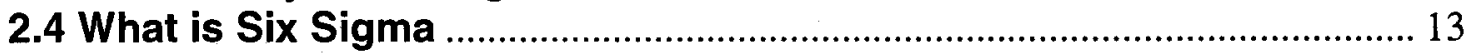

2.5 The Six Sigma Roadmap ................................................................... 17

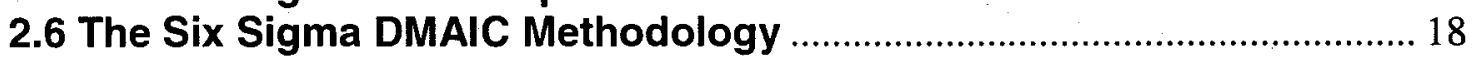

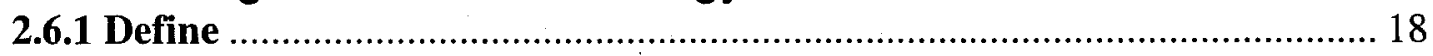

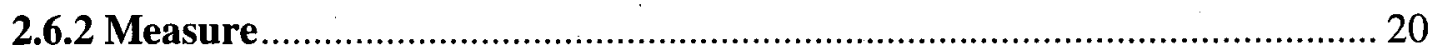

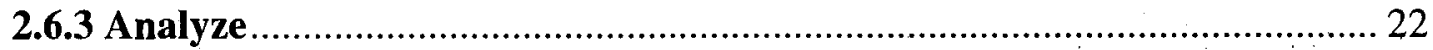

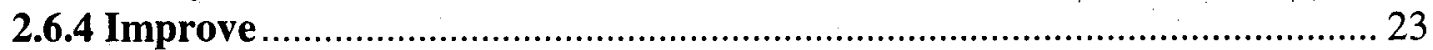

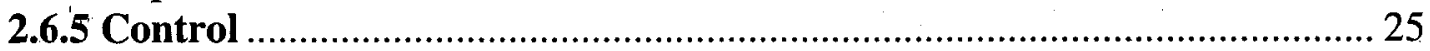

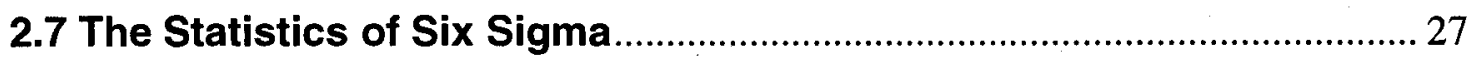

2.8 Design For Six Sigma (DFSS) / DMADV ................................................... 32

2.9 The Six Sigma Business Scorecard ....................................................... 35

2.10 The Six Sigma Belt System …………………..................................... 36

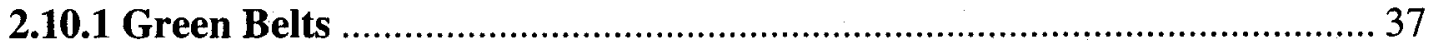

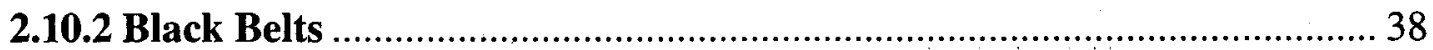

2.10.3 Master Black Belts .................................................................................... 39

2.10.4 Six Sigma Project Champions and Sponsors........................................... 40

2.11 Evidence of Six Sigma Success............................................................ 42

2.12 Why Six Sigma is not Total Quality Management (TQM)...................... 45

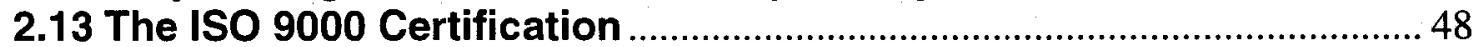

3.0 Theoretical Framework ....................................................................51

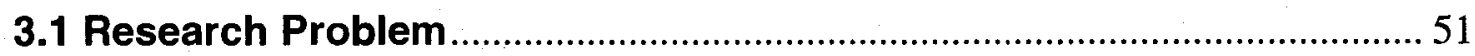

3.2 Research Objectives .................................................................................. 51

3.3 Factors in the Successful Implementation of Six Sigma........................ 52

3.4 How Success is Measured in the Implementation of Six Sigma ...........6 63

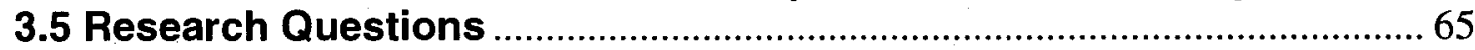

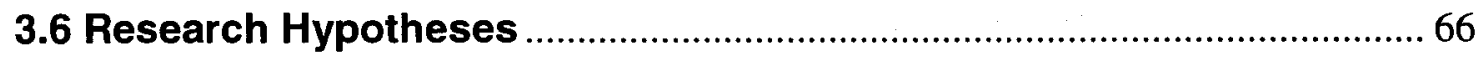

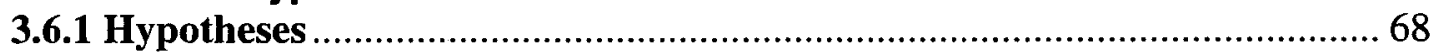

4.0 Research Methodology ................................................................. 71

4.1 Survey Instrument...................................................................................... 74

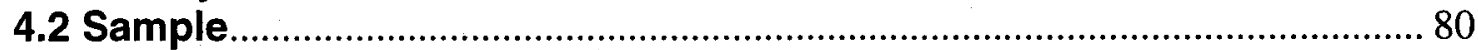

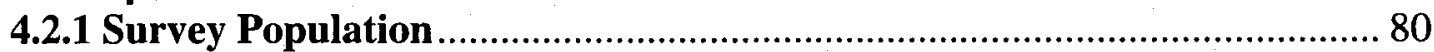

4.2.2 Sample Frame and Sample Size ……………….................................... 81

4.2.3 Unit of Analysis ....................................................................................... 82 


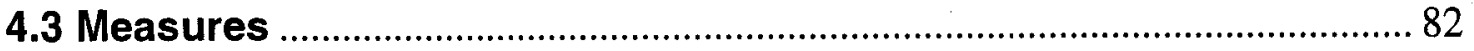

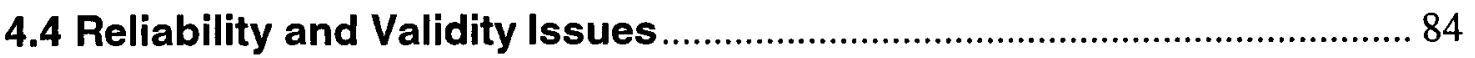

5.0 Data Collection and Analysis ................................................. 88

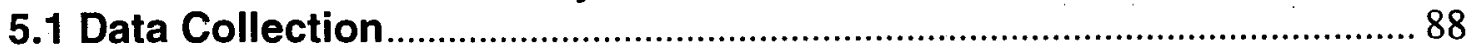

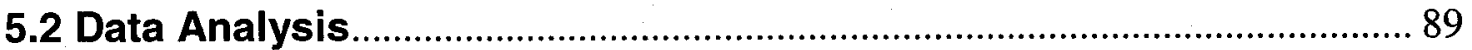

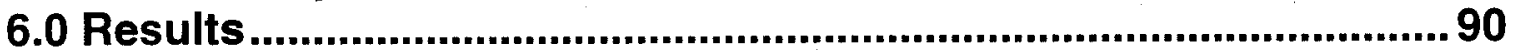

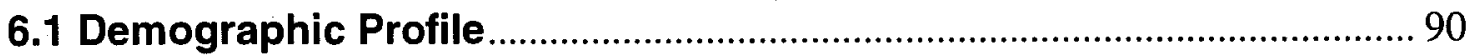

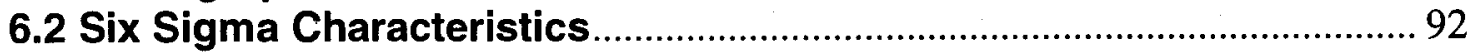

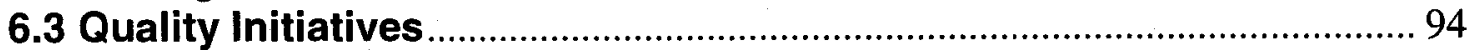

6.4 Most and Least Important Factors in Six Sigma Success .................. 95

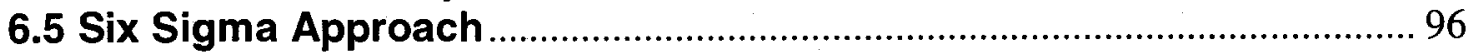

6.6 Successes of Six Sigma Implementation ............................................ 103

6.7 Impact of Key Factors to Six Sigma Success..................................... 106

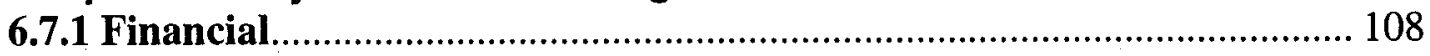

6.7.2 Defects Per Million Opportunities (DPMO) ....................................... 110

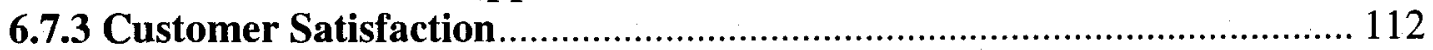

6.7.4 Performance of Internal Work Processes............................................ 114

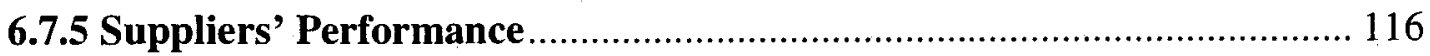

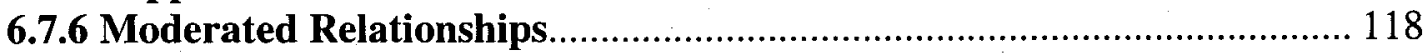

7.0 Benefits and Limitations .................................................... 120

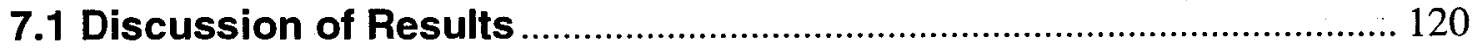

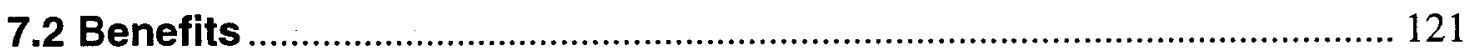

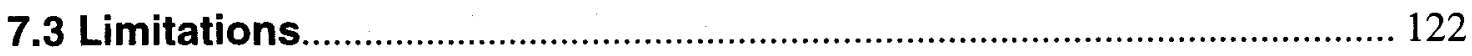

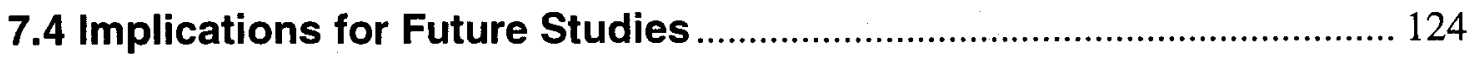

References .......................................................................................... 126

Appendices ....................................................................................... 133

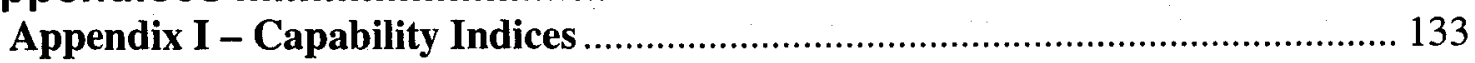

Appendix II - Types of Tests on Theories Developed ...................................... 135

Appendix III - Types of Statistical Analysis in Six Sigma ................................ 136

Appendix IV - Types of Charts used in Six Sigma ......................................... 137

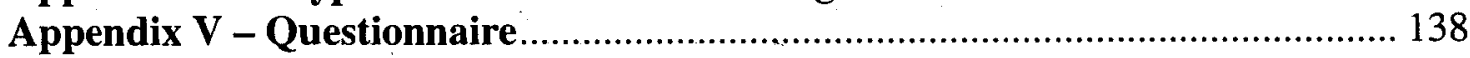

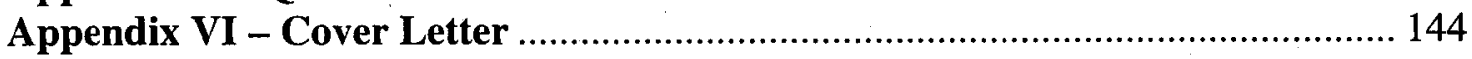




\section{List of Tables}

Table $2.0 \quad-\quad$ Overview of Literature Review Sections

Table $2.3 \quad$ - $\quad$ Contributors to Six Sigma

Table $2.7 \quad-\quad$ Six Sigma Performance Levels

Table 2.11 - Companies and their Six Sigma results

Table $2.12 \quad-\quad$ TQM vs. Six Sigma

Table 4.0 - A Comparison of the Major Types of Research Designs

Table 4.0.1 - Advantages versus Disadvantages of Survey Types

Table 4.0.2 - A Comparison of Data Collection Methods

Table 4.0.3 - $\quad$ Association of Questions to Measures of Factors to Success

Table 4.0.4 - $\quad$ Association of Questions to Measures of Success

Table 6.1(a) - Number of Employees

Table 6.1(b) - Six Sigma Positions Held

Table 6.3 ' - Q Quality Initiatives Used

Table 6.5(a) - Descriptive Statistics on Grouped Variables

Table 6.5(b) - Cronbach's Alpha

Table 6.5(c) - Descriptive Statistics on Grouped Variables

Table 6.5(d) - Six Sigma Approach by Organizations

Table 6.5(e) - Factors with Six Sigma

Table 6.6(a) - Descriptive Statistics on Dependent Variables

Table 6.6(b) ${ }^{*}$ - $\quad$ Performance of Variables with Six Sigma

Table 6.7(a) - Descriptive Statistics on Dependent Variables

Table 6.7(b) - Financial Success

Table 6.7(c) - DPMO Success

Table 6.7(d) - Customer Satisfaction Success

Table 6.7(e) - $\quad$ Performance of Internal Work Processes Success

Table 6.7(f) - $\quad$ Suppliers' Performance Success 


\section{List of Figures}

Figure $3.6 \quad-\quad$ Model of Research of Six Sigma Success

\section{List of Appendices}

\begin{tabular}{|c|c|c|}
\hline Appendix I & - & Capability Indices \\
\hline Appendix II & - & Types of Tests on Theories Developed \\
\hline Appendix III & - & Types of Statistical Analysis in Six Sigma \\
\hline Appendix IV & - & Types of Charts used in Six Sigma \\
\hline Appendix V & - & Questionnaire \\
\hline Appendix VI & - & Cover Letter \\
\hline
\end{tabular}

viii 


\subsection{Introduction}

In the competition intensive world that is today's marketplace, quality is of the utmost importance. Quality in production, quality in service and quality in learning is only the tip of the iceberg when trying to ensure the highest profitability within a company. Developing a product or service is simply not good enough any longer. In the $21^{\text {st }}$ century the need for conformance and design are essential to ensure the long term success of any firm. A system within an organization to promote the elimination of defects and to increase profitability is vital to the development of a competitive advantage. One method of achieving such an advantage is through the use of Six Sigma.

Quality has been recognized as an important aspect in a business environment for a long time but the identification of quality as a core concern has evolved through a number of changing business conditions, they include: competition, the customer focused organization, higher levels of customer expectation, performance improvement, changes in organization forms, changing workforce, information revolution, electronic commerce and the role of the quality department (Gryna, 2001). Near perfection is the ultimate goal of Six Sigma. When an organization has achieved true Six Sigma quality, they will have eliminated defects and non-conformance to virtually zero.

It is to the knowledge of the researcher that there exist only a handful of studies specifically on this area of Six Sigma which deals with the Factors in Successful Implementation. In one of the few academic papers, Schroder (2000) provides a definition of Six Sigma and discusses the importance of academic research in this area. Given that theories on Six Sigma are not in abundance, there is no basis for research 
other than "best practice" studies. Therefore, in order to conduct research on Six Sigma, the starting foundation must be the formulation and identification of useful theories that are related to the Six Sigma phenomenon (Linderman et al., 2002). The study of Six Sigma especially in medium and large firms is important because Six Sigma is today's quality equivalent to TQM in the past. Six Sigma has been such a successful methodology in the quality field, but yet there has not been many studies done on this subject. This is precisely the reason why a study of this sort is important. This study will further the knowledge of the quality field and give firms the understanding to allow for sustainability and growth in their respective industries.

The focus of this study is to view the different elements that lead to the successful implementation of Six Sigma in order to improve quality and increase profitability for medium and large firms in the manufacturing sector. This research examines the extent of use of Six Sigma in medium and large firms and identifies the key success factors of Six Sigma. Success of Six Sigma is measured in Financial terms, Defects Per Million Opportunities, Customer Satisfaction, Performance of Internal Work Processes and in Suppliers' Performance. Finally, this research attempts to identify the key factors, in the eyes of Six Sigma practitioners, which have the most effect on the different types of measures of success within a Six Sigma organization.

In order to study the success factors of Six Sigma implementation, a model has been developed. This model proposes a set of variables that influence the success of Six Sigma implementation which for the purpose of this research is measured in terms of the five variables mentioned in the previous paragraph. The factors that lead to the measures of success in Six Sigma include: Financial Support; Integrating Six Sigma to Business 
Strategy; Management Involvement \& Commitment; Organizational Infrastructure; Integrating Six Sigma to Human Resources; Integrating Six Sigma to Suppliers; Training; Project Management Skills; Project Prioritization, Selection, Review \& Tracking; Understand Six Sigma Methodology, Tools \& Techniques; Statistical Tools; Rewards; Corporate Culture; Linking Six Sigma to the Customer; Communication; and Goal Setting.

The main sections of this thesis are divided into seven different chapters. Chapter 2 begins with a review of literature associated with Six Sigma. The literature review will consist of a review of previous studies done on Six Sigma along with the foundation of the Six Sigma methodology. Chapter 3 presents details on the research objectives, the investigative questions, and a research model together with hypotheses to be tested for the relationship between the key factors to Six Sigma success and the various measures of success. Chapter 4 consists of the research methodology that will be used in this study including the survey instrument, sample and different measures. Data collection and analysis will be the focus of Chapter 5 while Chapter 6 will present the results of the study and Chapter 7 will discuss the benefits and limitations of the study including a brief on implications for future studies. 


\subsection{Literature Review}

The literature review portion of this paper will be more than just a summarization of previous studies. As mentioned above, there have not been a lot of studies done specifically on the topic of this paper. Because of this, the attempt of the literature review section will be twofold. First it will try to establish a basic understanding of the Six Sigma concepts from the definition of Six Sigma to the steps involved in and the practices surrounding this phenomenon. Second, this section will involve the review of studies previously done on Six Sigma. Both parts of this chapter are needed to further support the construction of this thesis as well as lay the foundation to the research herein. Table 2.0 outlines the different sections of this chapter through which the literature on Six Sigma is reviewed.

\begin{tabular}{|c|l|}
\hline SECTION & \multicolumn{1}{c|}{ CONTENT } \\
\hline 2.1 & Introduction to the field of quality. \\
\hline 2.2 & Presenting the costs of quality. \\
\hline 2.3 & $\begin{array}{l}\text { Describes how Six Sigma was started and where it } \\
\text { came from. }\end{array}$ \\
\hline 2.4 & $\begin{array}{l}\text { Draws up the different definitions of Six Sigma } \\
\text { and the definition used in this study. }\end{array}$ \\
\hline 2.5 & Tools that are a part of the Six Sigma roadmap. \\
\hline 2.6 & The DMAIC methodology explained. \\
\hline 2.7 & $\begin{array}{l}\text { Touches on the statistics used in Six Sigma } \\
\text { initiatives. }\end{array}$ \\
\hline 2.8 & The DFSS methodology explained. \\
\hline 2.9 & $\begin{array}{l}\text { Describes what is in the Six Sigma Balanced } \\
\text { Scorecard and how it should be used. }\end{array}$ \\
\hline 2.10 & $\begin{array}{l}\text { Discusses the different levels of the belt system } \\
\text { apparent in Six Sigma organizations. }\end{array}$ \\
\hline 2.11 & $\begin{array}{l}\text { Presents the results that have been achieved by } \\
\text { larger corporations as a result of Six Sigma. }\end{array}$ \\
\hline 2.12 & $\begin{array}{l}\text { Summarizes the differences between TQM and } \\
\text { Six Sigma. }\end{array}$ \\
\hline 2.13 & $\begin{array}{l}\text { Summarizes the differences between ISO 9000 } \\
\text { and Six Sigma. }\end{array}$ \\
\hline
\end{tabular}

Table 2.0 - Overview of Literature Review Sections 


\subsection{Quality}

Quality is an essential and distinguishing attribute in products and services. In today's marketplace, consumers make quality to be one of the most important aspects in the products and services that they consume. It has been stated that there have been two major forces that had a major impact in the need for quality, the Japanese revolution in quality and the prominence of product quality in the public mind (Gryna, 2001). Gryna (2001) stated that there have been a number of factors contributing to the need for quality, they include: product liability cases, concern about the environment, some major/near disasters, pressure by consumer organizations, the awareness of the role of quality in trade, weapons and other areas of international competition.

In the quality domain, there are two major areas where quality initiatives have paid particular interest to. These areas include quality of design and quality of conformance. When we are concerned about product features this usually refers to quality of design, where increasing quality of the design generally leads to higher costs. Freedom from deficiencies refers to quality of conformance where increasing the quality of conformance usually results in lower costs. In turn, higher conformance means fewer complaints and therefore increased customer satisfaction (Gryna, 2001). Emphasizing on quality has a positive impact on productivity, costs, cycle time and value. This means that quality is important to the success of any company. There are essentially two types of problems that are associated with poor quality, they are known as sporadic and chronic problems. A sporadic problem is a sudden, unfavorable change to the status quo, this would require a remedy through restoring the status quo. A chronic problem is a continuous problem that requires changing the process which in turn changes the status 
quo for the better. A way in which both these types of problems can be helped is through continuous improvement. Continuous improvement has acquired a broad meaning, it can be interpreted as to act upon both chronic and sporadic problems and to make improvement to processes.

Due to the consistent problems that occur (chronic and sporadic), and due to the need for customer satisfaction, quality has come to the forefront of a company's ability to increase profits. One of the main objectives of a company is being able to satisfy customers. More and more, customer retention have become a major factor in the success of an organization. Having higher quality of service/products would allow for higher customer retention. Some studies have shown that customer retention results in above average profits and superior growth in market share. Simmerman (1993) showed that companies will boost profits by about $100 \%$ by just retaining $5 \%$ more of their customers. For example, an average shopper at a Home Depot store spends about $\$ 38$ per visit, but if they shop 30 times annually, this totals to $\$ 23,000$ in the customer's lifetime (Behara et al., 1995). The view of customer retention potentials allows companies to emphasize on the importance of customer retention and the importance of quality. 


\subsection{Costs of Poor Quality}

Quality itself is not the only consideration when wanting to increase profitability. The costs associated with poor quality should also come into consideration as well. The costs of poor quality are those costs that are associated to quality that doesn't necessarily have to be. The cost of poor quality can be attributable to numerous areas within a business. Monetary losses are most prevalent, but the costs associated with productivity and customer satisfaction must also be looked at as important aspects of quality. In order to assess the impact of quality on an organization, costs of quality (COQ) measures must be implemented within the business system to measure the costs of quality. There are generally four types of quality costs which are used as the basis of any COQ system (Berte and Nevalainen, 1997):

1) Prevention costs are the investments to make sure that failures are prevented.

2) Appraisal costs are those seen in measuring, evaluating and auditing products and services to assure conformance to quality standards and compliance requirements.

3) Internal failure costs are incurred prior to the delivery of product or service to the customer.

4) External failure costs occur after delivery of product or service to the customer.

The cost of poor quality is the annual monetary loss of products and processes that are not achieving their quality objectives; companies estimate the cost of poor quality for several reasons (Gryna, 2001):

- using money based results improves the communication between managers at all levels

- there are major opportunities for cost reduction which can be identified 
- there is a chance to reduce customer dissatisfaction and the associated threats to whether or not a product/service can be sold

- measuring this cost provides a way of evaluating the progress of quality improvement initiatives

- it helps to develop a strategic quality plan which is consistent with organizational goals

It has been estimated that US companies find their total cost of quality to be $20 \%$ $40 \%$ of sales revenue (Berte and Nevalainen, 1997). It has also been stated that the major contributors of the COQ is internal and external failure costs. This essentially means that there is an opportunity for these companies to reduce failure costs and apply the gains to improve their margins and achieve a competitive advantage. The rationale for any improvement project is simple because failures have root causes, causes are preventable and prevention is almost always cheaper.

J. M. Juran initially introduced the concept of costs of poor quality (COPQ) (Juran and Gryna, 1988). Juran estimated that "In the United States, close to a third of the work done consisted of redoing what had been done before. Depending on the nature of the industry, the COPQ consumed between $20 \%$ and $40 \%$ of the total effort." Much like Juran, Armand Feigenbaum (1991) also proposed the costs of quality concept. He stressed that COPQ is central to management and engineering of total quality control and to business strategy planning. Philip B. Crosby (1979) considers "everything that would not have to be done if everything were done right." He sees nonconformance as a bacteria that must be treated with antibodies to prevent problems from recurring (Crosby, 1984). 
Many organizations have elected to follow the teachings of J. M. Juran, Armand Feigenbaum, and Philip B. Crosby. They applied cost of poor quality programs and achieved significant savings. For example, the U. S. Customer Operations division (USCO) of Xerox, in four years, saved more than $\$ 200$ million when it implemented costs of quality programs ( $\$ 53$ million in $1989, \$ 77$ million in $1990, \$ 60$ million in 1991 , and $\$ 20$ million in 1992) (Carr, 1992). Similarly, Tenneco decreased its failure costs from $\$ 2.9$ billion to $\$ 1.8$ billion, resulting in a rise in operating income of $\$ 900$ million in six years due to the improvements made through its costs of quality strategies (Feigenbaum, 1997). Westinghouse managed to increase its productivity by $15 \%$, reduce scrap by $58 \%$, improve cycle time by $66 \%$, decrease returns by $69 \%$ and improve service performance by $20 \%$ (Gupta and Campbell, 1995). From these few examples, we can already see that by implementing programs based on reducing the costs of poor quality can reduce production, design and development costs because money is no longer spent on waste and rework. The savings from these operations can instead be used to reinvest in acquiring new technologies and reducing the cost to customers.

When talking about the costs of poor quality, we should also mention that unsatisfied customers are also very hard to predict. Gryna (2001) stated that “...customers who have a problem but are unsatisfied with the resolution are unlikely to repurchase, customers who are very satisfied with the handling of a complaint have a much higher intention to repurchase and recommend purchase. Some companies seize upon a complaint as a special opportunity to generate additional sales revenue by providing dramatic, and memorable, recovery action. Finally note that some satisfied customers with no problem, will not repurchase." 


\subsection{The History of Six Sigma}

The quality initiative that was started which eventually became Six Sigma was initiated in the $1970 \mathrm{~s}$. In the 70 's, there was a time when a Japanese firm took over a Motorola factory and proceeded to make drastic changes. Under the new Japanese management, the factory had $1 / 20^{\text {th }}$ as many defects as they had produced under Motorola's management using the same workforce, technology and designs while lowering costs (Pyzdek, 2003). After observing this, Motorola could clearly see that their processes were not as optimal as they had originally thought. At the end, Motorola's management finally admitted that "Our quality stinks" (Main, 1994).

In the 1980 s, besides Motorola who was hurt by the Japanese companies, many other companies were also being driven out of business by Japanese competitors. Japanese companies had superior quality and innovative products that made North American products essentially obsolete. Motorola was only one out of many US companies who were being hurt by the foreigners. Motorola had to develop a method that would be able to allow them to compete with the Japanese, but more importantly, they needed to come up with a quality program that worked, or else face elimination (Harry and Schroeder, 2000). The new innovative improvement concept that Motorola developed was called "Six Sigma". Six Sigma originated at Motorola in the early 1980s by the late Bill Smith (Lucas, 2002). Bill Smith is considered the father of Six Sigma. Mr. Smith was also a senior engineer and scientist at Motorola. He crafted the original statistics and formula that were the beginnings of the Six Sigma culture (Pavletic and Sokovic, 2002). Although Bill Smith was the person deemed to have started Six Sigma, he couldn't have been able to take Six Sigma organization-wide by himself. He needed a 
leader that would support Six Sigma at Motorola. Bob Galvin, who was Motorola's CEO at the time, was in full support of the Six Sigma system. Mr. Galvin started the company on the Six Sigma initiative which eventually led to Motorola being a quality leader (Pyzdek, 2003). After years of hard work and full dedication to the Six Sigma way, in 1988, Motorola was honoured with the Malcolm Baldrige National Quality Award, and prior to this, Motorola, for three consecutive years, had spent $\$ 170$ million on workers' education and training (Antony and Coronodo, 2002).

Motorola's Six Sigma success did not just happen overnight. Its success was only evident after much hard work and dedication to the system. After Motorola's success became public knowledge, the Six Sigma revolution initiated. Companies such as GE and AlliedSignal have taken up the Six Sigma method and have used it to lead themselves to higher levels of customer service and productivity. Even with the surge of the IT industry, we can see companies like Seagate, 3Com and Microsoft using the Six Sigma system. Microsoft has even gone so far as to develop the Microsoft Accelerator for Six Sigma. The Microsoft Accelerator for Six Sigma provides added functionality designed specifically for Six Sigma organizations (Pyzdek, 2003). Because Six Sigma was built on previous quality methodologies, a list of the pioneers of quality and their contribution is included in Table 2.3. 


\begin{tabular}{|l|l|}
\hline Contributor & Contribution to Six Sigma \\
\hline Philip B. Crosby & $\begin{array}{l}\text { Senior manager involvement } \\
\text { 4 absolutes of quality management } \\
\text { Quality cost measurements }\end{array}$ \\
\hline W. Edwards Deming & $\begin{array}{l}\text { Plan-Do-Study-Act (wide usage) } \\
\text { Top management involvement } \\
\text { Concentration on system improvement } \\
\text { Constancy of purpose }\end{array}$ \\
\hline Armand V. Feigenbaum & $\begin{array}{l}\text { Total quality control/management } \\
\text { Top management involvement }\end{array}$ \\
\hline Kaoru Ishikawa & $\begin{array}{l}\text { 4M (5M) or cause and effect diagram } \\
\text { Company wide quality control } \\
\text { Next operation as customer }\end{array}$ \\
\hline Joseph M. Juran & $\begin{array}{l}\text { Top management involvement } \\
\text { Quality trilogy (project improvement) } \\
\text { Quality cost measurement } \\
\text { Pareto Analysis }\end{array}$ \\
\hline Walter A. Shewhart & $\begin{array}{l}\text { Assignable cause vs. chance cause } \\
\text { Control charts } \\
\text { Plan-Do-Check-Act } \\
\text { Use of statistics for improvement }\end{array}$ \\
\hline $\begin{array}{l}\text { Loss function concepts } \\
\text { Experimental design methods } \\
\text { Concept of design robustness }\end{array}$ \\
\hline
\end{tabular}

Table 2.3 - Contributors to Six Sigma; Source: Wortman et al., (2001) 


\subsection{What is Six Sigma}

There is still no universal definition for Six Sigma because it has yet to be referred to consistently by all practitioners and academics. Its philosophies have been defined with respect to its statistical prowess while at the same time some definitions try to make its business applications more apparent. No matter which way you try to define Six Sigma, it is a methodology using different approaches to come up with the same goal. A summary of the top Six Sigma definitions are included below from some well known Six Sigma practitioners:

- A comprehensive and flexible system for achieving, sustaining and maximizing business success. Six Sigma is uniquely driven by close understanding of customer needs, disciplined use of facts, data, and statistical analysis, and diligent attention to managing, improving and reinvesting business processes. (Pande et al., 2000)

- The purpose of Six Sigma is to reduce variation to achieve very small standard deviations so that almost all of your products or services meet or exceed customer expectations. (Pande et al., 2002) [Statistical terms]

- Six Sigma is a highly disciplined process that focuses on developing and delivering near-perfect products and services consistently. Six Sigma is also a management strategy to use statistical tools and project work to achieve breakthrough profitability and quantum gains in quality. (Wortman et al., 2001)

- Six Sigma is a rigorous, focused and highly effective implementation of proven quality principles and techniques. Incorporating elements from the work of many quality pioneers, Six Sigma aims for virtually error free business performance. (Pyzdek, 2003)

- The Six Sigma approach is a collection of managerial and statistical concepts and techniques that focus on reducing variation in processes and preventing deficiencies in product. (Gryna, 2001)

- Six Sigma is a business improvement strategy used to improve profitability, to drive out waste, to reduce quality costs and improve the effectiveness and efficiency of all operations that meet or even exceed customers' needs and expectations. (Antony and Banuelas, 2001) [Business Terms] 
- Six Sigma is a term that refers to 3.4 defects per million opportunities (DPMO), where sigma is a term used to represent the variation about the process average. (Antony and Banuelas, 2002) [Statistical Terms]

- Six Sigma is a philosophy to continuously reduce variation in processes and aim at the elimination of defects or failures from every product, service and transactional process (Hoerl, 1998)

- Six Sigma is an organized and systematic method for strategic process improvement and new product and service development that relies on statistical methods and the scientific method to make dramatic reductions in customer defined defect rates. (Linderman et al., 2002)

- A quality improvement program with the goal of reducing the number of defects to as low as 3.4 parts per million opportunities. (Pavletic and Sokovic, 2002)

- Six Sigma is a program and toolkit for improving quality in manufacturing processes. It is a methodology which aims to reduce variations in a process. (Prewitt, 2003)

- Six Sigma is a rigorous and a systematic methodology that utilizes information (management by facts) and statistical analysis to measure and improve a company's operational performance, practices and systems by identifying and preventing 'defects' in manufacturing and service-related processes in order to anticipate and exceed expectations of all stakeholders to accomplish effectiveness. (Tonner, 2003)

- Six Sigma is a formal methodology for measuring, analyzing, improving and then controlling or "locking in" processes. This statistical approach reduces the occurrence of defects from a three sigma level or 66,800 defects per million (average for most companies) to a Six Sigma level - less than four defects per million. (Bolze, 1998)

- By definition, Six Sigma is a statistical term that refers to 3.4 defects per million opportunities (or 99.99966 percent accuracy), which is as close as anyone is likely to get to perfect. A defect can be anything from a faulty part to an incorrect customer bill. (Paul, 1999)

- Six Sigma, a comprehensive, statistics-based methodology that aims to achieve nothing less than perfection in every single company process and product (Paul, 1999)

- Six Sigma is a quality initiative that employs statistical measurements to achieve 3.4 defective parts per million - the virtual elimination of errors. (Murphy, 1998) 
The definitions above sum up quite clearly how vast Six Sigma is. We can however, see some similarities amongst all of the definitions provided. Six Sigma is more than just a method by which your organization goes through steps like an assembly line. Six Sigma is more of a methodology that captures your organization as a complete system. It utilizes specific leaders that guide the organization at every level imaginable within your company. Intensive training and leadership are important aspects of the implementation of Six Sigma. The Six Sigma approach is a collection of managerial and statistical concepts and techniques that focus on reducing variation in processes and preventing deficiencies in product (Gryna, 2001). Six Sigma is not only a system of improving quality; it is a total change of your organizational culture by redefining each and every business component within your company. As Pande et al. (2002) put it "Six Sigma is not just about data tools and defect calculations. Nor is it just about having people work in teams. Teams alone cannot change corporate structures."

As in statistics, variation in a process is denoted by the term sigma. Sigma is the standard deviation of measurements around the process mean. In a process that has achieved Six Sigma capability, the variation is small compared to the range of the specification limits. There are six standard deviations between the process mean and either specification limit.

The crucial aspects of the corporate-level preparation for the Six Sigma methodology include establishing key business performance measurements, ensuring organizational effectiveness, readying the organization for Six Sigma, and establishing goals for improvement (Gupta, 2004). If an organization is able to put into place this foundation for Six Sigma, then it has the potential to generate sustained success, set a 
performance goal for everyone in the company, enhance value to customers, accelerate the rate of improvement, promote learning and be able to execute strategic change (Pande et al., 2000).

There have been many different definitions of Six Sigma provided by many authors previous to this paper. For the purposes of this paper, we will sum up what Six Sigma is by the fact that Six Sigma is a disciplined methodology that encapsulates the use of statistical analysis and the processes of an organizational system to perfect products and services. Because of this, we will define Six Sigma in its natural elements, that of its business elements and that of its statistical characteristics.

Business Definition: Six Sigma is a methodology used to increase the profitability of a system by optimizing business processes through the use of incremental improvement projects.

Statistical Definition: Six Sigma is a methodology used to reduce variation with small standard deviations in order to ultimately achieve 3.4 defects per million opportunities.

The author believes that this definition covers all elements of Six Sigma in two simple phrases. At this point in time, it should be noted that Joseph M. Juran stated that "all quality improvement occurs on a project by project basis and in no other way" can be considered an important element in the foundation of Six Sigma. To put Six Sigma in perspective, when we consider spelling errors, three sigma corresponds to 7.6 misspelled words per page in a book; four sigma corresponds to about one misspelled word per chapter in a book; Six Sigma in turn is considered to be one misspelled word in all the books contained in a small library (Behara et al., 1995). 


\subsection{The Six Sigma Roadmap}

When implementing Six Sigma in any organization, a good way to go about it is to design a Six Sigma Roadmap that will guide you through the entire execution of Six Sigma. A Six Sigma Roadmap can be thought of as the DMAIC (Define, Measure, Analyze, Improve, Control) methodology which is followed by many in their quest for Six Sigma quality. The DMAIC methodology outlines a clear-cut sequence of steps that would guide an organization through its implementation of Six Sigma. Gross (2001) stated that "What is needed in an effective Six Sigma implementation is a road map in order to provide a structured approach for implementing a Six Sigma program." The roadmap is a way to set up a plan so that decision makers can have expectations of the program's success. The steps to take in order to develop a Six Sigma roadmap include (Gross, 2001): appoint a champion, select a cross functional team, develop quantifiable goals, develop implementation plan (establish training program, address data collection, develop program maintenance plan), and coordinate the roadmap.

Pande et al. (2000) also stresses the need for a Six Sigma Roadmap and list some clear advantages that one can expect from using such:

- A clearer understanding of the business as an interconnected system of processes and customers

- Better decisions and uses of resources, to get the greatest possible amount of benefit out of your Six Sigma improvements

- Shorter improvement cycle times, because of better upfront data and selection of projects 
- More accurate validation of Six Sigma gains - whether in dollars, defects, customer satisfaction or other measures

- A stronger infrastructure, to support change and sustain results

\subsection{The Six Sigma DMAIC Methodology}

The foundation of Six Sigma is not completely new. Its origins can be traced back to the decades upon decades of quality improvement methodologies. The Six Sigma methodology itself is built from concepts introduced by W. Edwards Deming - Plan-DoCheck-Act, or P-D-C-A - which describes the basic logic of data-based process improvement (Pande et al., 2000). The Six Sigma DMAIC (Define, Measure, Analyze, Improve, Control) methodology is based on Deming's PDCA idea. It can be thought of as a roadmap for problem solving and product/process improvement. The DMAIC methodology is considered to be a newer approach to Six Sigma and is sometimes referred to as the "Breakthrough Approach" developed by Mikel Harry and Richard Schroeder (2000) (Gupta, 2004). The DMAIC methodology is the most well known and most widely used methodology in Six Sigma. Most companies begin implementing Six Sigma using the DMAIC methodology, and later add the DFSS (Design for Six Sigma, also known as DMADV or Define, Measure, Analyze, Design, Verify) methodologies when the organizational culture and experience level permits.

\subsubsection{Define}

The Define stage of the Six Sigma methodology is the beginning of the spectrum for a Six Sigma project. This step's purpose is to identify potential projects, to select and 
define a project and to set up the project team. Gryna (2001) specified five general steps of the define stage, they are summarized as:

1. Identify Potential Projects: This stage includes the nominating, screening and selection of projects. The focus of this stage should be on the opportunities that will increase customer satisfaction and reduce COPQ.

2. Evaluate Projects: The evaluation of projects includes a review which goes from an analysis of the scope and benefit to an assessment of factors to help set priorities.

3. Select Project: The initial project should be a successful one. This is because a successful project is a form of evidence to the project team that the process works and helps to build momentum to future endeavors.

4. Prepare Problems and Mission Statement for Project: Establishing a problem statement brings to the forefront what it is while allowing to see a planned outcome. A mission statement is based on the problem statement but it provides direction to the project team.

5. Select and Launch Project Team: Generally, a project team has a sponsor, a leader, a recorder, team members and a facilitator. An option that may help in this step is to develop a charter that defines what the team will do and how the team will function.

This Define phase essentially sets the tone for the entire design project where management defines the design problem, projects are nominated which are consistent with overall business strategy and selected based on benefits (De Feo et al., 2002). A 
way to assess the potential projects is to use the Pareto Principle. The Pareto Principle states that a few contributors to the cost are responsible for the bulk of the cost. These vital few contributors need to be identified so that quality improvement resources can be concentrated in those areas.

\subsubsection{Measure}

The Measure phase of the Six Sigma methodology identifies key product parameters and process characterized and measures the current process capability. This phase also concentrates on key customers and their critical needs (De Feo, 2002). The steps in this stage as outlined by Gryna (2001) include:

1. Measure the baseline performance and verify the project need: It is a good idea to confirm the size of the problem in numbers because it allows for a clear view of the problems that you have to deal with. It helps in justifying the time spent on the project as well as helping to overcome the resistance to accepting and implementing a remedy.

2. Document the Process: Documenting the process allows for others to see the problems you're dealing with. Using tools such as process flow diagrams or process maps are useful in this stage.

3. Plan for Data Collection: This stage involves an outline of symptoms, quantification of symptoms and the formulation of theories.

4. Validate the Measurement System: Variation comes in many different ways, from the process itself or even from the measurement system. Validating the measurement can involve such things as reproducibility, repeatability, accuracy, stability, and linearity. 
5. Measure the Process Capability: Process capability refers to the inherent ability of a process to meet the specification limits for a product. Knowing the initial process capability helps to define the work to be done in the analysis and improve phases to achieve a capability at the six sigma level.

In the planning aspects of operations it is very important that the processes will be able to meet the specifications. One way of ensuring that the process can meet specifications is to use process capability ${ }^{1}$ measurements. A good reason for being able to quantify process capability is to be able to compute the ability of the process to hold product specifications. Planners try to select processes with the $6 \sigma$ process capability well within the specification width; a measure of this relationship is the capability ratio $(C p)^{2}$. Because the average is often not at the midpoint, it is useful to have a capability index that reflects both variation and the location of the process average, such an index is $C p k^{3}$. If the average is equal to the midpoint of the specification range, then $C p k$ is equaled to $C p$. The higher the $C p$, the lower the amount of product outside specification limits, most capability indexes assume that the quality characteristic is normally distributed (Gryna, 2001). For further explanation of the process capability and the process capability index please refer to Appendix I.

\footnotetext{
${ }^{1}$ Process capability provides a quantified prediction of process adequacy; it is the measured, inherent variation of the product turned out by a process. Process capability $=+-3 \sigma$ (a total of $6 \sigma)$, if the process is centered at the nominal specification and follows a normal probability distribution, $99.73 \%$ of production will fall within $+-3 \sigma$ of the nominal specification (Gryna, 2001).

${ }^{2} \mathrm{Cp}=$ Capability Ratio = Specification Range $/$ Process Capability $=($ USL - LSL $) / 6$ s. The Cp index measures potential capability, assuming that the process average is equal to the midpoint of the specification limits and the process is operating in statistical control (Gryna, 2001).

${ }^{3} \mathrm{Cpk}$ reflects the current process mean's proximity to either the USL or LSL, Cpk is estimated by Cpk = $\min [(\mathrm{Xbar}$ - LSL)/3s, (USL - Xbar)/3s] (Gryna, 2001).
} 


\subsubsection{Analyze}

The Analyze phase of the Six Sigma paradigm essentially analyzes the past and current performance data to identify the causes of variation and process performance. The main purpose of this phase is to select a high-level design from several different alternatives and develop detailed requirements against which a design will be optimized (De Feo, 2002). The steps of this again as stated by Gryna (2001) include:

1. Collect and Analyze Data

2. Develop and Test Theories on Sources of Variation and Cause \& Effect Relationships

A large part of the Analyze phase is to be able to test the theories of management controllable problems. To do this would require the use of facts, rather than opinions to reach conclusions about the causes of a quality problem. The factual approach not only determines the true cause but also helps to gain agreement on the true cause by all of the parties involved (Gryna, 2001). For a full list of the possible tests that can be done on the theories developed, please refer to Appendix II for further details.

Ways to test theories that have been developed are to collect new data. Data is required to be collected in the new processes that have been developed in order to see how well it is doing as compared to the processes before. Some measures that can be done include (Gryna, 2001):

- Measurement at intermediate stages of a single operation

- Measurement following non-controlled operations

- Measurement of additional or related properties of the product or process 
- Study of worker methods

In analyzing errors of processes and procedures there will no doubt be some errors that are attributable to the way things are done. However, not all errors can be blamed on the processes or even the machines being used. There are also human errors that management will have to contend with. There are in general four types of errors that can be attributable to workers, they include inadvertent errors ${ }^{1}$, technique errors ${ }^{2}$, conscious errors ${ }^{3}$ and communication errors ${ }^{4}$ outlined by Gryna (2001).

\subsubsection{Improve}

The Improve phase of Six Sigma essentially designs a remedy, proves its effectiveness and prepares an implementation plan. In this stage, the team must be ready to veer back and forth between far out ideas along with the details of executing a plan (Pande et al., 2002). The steps as outlined by Gryna (2001) include:

1. Evaluate Alternative Remedies: Reviewing the remedies given, assess which of these are viable and which ones would have the largest impact. The remedy selected should make an improvement on the original problem and it should optimize both company costs and customer costs.

2. Design Formal Experiments to Optimize Process Performance (if necessary): The designing of experiments can include evaluating suspected dominant

\footnotetext{
${ }^{1}$ Workers are unable to avoid these errors as they are the basis for human error. Remedies for inadvertent errors involve two approaches: reducing the extent of dependence on human attention and helping workers remain attentive to their work at hand.

${ }^{2}$ Comes about because the worker lacks some essential technique, skill or knowledge needed to prevent the error from happening. These errors are unintentional, specific, consistent and unavoidable.

${ }^{3}$ These are knowingly committed by the worker. These errors are witting, intentional and persistent.

${ }^{4}$ These errors happen due to a lack of communication given to the employee. These errors can be inadvertent, technique or conscious.
} 
variables, exploratory experiments to determine dominant variables, production experiments, response surface experiments and simulation.

3. Design a Remedy: The remedy designed must fulfill the original project mission, particularly with respect to meeting customer needs. This step identifies customers, defines their needs and proves the effectiveness of the remedy.

4. Prove Effectiveness of the Remedy: Before any remedy is accepted, it must be proven. There are two main steps that can be taken to prove the remedy. Either by a preliminary evaluation of the remedy under conditions that simulate the real world and have a final evaluation under real world conditions.

5. Deal with Resistance to Change: Resistance to change is very common in this type of implementation, but a way to deal with this resistance is to educate the people involved in the change.

6. Transfer the Remedy to Operations: Transferring the remedy to operations may include revisions in operating standards and procedures. This stage includes changes in staffing and responsibilities. Additional equipment, materials and supplies along with extensive training may be involved.

A useful tool in the Improve phase is the use of evolutionary operations or EVOP. EVOP is based on the concept that every manufactured lot has information to contribute about the effects of process variables on a quality characteristic (Gryna, 2001). The use of EVOP introduces small changes into variables according to a planned pattern of changes, these changes are small enough to avoid a detour from the status quo but large enough to gradually establish which variables are important. 
The Six Sigma approach makes the use of the Design of Experiments (DOE) as an important part of its processes. Giving detail to the designing of experiments would allow easier conformance to quality in the future. Experiments can have numerous objectives, and the best strategy depends on the objective. DOE allows for establishing the important variables that affect quality. Using DOE is like setting a concrete plan to conduct the experiment.

Six Sigma teams have to keep their options open in the Improve stage. They should not jump at the first solution that comes along (Pande et al., 2002). By jumping too quickly into an idea that has not been thoroughly thought through can ultimately bring the team worst off than they had originally started. The lesson here is to be critical and cautious of the ideas generated before fully implementing the improvement projects.

\subsubsection{Control}

The Control phase which is the last phase of the Six Sigma methodology is where the designing and implementation of certain activities to hold the gains of improvement occur. Statistical Process Control (SPC) is something that can be used in this phase. SPC is a technique for applying statistical analysis to measure, monitor, and control processes where the major component is the use of control charting methods (Wortman et al., 2001). The use of control charts has many benefits. When a control chart shows that a process is in control and within specification limits, it is often possible to eliminate the costs relating to inspection (Grant, 1988). The Control phase refers to the process used to consistently meet standards. The steps according to Gryna (2001) are:

1. Design Controls and Document the Improved Process: Control during operations is done through use of a feedback loop which is a measurement of actual 
performance, comparison with the standard of performance and action on the difference.

2. Validate the Measurement System: After setting up the measurement system for the improved process, it must be evaluated and made capable. This step could include new measurement devices, the collection of new data and additional training for process personnel.

3. Determine the Final Process Capability: Essentially, this step ensures that the process capability gained can be held during normal operating conditions. The process changes implemented should be irreversible.

4. Implement and Monitor the Process Controls: In this step, all of the remedies are implemented into the operations. The steps mentioned above are used to monitor the processes and product performance. Implementing and monitoring the improved process is the final step in a quality improvement project.

According to Gryna (2001), the control process is in the nature of a feedback loop, control involves a sequence of steps: choose the control subject, establish measurement, establish standards of performance, measure actual performance, compare actual measured performance to standards and take action on the difference. Pande et al. (2002) states that the main purpose of the Control phase is quite simple: "once the improvement's been made and results documented, continue to measure the performance of the process routinely, adjusting its operation when the data clearly indicates you should do so or when the customer's requirements change." 


\subsection{The Statistics of Six Sigma}

This section of the Six Sigma literature review deals with the statistics involved with Six Sigma. However, this section is not an attempt to cover all possible statistical techniques that can be used in a Six Sigma implementation. Instead, it will provide an overview as to the different statistical techniques within the Six Sigma system and give the reader an idea of what can be done within a Six Sigma implementation program.

As we know, a large part of Six Sigma is not necessarily number crunching. Instead, a very useful tool used in the Six Sigma system is that of Run Charts. Run charts plot data in a time sequence and analysis is performed to determine if the patterns can be credited to common causes of variation, or if special causes of variation are present (Pyzdek, 2003). Run charts should generally be used for preliminary data analysis on a time scale. It gives the user an insight as to how the process is doing, and could be a catalyst to initiating any action in the future.

In statistics, sigma denotes the standard deviation of a set of data; it provides a measure of variability which indicates how all data points in a statistical distribution vary from the mean value. When specifications are set at \pm six sigma the result is a near zero defect rate. This holds true even when the process mean shifts and when multi-stage processing is involved. Statistically speaking, Six Sigma is based on the normal distribution. However, if you were to take true Six Sigma results, it actually translates to about 2 defects per billion opportunities, this is a far cry from the 3.4 DPMO stated previously. The reason for this discrepancy was determined by Motorola in their early days in developing Six Sigma. Motorola determined, through their own experience, that processes drift over time and they referred to this phenomenon as the "Long-Term 
Dynamic Mean Variation", where this variation generally falls between 1.4-1.6 sigma (Swinney, 2003). Harry and Schroeder (2000) summarizes this 1.5 sigma shift phenomenon in their own words: "By offsetting normal distribution by a 1.5 standard deviation on either side, the adjustment takes into account what happens to every process over many cycles of manufacturing... Simply put, accommodating shift and drift is our 'fudge factor,' or a way to allow for unexpected errors or movement over time. Using 1.5 sigma as a standard deviation gives us a strong advantage in improving quality not only in industrial process and designs, but in commercial processes as well. It allows us to design products and services that are relatively impervious, or 'robust,' to natural, unavoidable sources of variation in processes, components, and materials." A summary of the defects associated with the various sigma levels is included in Table 2.7:

\begin{tabular}{|c|l|}
\hline \multicolumn{2}{|c|}{ SIGMA PERFORMANCE LEVELS } \\
\hline Sigma Level & $\begin{array}{l}\text { Defects Per Million } \\
\text { Opportunities (DPMO) }\end{array}$ \\
\hline 1 & 690,000 \\
\hline 2 & 308,537 \\
\hline 3 & 66,807 \\
\hline 4 & 6,210 \\
\hline 5 & 233 \\
\hline 6 & 3.4 \\
\hline
\end{tabular}

Table 2.7 - Six Sigma Performance Levels

Many different types of descriptive statistics are involved in assessing Six Sigma performance and analysis. Typically, descriptive statistics are used to explain properties 
of data from samples (Pyzdek, 2003). Pyzdek (2003) stated three areas of interest in descriptive statistics within Six Sigma: the distribution's location or central tendency, its dispersion and its shape. Summarized in Appendix III are a set of common descriptive statistics used in Six Sigma.

Statistical Process Control (SPC) is another big dimension within the Six Sigma system. SPC is used to measure a process to ensure that it is within control or within specification limits. SPC involves the measurement and assessment of variation in a process, and the efforts made to limit or control such variation (Pande et al., 2000). There are generally two broad categories of control charts used within SPC, they include those that are used with continuous data and those used with attributes data (Pyzdek, 2003). As there are numerous types of control charts and uses, a summary of the different types are displayed in Appendix IV. Pande et al. (2000) summarizes several indicators of an out of control situation, they include: outliers ${ }^{1}$, trends ${ }^{2}$, shifts/runs ${ }^{3}$, cycles/periodicity ${ }^{4}$ and tendencies ${ }^{5}$.

Using tests for statistical significance is an extremely important technique to look for patterns or to test assumptions about data. In Six Sigma, tests of statistical significance can have various possible applications, including (Pande et al., 2000):

- Verify a problem or significant change in performance

- Checking the validity of the data collected

- Determining the type of pattern or "distribution" in a group of continuous data

- Developing a root-cause hypothesis based on patterns

\footnotetext{
${ }^{1}$ Any point outside the control limits.

${ }^{2}$ A series of points continually rising or falling.

${ }^{3} \mathrm{~A}$ continuous sequence of points above or below the average.

${ }^{4}$ A series of points alternating up and down or trending up and down in "waves".

${ }^{5}$ Situations in which the points continually fall close to the center line or to either of the Control Limits.
} 
- Validating a root-cause hypotheses

Using the Null Hypothesis approach can allow for a test of statistical significance. The Null Hypothesis is a means to disprove any other explanation that may be different to the one stated. To statistically test hypotheses, there are a few different methods that one can choose from including the Chi-Square Test, the $t$-test, Analysis of Variance (ANOVA) or Multivariate Analysis (MANOVA).

Correlation and Regression Analysis is another statistical dimension of Six Sigma. Correlation and Regression Analysis is a means to analyze the relationships between two or more factors being studied. The uses of Correlation and Regression Analysis include (Pande et al., 2000):

- Test root cause hypotheses

- Measure and compare the influence of various factors on the results

- Predict the performance of a process, product, or service under certain conditions

Some of the common uses include (Harnett and Murphy, 1993): correlation coefficient ${ }^{1}$, correlation percentage $^{2}$, regression ${ }^{3}$ and multiple regression ${ }^{4}$.

Obviously, there are endless tools that can be used within Six Sigma. Some additional tools used in the Six Sigma system includes Design of Experiments (DOE), Failure Modes and Effects Analysis (FMEA), Mistake-Proofing (Poka-Yoke), Quality Function Deployment (QFD) and Evolutionary Operations (EVOP). DOE is an organized method for determining the relationship between factors affecting a process

\footnotetext{
${ }^{1}$ A measurement of how well two (or more) variables vary together where a perfect positive correlation will result to a 1.0 value and the values range from -1.0 to +1.0 .

${ }^{2}$ Reflects the percent of variation, is essentially a square of the correlation coefficient.

${ }^{3}$ Used to model and predict the value of the dependent variable on the basis of other measured characteristics.

${ }^{4}$ Like regression, but involves the relationship among several factors and the results.
} 
and the output of that process (Gryna, 2001). "FMEA is a set of guidelines, a process, and a form to identify and prioritize potential problems (failures)" (Pande et al., 2000). Poka-Yoke is a way to prevent mistakes before they happen. QFD is "a structured and disciplined process that provides a means to identify and carry the Voice of the Customer through each stage of product or service development and implementations. This process can by deployed horizontally through marketing, product planning, engineering, manufacturing, service and all other departments in an organization involved in product or service development" (ReVelle et al., 1998). EVOP uses a conservative experimental strategy for continuous process improvement where very few variables are changed in each iteration to limit change and make sure what's being modified should be modified (Wortmä et al., 2001).

A major emphasis in Six Sigma is the reduction of variation within a process. It should be noted however, that the reduction of process variation is not a new concept. It had been pushed by quality enthusiasts for a long time. Deming and Taguchi had expressed the importance of variation reduction as the key to improved business performance. Being able to set clear objectives and deploy these down to lower levels within the organization is not new and has been discussed by Merli, Kaplan and Norton among many others (Caulcutt, 2001).

As most practitioners of Six Sigma would agree, statistics in Six Sigma is an important element to its success. However, it should be noted again that statistics is only a small part of the entire Six Sigma paradigm. The most important thing is that people practicing Six Sigma exercise process thinking. In process thinking, outliers in a dataset are considered to be important information that contributes to knowledge of the process 
behaviour (Maleyeff and Kaminsky, 2002). Maleyeff and Kaminsky (2002) further notes that you "must continually be reminded that the focus of your analysis is not on describing the data, but describing the process that generated the data, as this distinction is critical to the application of process thinking" and will maximize the benefit that the data will bring to your Six Sigma efforts.

\subsection{Design For Six Sigma (DFSS) / DMADV}

In the Six Sigma paradigm, the DMAIC methodology is usually thought of first when thinking of ways to implement Six Sigma. However, there is another methodology within Six Sigma that is widely used as well. There is often the mention of the DFSS (Design For Six Sigma) or DMADV (Define-Measure-Analyze-Design-Verify) methodology. The term Design for Six Sigma is used interchangeably with DMADV, where DMADV is the steps used in order to achieve DFSS. DFSS is essentially a problem prevention tool to avoid the need to fix problems further down the production chain. DFSS acts to eliminate problems before they occur and it allows the creation of products that will meet customer expectations under all operating conditions through robust designs that can be manufactured to the highest quality levels (Olexa, 2003).

Antony (2002) refers to DFSS as a powerful approach to designing products, processes and services in a cost effective and simple manner to meet the needs and expectations of the customer while driving down quality costs. Like the DMAIC approach, Design for Six Sigma uses statistical tools to predict and improve quality. Antony (2002) further notes that it is a methodology to make the introduction of new 
products, processes and services more efficient, reliable and capable of meeting high customer expectations and requirements.

Design for Six Sigma is said to be the method that is suggested to bring order to product design. Hockman (2001), Suh (1990) and Paul (1996) noted that 70-80\% of all quality problems are design related. In general, problem solving at the downstream of a process is more costly and time consuming than fixing something at the source (Wortman et al., 2001). Simon (2000) gives a 5 step DMADV process for Six Sigma design which includes:

- Define: Define the project goals and customer requirements

- Measure: Measure and determine customer needs and specifications

- Analyze: Determine the process options to meet the customer needs

- Design: Design the details for the process to meet the customer needs

- Verify: Verify and validate the design

Due to the different approaches of each methodology, there are specific times when the DFSS/DMADV method should be used instead of the DMAIC method. Simon (2000) sums up when the DFSS/DMADV methodology should be used instead of the DMAIC methodology:

- A product or process is not in existence and one needs to be developed

- The product or process exists and has been optimized (either by DMAIC or some other quality initiative) but still does not meet the level of customer specification or Six Sigma level 
According to Conlin (1998), most companies produce a defect rate between 35,000 and 50,000 per million opportunities, this defect rate equates to a sigma quality level of 3 to 3.5 sigma.

Antony (2002) stated that in the DFSS methodology, the inputs can be customer needs and wants, business needs, raw materials, and so on. The outputs are quality products, processes or services. Antony (2002) sees the DFSS methodology in four stages: identify, design, optimize, and validate where:

1. Identify: This stage ensures that the organization understands the principle for success.

2. Design: As soon as the organization understands the parameters of design, these must be translated into the actual design.

3. Optimize: This stage involves the consideration of design to ensure effective "makeability" - so that the organization is certain that the product can be manufactured within the design parameters and within the stated budget.

4. Validate: The final stage checks that the process is complete, valid and will meet requirements in practice. If this stage suggests that the design of the product does not meet the required capability, then it is necessary to go back through steps 1,2 and/or 3 . 


\subsection{The Six Sigma Business Scorecard}

The concept of a Balanced Scorecard was originally developed by Kaplan and Norton (1992). Kaplan and Norton (1992) stated that "The balanced scorecard is like the dials in an airplane cockpit: it gives managers complex information at a glance." They developed this concept by studying different companies in their environment in order to see what can be measured in order to allow managers a quick glance at how their company was doing. The Balanced Scorecard is a way to make managers focus on the most important measures within their organizations (Kaplan and Norton, 1992). Kaplan and Norton (1996) took their original idea of the balanced scorecard and developed four perspectives from which organizations can create their balanced scorecards, those include: financial, customer, internal business process and learning \& growth.

The Six Sigma Business Scorecard is a newly transformed version of Kaplan and Norton's original Balanced Scorecard. The Six Sigma Business Scorecard is still considered a fairly new concept to the Six Sigma paradigm. It incorporates the methodologies of the Six Sigma system with the underpinnings of a Balanced Scorecard from traditional business strategy. A key to the understanding of the Six Sigma Business Scorecard is being able to understand profitability. Gupta (2004) stated that "The Six Sigma Business Scorecard is a complete corporate performance system that requires leadership to inspire, managers to improve, and employees to innovate to achieve the optimum level of profitability and growth."

The Six Sigma Business Scorecard helps in the implementation of Six Sigma by combining information from the strategic, operational, and execution aspects of the business. The main purpose of the Six Sigma Business Scorecard is to address the 
purpose of the business, future performance, all business processes and measurements that can be aggregated to the corporate level (Gupta, 2004). Gupta (2004) states that the Six Sigma Business Scorecard combines different measurements into seven elements: leadership and profitability; management and improvement; employees and innovation; purchasing and supplier management; operational execution; sales and distribution; and service and growth.

However wonderful the idea of a Balanced Scorecard or a Six Sigma Business Scorecard seems, there are some potential pitfalls of the concepts. Ittner and Larcker (2003) stated four general mistakes that are related to the Scorecards, and they include: not linking measures to strategy, not validating the links, not setting the right performance targets and measuring incorrectly. Ittner and Larcker (2003) further goes on to state that organizations are required to develop a causal model, pull together the data, turn data into information, continually refine the model, base actions on findings and assess outcomes to avoid the pitfalls stated.

\subsection{The Six Sigma Belt System}

One of the most distinguishing attributes of Six Sigma is its formal belt system which is put in place within an organization. The belt system is derived from the different levels of karate skills apparent in the martial arts. Project Sponsors, Champions, Master Black Belts, Black Belts and Green Belts serve as role models and influence peers which contribute to increasing the commitment level for Six Sigma goals (Linderman et al., 2002). The Six Sigma belt system allows for the systematic monitoring and management of projects throughout the organization. An important aspect of the belt 
system is that it attempts to mold the organization's corporate culture and structure. One way to view the renovation of the new structure is to review the roles of people in the evolving Six Sigma organization (Pande et al., 2002). The following sections will explain the roles and purposes for each level of the belt system, as each level is crucial to the ultimate success of Six Sigma.

\subsubsection{Green Belts}

Green Belts are considered the most basic level of the Six Sigma belt system. It is essentially the people in the trenches plowing away at the everyday underpinnings of the Six Sigma system. Green Belts generally have less training and are usually involved in process improvement projects as a team member or team leader (Pavletic and Sokovic, 2002). Green Belts bring the brain and muscle for collection and analysis of data which is required to improve processes and they must be willing to: ask "dumb" questions, carry out instructions for data collection and analysis, listen actively to others, carry out assignments and review the efforts of the team they are involved in (Pande et al., 2002). In general, Green Belts should spend about $20 \%$ of their working time on projects while being mainly responsible for: process expertise contribution, data collection, acceptation and completion of all assigned action items and improvement implementations (Pavletic and Sokovic, 2002).

An important purpose that Green Belts play is to help Black Belts (Smith, 2003). They are essentially part time improvement specialists that receive less training since they provide supporting roles on the improvement projects (Linderman et al., 2002) and are employees who have received enough Six Sigma training to participate in a team, or 
work individually on small scale projects directly related to their own job (Pande et al., 2002).

\subsubsection{Black Belts}

In the Six Sigma belt system hierarchy, Black Belts are a level above that of Green Belts. Black Belts are fully trained Six Sigma experts who lead improvement teams, work on projects and mentor Green Belts (Pavletic and Sokovic, 2002). Full time Black Belts lead improvement projects and in general receive about four weeks of training with certification (Linderman et al., 2002). Members of an organization's management team will certify a Black Belt after he or she have led two successful project teams where one is under the guidance of a Master Black Belt and the other is done more independently (Lucas, 2002). Black Belts can't simply be a consultant who is hired in to help out in a project. Black Belts should be committed because if a division or department fails, then Six Sigma will fail (Lexa, 2003).

There is no magic number that can tell an organization that they have the correct number of Black Belts. The requirements will change from company to company depending on the number of projects that it is willing to take on at a given time. Getting the correct number of Black Belts for your organization is important though simply because a major cost of Six Sigma is backfilling for the employees who become Black Belts (Lucas, 2002). Pavletic and Sokovic (2002) stated that Black Belts have to: develop and manage a detailed project plan; select, teach and use the most effective tools; schedule and lead team meetings; lead the team in the effective utilization of the Six Sigma methodology; oversee data collection and analysis; monitor critical success factors; calculate project savings; track and report milestones and tasks; complete four to 
six projects a year; mentor Green Belts, lead change and disseminate the Six Sigma visions.

Black Belts are the persons who accepts primary responsibility for the routine work and results of a Six Sigma project and their responsibilities include (Pande et al., 2002): reviewing/revising/clarifying the project rationale; working with team members; selecting or helping to select project team members; identifying and finding resources and data for the team; supporting team members; making sure the team uses its time effectively; maintaining the team's project schedule; supporting the transfer of new solutions or processes; and documenting final project results.

As can be seen here, Black Belts' responsibilities are plenty and vast. They are required to serve as role models, to be managers and to act as workers. They need a diverse set of skills, from an in depth knowledge of Six Sigma methodology to an in depth knowledge of project and people management.

\subsubsection{Master Black Belts}

Master Black Belts, as its name states, is the next step up in the belt system from being a Black Belt. Master Black Belts generally train Black Belts and they mentor them in their projects while also having to show progress and success to upper management (Smith, 2003). Master Black Belts receive even further training than Black Belts and they serve as instructors and internal consultants to the organization (Linderman et al., 2002).

Becoming a Master Black Belt is no easy task. It requires much work and dedication to the Six Sigma way. Master Black Belts usually require at least 20 successful projects, half of which could be done while they were a Black Belt and the 
remainder while mentoring Black Belts (Lucas, 2002). Having the Master Black Belt title means that you are a fully trained business leader who promotes and leads the deployment of Six Sigma in significant areas of the business (Pavletic and Sokovic, 2002). Pavletic and Sokovic (2002) summarizes what a Master Black Belts' responsibilities are: to formulate business strategies with senior management, aid in selecting projects that fit strategic business needs, conduct and oversee Six Sigma training, coach multiple Black Belts, leverage projects and resources, improve overall project execution efficiency, share Six Sigma methodology expertise, coordinate activities to drive project completion, participate in multiple projects, motivate others toward a common vision, communicate the Six Sigma vision, function as a change agent to leverage new ideas and best practices and to approve completed projects.

Master Black Belts, while being a knowledge base for all Six Sigma proceedings within an organization must not practice micromanagement ${ }^{1}$. Master Black Belts need to balance between advising and meddling (Pande et al., 2002). Pande et al. (2002) suggest that Master Black Belts should be able to provide guidance on: communicating; establishing and sticking to a firm schedule; dealing with resistance; estimating, measuring and validating dollar and other savings; helping to resolve team and other conflicts; gathering and analyzing data about team activities; helping teams promote and celebrate their successes.

\subsubsection{Six Sigma Project Champions and Sponsors}

Six Sigma Project Champions and Sponsors aren't necessarily skilled at Six Sigma methodologies and procedures. Project champions typically receive an orientation

\footnotetext{
${ }^{1}$ Micromanagement: the process of managing in a detailed, microscopic way; there is no empowerment and lack of freedom from upper management.
} 
to Six Sigma rather than detailed training (Linderman et al., 2002). They are usually a member of upper management who supports the project and removes any potential roadblocks. A likely source from where a Project Champion or Sponsor to come from is the CEO. The Champion is responsible for the success of the project, providing necessary resources and breaking down organizational barriers (Lucas, 2002). An important job of the Champion/Sponsor is to get upper management involved. Doing this helps guarantee the projects will have a large impact on the business. Pavletic and Sokovic (2002) stated that "champions in Six Sigma implementation are primarily responsible for the selection of Black Belt candidates, project selection criteria determination, Six Sigma project selection, allocation of the necessary project resources, removal "of all barriers to Six Sigma initiatives, Six Sigma promotion and change implementation completed projects approval."

It is important to note however that the Champion's role must be to give the project improvement team clear guidelines on their project, run interference for the team when it meets roadblocks within the organization, but avoid taking over the team or dictating a set solution for the team to implement (Pande et al., 2002). Pande et al. (2002) stated that the Champion's responsibilities should include: setting rationale and goal, being open to changes, coaching on and approving changes, finding resources, advocating for the team's efforts, running interference, working with other managers, learning the importance of data driven management.

Sponsors in a Six Sigma system play a very similar role to that of a Champion. Sponsors are owners of the processes and systems that help initiate and coordinate Six Sigma improvement activities in their areas of responsibility. Six Sigma sponsors are 
required to obtain the necessary approval for any process changes, select team members, communicate process knowledge, maintain team motivation and accountability, ensure that process improvements are implemented and sustained, communicate the Six Sigma vision (Pavletic and Sokovic, 2002).

\subsection{Evidence of Six Sigma Success}

From time to time Six Sigma may be referred to as a fad, but these statements are only made by the naïve who do not know the intricate details that is Six Sigma. Six Sigma is not a business fad tied to a single method or strategy, but rather, it is a flexible system for improved business leadership and performance. It builds on many of the most important management ideas and best practices of the past century (Pande et al., 2000). Although it still could be easy for some to dismiss Six Sigma as a fad if it weren't for the caliber of the results Six Sigma is producing and the companies adopting it. There is a stronger implication of Six Sigma moving in the opposite direction of a fad due to the number of well-known companies in industries from financial services to transportation to high tech that are quietly implementing Six Sigma efforts and reaping the benefits of doing such.

One of the more well-known companies who have implemented Six Sigma with great success is General Electric Company (GE). GE's 1999 annual report saw phenomenal results. After the Six Sigma initiative reached its fifth year in operation, it had flourished to the point where it produced more than $\$ 2$ billion in benefits for that year and the estimated annual savings in 2000 is about $\$ 6.6$ billion (Antony and Coronado, 2001). Mount Carmel Health System has been using Six Sigma since July 2000 and 
reports a financial return of $\$ 2.4$ million through the end of 2001. Mount Carmel credits its 43 black belts, who were working on 95 active Six Sigma projects (Burrington-Brown, 2002). Burrington-Brown (2002) stated that “...to the leadership of Mount Carmel, Six Sigma is not just a business management system, but performance improvement on steroids."

Motorola, where Six Sigma originated, have also seen many benefits coming from the system. During 1987 to 1994 Motorola reduced in process defect levels by a factor of 200 and reduced manufacturing costs by $\$ 1.4$ billion (Antony and Coronado, 2001). Seagate's IT department booked direct savings from Six Sigma estimating it to be about \$3.7 million during the previous fiscal year. This, while the company overall reported savings of more than $\$ 956$ million from Six Sigma since adopting the methodology (Prewitt, 2003).

Ford has had Six Sigma in the works since 1999. When the company's former director of corporate deployment for consumer driving sought an effective method to improve quality they elected Six Sigma as their program of choice. Top management soon joined the cheering section and Six Sigma efforts have been persistent ever since. Since Six Sigma's inception, Ford has saved about $\$ 1$ billion in waste elimination globally, while year over year savings worldwide was $\$ 359$ million (Smith, 2003). Smith (2003) stated that what's even more important is that customer satisfaction has risen five percentage points in the company's internal customer satisfaction survey. In 2001, when Ford's Six Sigma initiative was just getting underway JD Power and Associates Initial Quality Study ranked Ford last among the big seven automakers. In 2003's Initial Quality Study, Ford was the most improved automaker and was ranked No. 4. This is not 
the No. 1 position Ford wanted, but it is definite proof that its quality improvement efforts are on the right track.

Citibank searched for different quality methodologies that would help their processes to increase accuracy and get better customer satisfaction. They identified the entire funds transfer process, tabulated defects and analyzed them using Six Sigma tools. After the analysis, they saw that the internal call-back procedures were deemed the main defect and then focused on solving this problem. By using Six Sigma, they saw an astonishing $73 \%$ decrease in call-backs (Rucker, 2000).

Ultimately, Six Sigma is about saving money as well as improving quality (Burrington-Brown, 2002). However, companies that have decided to adopt Six Sigma must know that to see benefits, they need to wait and they need to be long term focused (Dale, 2000). It should be noted that not all processes should necessarily be at the Six Sigma level, the level that the process is at will depend on the strategic importance of the process and the cost of the improvement relative to the benefit (Linderman et al., 2002). Antony and Banuelas (2002) summarized some of the major savings and quality improvement efforts which are presented in Table 2.11 . 


\begin{tabular}{|c|c|}
\hline Company & Improvements/Savings \\
\hline Motorola (1987-1994) & $\begin{array}{l}\text { - Reduced in-process defect levels by a factor of } 200 \\
\text { - Reduced manufacturing costs by } \$ 1.4 \text { billion } \\
\text { - Increased stockholders share value four-fold }\end{array}$ \\
\hline $\begin{array}{l}\text { Allied Signal (1992- } \\
\text { 1996) }\end{array}$ & $\begin{array}{l}\text { - Reduced new product introduction time by } 16 \% \\
\text { - Reduced manufacturing costs by more than } \$ 1 \\
\text { billion }\end{array}$ \\
\hline $\begin{array}{l}\text { General Electric (1995- } \\
1998)\end{array}$ & - Company wide savings of over $\$ 1$ billion \\
\hline $\begin{array}{l}\text { Service \& Transactional } \\
\text { Processes }\end{array}$ & $\begin{array}{l}\text { - Reduced medication and laboratory errors and } \\
\text { thereby improved patient safety (Buck, 2001) } \\
\text { - Significant savings in process timeliness, } \\
\text { improvements in cash management and increased } \\
\text { customer loyalty and satisfaction (Rucker, 2000) }\end{array}$ \\
\hline
\end{tabular}

Table 2.11 - Companies and their Six Sigma results

\subsection{Why Six Sigma is not Total Quality Management (TQM)}

Six Sigma essentially builds on top of a lot of the TQM tools. Both Six Sigma and TQM emphasize the importance of top-down support and leadership. The two approaches preach that continuous improvement of quality is critical to long term business success. A big difference between the two is management. TQM provided only very broad guidelines for management to follow while at the same time the guidelines were generally abstract that only the most gifted leaders were able to knit together a successful deployment strategy for TQM (Pyzdek, 2001). Pyzdek (2001) also noted that TQM offered a mushy set of philosophical guidelines and there was no way to prove that 
one had accomplished their quality goals. This made TQM very hard to track and allowed many within the organization to only say at face-value that they were practicing TQM.

Six Sigma introduces the concept of fulltime, temporary change agents (black belts) making up about one percent of the workforce. They are dedicated to producing change and their performance is judged by their innovation in producing improvement that benefit customers, shareholders or employees (Burrington-Brown, 2002).

In many TQM programs of the past, people were unable to point to specific bottom-line benefits, so interest gradually faded and the programs were ended when times got tough (Pyzdek, 2003). Ford found that one of the biggest differences between Six Sigma and TQM is that previous philosophies focused on fixing the problem and did not worry about the cost (Antony and Coronodo, 2002). Ford found that Six Sigma is a lot more structured and profit-oriented than TQM.

Niles (2000) stated that Six Sigma is different from TQM in the sense that it builds on TQM in terms of tools, techniques and principles. From a global perspective, it's a whole new methodology in terms of (Niles, 2000):

1. A New Type of Top Level Support

2. Problem Solving and Team Leading Super Stars

3. Extensive Training

4. New Metrics are used (ie. DPMO)

5. Better Use of Teams

6. New Level of Process Comparisons

7. New Corporate Attitude / Culture 
8. Closer Look at Old Metrics

Pande et al. (2000) summarizes the TQM pitfalls along with the Six Sigma solutions. A summary of the table by Pande et al. (2000) is summarized in Table 2.12:

\begin{tabular}{|c|c|}
\hline TQM Pitfall & Six Sigma Solution \\
\hline - Lack of integration & $\begin{array}{l}\text { - Links to the business and personal } \\
\text { "bottom line" }\end{array}$ \\
\hline - Leadership apathy & - Leadership at the Vanguard \\
\hline - A Fuzzy Concept & $\begin{array}{l}\text { A Consistently Repeated, Simple } \\
\text { Message }\end{array}$ \\
\hline - An Unclear Goal & $\begin{array}{l}\text { - Setting a No-Nonsense, Ambitious } \\
\text { Goal }\end{array}$ \\
\hline $\begin{array}{l}\text { Purist Attitudes and Technical } \\
\text { Zealotry }\end{array}$ & $\begin{array}{l}\text { - Adapting Tools and Degree of Rigor to } \\
\text { the Circumstances }\end{array}$ \\
\hline $\begin{array}{l}\text { Failure to Break Down Internal } \\
\text { Barriers }\end{array}$ & $\begin{array}{l}\text { - Priority on Cross Functional Process } \\
\text { Management }\end{array}$ \\
\hline $\begin{array}{l}\text { Incremental vs. Exponential } \\
\text { Change }\end{array}$ & - Incremental Exponential Change \\
\hline - Ineffective Training & $\begin{array}{l}\text { - Blackbelts, Greenbelts, Master } \\
\text { Blackbelts }\end{array}$ \\
\hline - Focus on Product Quality & - Attention on All Business Processes \\
\hline
\end{tabular}

Table 2.12 - TQM vs. Six Sigma 


\subsection{The ISO 9000 Certification}

Besides the use of TQM and the use of Six Sigma, the ISO standard is another quality initiative that is widely used. ISO 9000 have been used by many organizations in various industries to mark their quality initiatives (Lee et al., 1999). ISO 9000 is a series of standards which is based on the concepts of quality, management and system (Lim, 1998). The acronym ISO stands for the International Organization for Standardization, which is a worldwide federation of national standards bodies from more than 150 countries established in 1947 . There are many reasons as to why an organization chooses to get certification with the ISO 9000 standard. Many companies choose to put in place ISO 9000 because they simply want to improve the image and reputation of their company, in order to satisfy external requirements and market pressures, to help in their procedures and contracts with their clients, and to improve their productivity, the organization and the operation of their quality system (Tsiotras and Gotzamani, 1996).

There are some ISO 9000 practitioners who state two different types of benefits in using ISO 9000. Brown et al. (1998) revealed three important internal benefits derived from ISO 9000 certification:

- Improvement in the awareness of the importance of quality

- Improvement in the awareness of the problems of the company

- Improvement in the product quality

Quazi and Padijbo (1998) however, summed up four types of external benefits of the ISO 9000 certification:

- Increase in customer satisfaction

- Improvement of the product quality 
- Competitiveness in the market

- Satisfying customers requirements

However many advantages that the ISO 9000 certification may bring; there are also some drawbacks that it may also reveal. Most of these drawbacks though, may be overcome using the Six Sigma system. As a quality assurance management model, ISO 9000 only prescribes the minimum requirements for certification. This is compared to the Six Sigma system where there is no minimum requirement; rather it is a never-ending system that improves quality with each iteration. To pass the certification audit that is part of the ISO 9000 certification, the company is only required to document its management system and keep the relevant records, the company does not have to aim for excellence, just a "good enough" mentality (Lee et al., 1999). This is in fact the opposite of Six Sigma where there is no stop until near perfection is reached.

A survey was done on the ISO 9000 standard to investigate the usefulness of the certification. This survey took place from August to November 1997 and a report on the survey, together with a number of recommendations was published in December 1997 (Lee et al., 1997). The results of this survey showed that a majority of certified companies would still like to further improve their quality systems while also stating that there is a lack of understanding on how quality can be improved on the basis of ISO 9000 (Lee et al., 1999). Many other practitioners and academics of ISO 9000 also state that another weak point of ISO 9000 is that there is no requirement on business results while the requirements on performance measurement and indicators are also very scarce (Lee et al., 1999). 
However weak that ISO 9000 maybe on its own, the International Organization for Standardization have tried to correct its shortfalls by introducing ISO 9000:2000. ISO 9000:2000 builds on the previous standard but it presents a structure more focused on procedures, in which the continuous improvement and the measure of customer satisfaction has a very important role in (Casadesus and Gimenez, 2000). 


\subsection{Theoretical Framework}

\subsection{Research Problem}

It has been said that Six Sigma can be implemented in either at a tactical level (in a part of a process or of the company, with only local management support) or as a strategic initiative (company wide, covering entire business processes, with senior management support \& funding). This study provides insight to the strategic initiatives of companies by studying the variables that affect the successful implementation of Six Sigma in medium to large size Canadian manufacturing firms.

\subsection{Research Objectives}

In implementing Six Sigma it is important to recognize the key factors of the methodology because Six Sigma itself can be a very complex and central process (Coronado and Antony, 2002). Key factors in Six Sigma can be defined as those that are vital to the success of implementation. In other words, the key factors in a Six Sigma implementation process are those that, if not present, would make the project more likely to fail. The methodologies of Six Sigma are still considered to be very novel in the quality field and because of this there has not been much research done on this topic. Of the studies that were reviewed in this research, there only exists a handful that investigated key success factors for a successful Six Sigma implementation.

In order to study the factors in the successful implementation of Six Sigma, the objective of the research are threefold. The first objective of this research is to examine the extent of use of Six Sigma in medium to large size Canadian manufacturing firms. Medium and large size firms are being focused on because many SMEs fail to utilize Six 
Sigma due to its costs of deployment and implementation (Dusharme, 2003). Harry (2000) stated that "Smaller companies don't have the resources to train the way that large-scale corporations do... It's not just the cost but the operational management in terms of human resources. How many engineers can a company free up for four months of learning?" The second objective is to examine the top three most important success factors and the three least important success factors to organizations that utilize Six Sigma. The third objective is to identify which key success factors influence the different types of success the most, where success is measured by the elements stated below and elaborated on in the following sections:

- Financial

- Defects Per Million Opportunities (DPMO)

- Customer Satisfaction

- Performance of Internal Work Processes

- Supplier Performance

\subsection{Factors in the Successful Implementation of Six Sigma}

The factors that affect Six Sigma implementation success can be vast and many. However, summed up here are the general categories which are important to the implementation of Six Sigma. In order to establish the key factors for the successful implementation of Six Sigma, an exploratory study was used to find similar studies that have been done by different authors. Authors such as Pande et al. (2000), Henderson and Evans (2000), Locke and Latham (1990) and Antony and Banuelas (2002) have done similar studies. Henderson and Evans (2000) stated that upper management involvement, 
organization infrastructure, training and statistical tools are the major components for a successful Six Sigma implementation. On the other hand, Antony and Banuelas (2002) used previous studies to conclude that management involvement \& commitment, cultural change, organization infrastructure, training, project management skills, project prioritization \& selection, review and tracking, understanding the Six Sigma methodology, tools and techniques, linking Six Sigma to business strategy, linking Six Sigma to the customer, linking Six Sigma to human resources and linking Six Sigma to suppliers are the key ingredients to Six Sigma success. Locke and Latham (1990) stated that organizational change efforts require a high level of commitment from organizational members. It is also desirable to understand the factors that promote or deter commitment. They found that factors which help to promote and deter commitment are: authority, peer influence, public awareness, incentives, rewards and punishment.

In addition, practitioners like Sandholm and Sorqvist (2002), Goldstein (2001), Badri et al. (1995), Mann and Kehoe (1995) and Chang (2003) also studied success factors. Sandhold and Sorqvist (2002) and Goldstein (2001) both studied the keys to success of Six Sigma. Badri et al. (1995) used an empirical study to find the keys to quality management and Mann and Kehoe (1995) studied the keys to TQM success all of which play a large part in assessing the factors to Six Sigma success. Chang (2003) recently did a survey study that looked at the keys to Six Sigma success which saw the researcher find ten variables and ranked them according to importance.

The purpose of this paper is not to prove or disprove any of the previous studies done. Rather, the attempt here will be to expand on our understanding of the issues at hand which is to find the key factors in the successful implementation of Six Sigma, 
especially the factors related to medium to large size Canadian manufacturing firms. Descriptions of the different factors that affect successful Six Sigma implementation are described below. An elaboration of each element is included. The reader should note that the variables used here may be correlated in some cases as the researcher's approach for this thesis is to put into place a combination of variables that were used prior to this study while ultimately using stepwise multiple linear regression analysis to test these variables

Financial support is an important aspect of Six Sigma in order to get the initiative started. Education is a key component of establishing a good foundation in your Six Sigma program. Even though teaching by books and video are able to get the job done, they can only achieve the end goal by the most minimal standard. To really allow Six Sigma to thrive, the organization has to invest in the program by funding training in-house or training offsite. The Six Sigma program requires the financial backing from top management to do what it takes to implement Six Sigma completely. Failure to have enough financing to implement Six Sigma can spell disaster due to a lack of knowledge and the lack of knowing what Six Sigma truly can do for your company. In this study financial support is measured by the amount of financing directed towards Six Sigma initiatives. Issues such as budgets allocated to Six Sigma deployment and the amount invested in education are both areas that are considered financial support of Six Sigma.

Integrate Six Sigma to Business Strategy is also very important. Six Sigma cannot be treated as something by itself, but instead it must be targeted for process and product improvements that have a direct impact on both financial and operations goals 
(Antony and Coronodo, 2002). Six Sigma requires adherence to a whole philosophy rather than just the usage of a few tools and techniques of quality improvement (Dale, 2000). It needs to be clear how Six Sigma projects and other activities link to customers, core processes and competitiveness (Pande et al., 2000). It is usually obvious that the goal of every organization is to increase profits. Six Sigma projects help to make business processes more profitable. Integrating Six Sigma to Business Strategy is measured by assessing to what extent Six Sigma is used in a company's strategy process along with the extent to which Six Sigma is apparent throughout the organization. If Six Sigma is well known across the company and is relayed to employees as a key strategy to the overall company success, then it is thought that Six Sigma is well integrated into the company strategy.

Management Involvement and Commitment is an essential part to the success of Six Sigma. Any initiative as vast as Six Sigma requires top management involvement and provision of appropriate resources and training (Halliday, 2001). The techniques and skills involved with Six Sigma must be taught to senior managers within the organization. Jack Welch, the CEO of GE, has strongly influenced and enabled the restructuring of the business organization and changed the attitude of the employees towards Six Sigma (Henderson and Evans, 2000). Without the continuous support and commitment from top management, the true importance of the initiative will be in doubt and the energy behind it will be weakened (Pande et al., 2000). Furthermore, the CEOs at Motorola, AlliedSignal, GEC and Seagate Technology all led the Six Sigma implementation efforts (Linderman et al., 2002). Management Involvement and Commitment in this study is measured by the extent to which management works within the Six Sigma system and by 
how well management has taken measures to implementing a sustainable Six Sigma environment.

Organizational Infrastructure is yet another important factor. An effective organizational infrastructure in place to support the Six Sigma introduction and development program is needed for the successful implementation of Six Sigma. In a large number of corporations, Six Sigma initiatives are led by the CEO or vice-president, who is considered as the Six Sigma champion. Following the champion, the creation of Master Black Belts, Black Belts, and Green Belts will be needed. Besides the belt system, the Six Sigma program also requires project sponsors who give guidance to the project team and find and negotiate resources and budget for any given project. The timing and readiness of the organization is also important. Having an effective belt system is only the beginning of having your organization ready to take on Six Sigma. It is highly desirable to have some degree of communication skills, long term focus/strategy and teamwork, moreover, it should have enough resources and investment to embark on Six Sigma (Antony and Coronodo, 2002). Organizational Infrastructure can be determined by measuring the extent of Champions, Master Black Belts, Black Belts and Green Belts within the organization. An organization with an infrastructure which is inclusive of the Six Sigma belt system, at all belt levels, is thought to have an infrastructure which is conducive to Six Sigma success.

Being able to Integrate Six Sigma to Human Resources is also important. Human resources based actions need to be put into effect to encourage desired behaviour and results. Being able to change behaviour over the long term requires Six Sigma goals to be internalized on the individual level (Antony and Coronodo, 2002). The success of 
Six Sigma requires an awareness of quality into the way all employees approach their everyday work (Pavletic and Sokovic, 2002). Integrating Six Sigma to Human Resources is measured by looking at the company's incentive systems for Six Sigma efforts, by its motivational commitments to Six Sigma and by its hiring processes for Six Sigma.

Integrating Six Sigma to Suppliers would also be useful. Organizations will find it beneficial to extend the application of Six Sigma principles to management of their supply chain. You simply cannot be a "Six Sigma Company" without your suppliers participating in the culture change (Hendricks and Kelbaugh, 1998). Under Six Sigma philosophies, one way to reduce variability is to have few suppliers with high Sigma performance capability levels (Pande et al., 2000). Integrating Six Sigma to Suppliers in this study is measured by looking at how many of the company's suppliers are practicing Six Sigma and whether or not the suppliers' performance has increased since Six Sigma had been initiated.

Training is a key component because it is critical to "communicate both the 'why' and the 'how' of Six Sigma as early as possible, and provide the opportunity to people to improve their comfort level through training classes" (Hendricks and Kelbaugh, 1998) before allowing employees to start using Six Sigma. There is typically a hierarchy of expertise, which is identified by the belt system. It should be mentioned however, that training is not effective for simple tasks; in fact training actually decreases performance for simple tasks (Linderman et al., 2002). Training is measured by assessing the amount of time each employee who is a part of the Six Sigma system receives formal training and the formality of the training program evident in the Six Sigma organization. 
Project Management Skills is also very important because the foundation of Six Sigma is based around the execution of successful projects. To this end, project managers must have at least some basic project management skills. Most of the projects while implementing Six Sigma fail due to poor management skills, setting agendas, setting and keeping ground rules, determining the meetings' roles and responsibilities or undesired facilitative behaviours (Eckes, 2000). Project Management Skills in this research is measured by looking at how many of the Six Sigma members have formal project management certification and how many different projects each Master Black Belt and Black Belt has overseen.

Along with the training in project management skills, being able to possess the skills in Project Prioritization, Selection, Review and Tracking are also important. When projects are selected, it is important to define their scope and limitations showing what the team will be and will not be working on; moreover, the project goals or objectives must reflect the critical quality requirements from the customer (Antony and Coronodo, 2002). Pande et al. (2000) provide three generic categories of project selection criteria, these are:

1. Business benefits criteria

2. Feasibility criteria

3. Organizational impact criteria

Project Prioritization, Selection, Review and Tracking is measured in this study by assessing whether there are formal procedures in place to select each given project and also on whether there are formal measures which gauge ongoing compliance status of the project's original specifications. 
Understanding the Six Sigma Methodology, Tools and Techniques is a key aspect within the Six Sigma implementation system. A healthy part of the Six Sigma system involves learning the principles behind the Six Sigma methodology. Equipping all the necessary people, from management to employees, with the tools for Six Sigma will give a positive impact to success (Chang, 2003). There are two methodologies that are predominant. They are the DMAIC methodology and the DFSS methodology, both of which are elaborated on above. Being able to understand Six Sigma Methodology, Tools and Techniques is measured in this study by assessing how apparent the comprehension of DMAIC and DFSS is within the organization.

Statistical Tools are also a main part of a Six Sigma organization. This is because Six Sigma involves utilizing statistics to monitor and analyze data. Control charts, hypothesis tests and regression analysis are only the beginning when thinking of the statistical tools that can be used in the Six Sigma process. The need for understanding different statistical tools required in a Six Sigma process is the starting point of any implementation process. Statistical tools use should at least start with a method of process thinking (Maleyeff and Kaminsky, 2002). The use of Statistical Tools in this study is measured by assessing which types of statistical methods are used, and whether or not statistical analysis techniques are used.

Rewards are also a key part of Six Sigma success. Being able to acknowledge and benefit the people who actually make Six Sigma successful is important. There must be recognition for a job well done in the part of management in order for employees to celebrate their success. Rewarding the employees or members of a Six Sigma team for their hard work and dedication to the program is important for the long term success of 
Six Sigma (Grazier, 1998). Rewards is measured by the type of incentives given to members of the Six Sigma system and also by what a team does after a full Six Sigma project is completed.

Corporate Culture is another important factor. A successful introduction and implementation of Six Sigma need an appropriate culture within the organization and a supportive attitude from its employees. Employees need to have motivation and accept responsibility for the quality of their own work. Six Sigma requires the right way of thinking and attitude of people working within the organization at all levels. A big part of Six Sigma implementation includes change. Usually when important change occurs, the people in the organization are afraid of the unknown and they do not understand the need for change. Companies that have succeeded in managing change have identified that the best way to tackle resistance to change is through increased and sustained communication, motivation and education (Antony and Coronodo, 2002). Eckes (2000) identifies four different factors of resistance to change, they include:

1. Technical: Frequently people find it difficult to understand statistics, in order to reduce this, information, education and involvement is needed.

2. Political: The strategy to avoid this is to educate the employees on the need for change then show them how change can benefit them.

3. Individual: This can include employees who are stressed due to personal problems and not associated with the company. This can be reduced by a smaller workload.

4. Organizational: This is usually set by the company as a whole which can be eliminated by communicating the benefits of the initiative. 
Corporate Culture is measured by assessing the respondents' perception of their organizational environment with respect to Six Sigma. If an organization's culture is quality oriented and Six Sigma is a term which is equivalent to its quality initiatives, then the organization is thought to have a Six Sigma culture. Examples that can be used in this study include flexibility, paying attention to detail, being results oriented, being demanding and having high expectations for performance (Mallak et al., 1997).

Linking Six Sigma to the Customer is important because projects should essentially begin with the determination of customer requirements. Pande et al. (2000) argue that before customer needs can be met successfully, there has to be a good understanding of the organization and its relation to various business activities. A key step in any Six Sigma improvement effort is determining exactly what the customer requires and then defining defects in terms of their "critical to quality" parameters (Linderman et al., 2002). Measuring the Linkage of Six Sigma to the Customer in this study is achieved by assessing how the organization uses customer feedback to adapt their Six Sigma projects and assessing where their ideas for new projects are derived.

Communication is important in order to involve the personnel with the Six Sigma initiative by showing them how it works, how it is related to their jobs and the benefits from it (Henderson and Evans, 2000). By doing this, resistance to change can be reduced. After implementation of Six Sigma projects, it is a good idea to publish results, but these should not be restricted to success stories but also admit and communicate setbacks as well because this will ultimately help build the employees' trust in future management initiatives (Antony and Coronodo, 2002). Communication in this study is 
measured by how often employees are updated on Six Sigma progress and how often management communicates the Six Sigma fundamentals to employees.

Goal Setting is yet another variable that plays a part in success in Six Sigma. Research has shown that there is a strong relationship between goal setting and performance. Linderman et al. (2002) identified several studies that showed evidence of goal setting with performance. White and Locke (1981) studied a multinational company and found goal setting correlated with performance for managers, clerical workers and professionals. Research also suggests that "A clear goal is the center piece of Six Sigma. It is an extremely challenging goal, but still believable, unlike past campaigns for zero defects" (Pande et al., 2000). Goal setting often begins in the early phases of a Six Sigma improvement project, when data is collected from the process (Linderman et al., 2002). There have also been many studies that identified the relationship between goal difficulty and performance. Locke (1967) showed that the performance of subjects with hard goals were $250 \%$ higher than those with easy goals. Locke and Latham (1990) also reviewed over 170 research papers on goal difficulty and performance, from which they found a positive relationship between goal difficulty and performance in over $90 \%$ of the articles reviewed. These studies lead them to conclude that in general difficult goals result in increased levels of performance; however, a decrease in performance was found if goals became too difficult. Specific quantitative goals tend to result in less deviation from the target level of performance than "do-best" goals (Linderman et al., 2002). Goal setting is measured in this study by assessing how goals in Six Sigma projects are defined and how often the goals are met within the organization. 


\subsection{How Success is Measured in the Implementation of Six Sigma}

An important aspect of being able to measure the success of Six Sigma is being able to define what success actually is within the Six Sigma system. Some Six Sigma consultants typically define successful deployments of Six Sigma in the following way: A successful Six Sigma deployment is one that provides an acceptable ROI and leaves a stand-alone program (not requiring further assistance from outside resources) (Carnell, 2000). However, ROI is not the only gauge used in the Six Sigma world that indicates success. Financial numbers are only a fraction of the measures used to define success in Six Sigma. From the review of literature there are generally five variables that repeatedly came up when measuring success, they include: Financial Measures, Defects Per Million Opportunities, Customer Satisfaction, Performance of Internal Work Processes and Suppliers' Performance.

With the many gauges that are used to measure the success of Six Sigma, Financial measurements are usually very apparent. Many companies have measures that show how much money is being saved from pre to post Six Sigma implementation (Antony and Banuelas, 2002). Many other companies will measure the profitability that they incur due to Six Sigma implementation, Henderson and Evans (2000) summarized how GE has become much more profitable as a direct result of Six Sigma. Obviously there are many other different types of financial measures that can be used to assess the success of Six Sigma besides profits and savings in dollars. Anything from ROI (Return on Investment), to ROE (Return on Equity) to EVA (Economic Value Added) can all be used to gauge Six Sigma's financial success. 
Another common measure of success in the Six Sigma system is the use of measuring the number of Defects Per Million Opportunities (DPMO). DPMO indicates how many defects would arise if there were one million opportunities (Pande et al., 2000). From time to time, DPMO will be referred to as Parts Per Million (PPM). The goal of Six Sigma is to reach 3.4 DPMO, where 3.4 DPMO translates to a process operating at Six Sigma quality (Lucas, 2002). Generally speaking, the lower the DPMO, the better is the process. Associated directly with DPMO is the obvious measure of sigma levels that a system is operating at. For further information about the association of DPMO and the sigma performance levels, please refer to Table 2.7.

In a Six Sigma system customers are at the centre of attention, which makes Customer Satisfaction another measure of Six Sigma success. By measuring performance against customer requirements would allow an organization to see exactly how they are doing in the customer's eyes with respect to their Six Sigma initiatives. Customer satisfaction of course, is what Six Sigma is all about (Olexa, 2003). Pande et al. (2000) stated that Six Sigma should always start and end at the customer, where Six Sigma measures require definition of what the customer's requirements are, then at the end of the process, it must also be assessed whether or not the customer's requirements have been satisfied.

The Performance of Internal Work Processes are also considered to be an important measure as to the success of Six Sigma. Things such as cycle times and product and service quality are all measures of an organization's internal processes. By being able to reduce new product introduction time can be a vital measure to how a Six Sigma system worked (Antony and Banuelas, 2002). The internal processes can also be 
measured in terms of the employee's productivity as well, where an increase in productivity would mean an improvement towards success of Six Sigma (Harry, 1998).

Being able to measure dollars and cents and internal processes in a Six Sigma system is not enough when trying to measure its total success. An organization should also measure the external results as well, namely its Suppliers' Performance. The performance of a supplier against an organization's own requirements is a good indication of Six Sigma success. The improvement of your suppliers over the course of your Six Sigma implementation will have a major say as to the success of your Six Sigma initiative (Goldstein, 2001). A good supplier quality management system is said to be a large factor as to whether or not an organization truly achieves Six Sigma levels of success (Badri, 1995).

\subsection{Research Questions}

By using the objectives stated above, along with the research problem, the following investigative questions can be critically examined:

1. What are the key factors to the successful implementation of Six Sigma?

2. How is success measured in a Six Sigma organization?

3. What are the three most important and the three least important factors to the successful implementation of Six Sigma?

4. How do each of the factors to the success of Six Sigma relate to the different measurements of success?

5. To what extent do medium to large Canadian manufacturing firms utilize the Six Sigma methodologies? 


\subsection{Research Hypotheses}

Based on the above discussion a research model for this study has been developed. Figure 3.6 shows the factors involved in Six Sigma success. It also shows measures of success of a Six Sigma system. The factors to the successful implementation of Six Sigma are split into four categories which reflect their respective characteristics. These categories include Financing Six Sigma, Integration Strategy for Six Sigma, Managerial System for Six Sigma and Six Sigma Educational Underpinnings. 

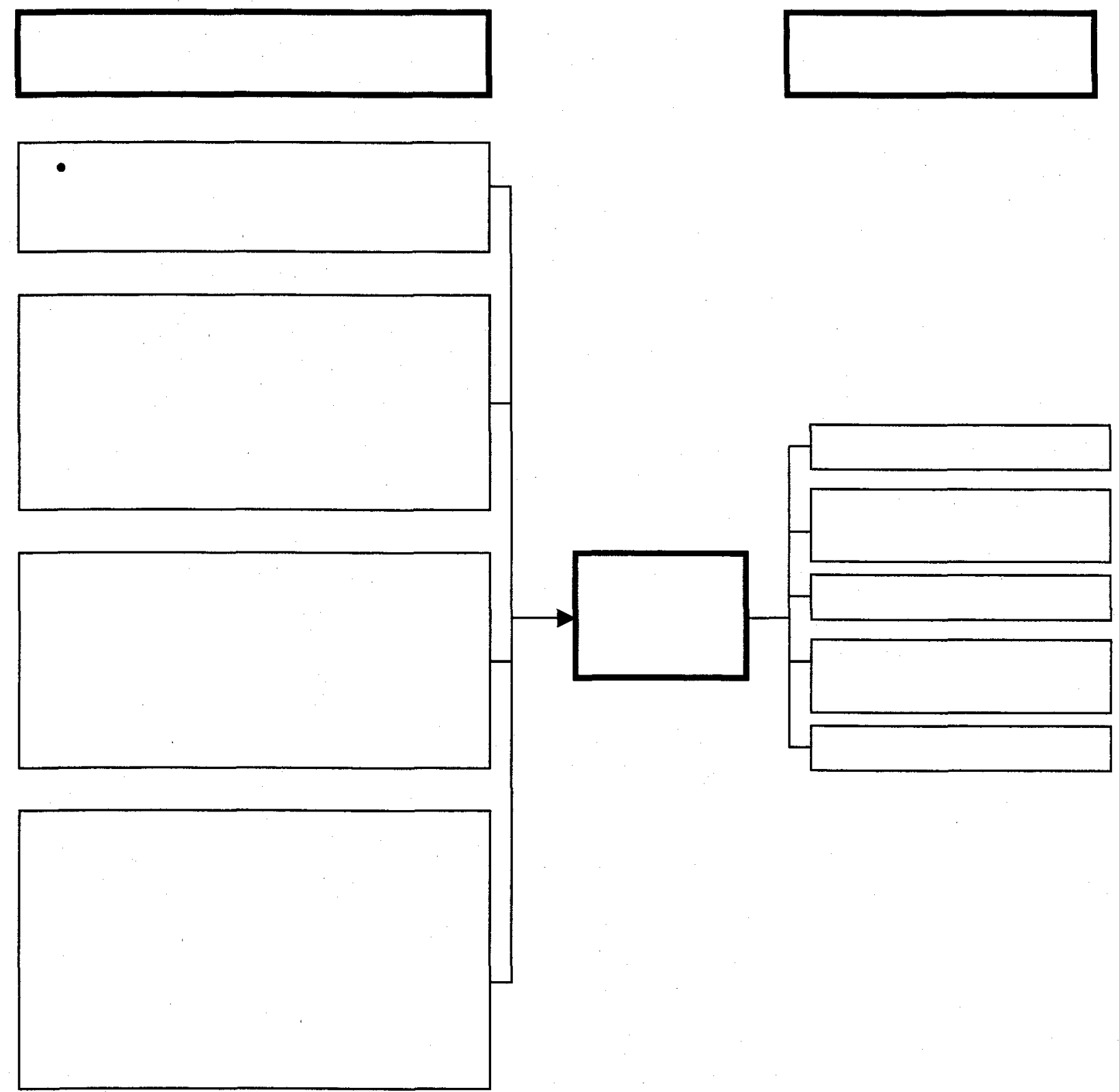

Figure 3.6-Model of Research of Six Sigma Success 


\subsubsection{Hypotheses}

Following is a list of hypotheses that were developed based on the above framework. The variables mentioned in the hypotheses are explained in detail in Sections 3.3 and Section 3.4. The hypotheses also takes into consideration all the information presented in this thesis and the literature review accompanying it. These are presented for means of being able to test them throughout the study.

\section{Financing Six Sigma}

Financing Six Sigma includes all the variables that were discussed above that involve a financial element for the variable to be used. Variables such as Financial Support and Rewards both fall under this category as they are both driven directly by financing.

\section{Hypothesis 1}

a) Using more Financing for Six Sigma implementation increases Financial Performance.

b) Using more Financing for Six Sigma implementation decreases Defects per Million Opportunities.

c) Using more Financing for Six Sigma implementation increases Customer Satisfaction.

d) Using more Financing for Six Sigma implementation increases the Performance of Internal Work Processes.

e) Using more Financing for Six Sigma implementation increases Suppliers' Performance.

\section{Integration Strategy for Six Sigma}

The Integration Strategy for Six Sigma includes those variables that have a direct impact on the organization's strategy. This group is defined by the elements that are required to be integrated into the corporate system. Variables such as Integrate Six Sigma to Business, Organizational Infrastructure, Integrate Six Sigma to Human 
Resources, Integrate Six Sigma to Suppliers and Linking Six Sigma to the Customer all

fall into this category.

\section{Hypothesis 2}

a) Use of Integration Strategy for Six Sigma implementation increases Financial Performance.

b) Use of Integration Strategy for Six Sigma implementation decreases Defects per Million Opportunities.

c) Use of Integration Strategy for Six Sigma implementation increases Customer Satisfaction.

d) Use of Integration Strategy for Six Sigma implementation increases the Performance of Internal Work Processes.

e) Use of Integration Strategy for Six Sigma implementation increases Suppliers' Performance.

\section{Managerial System for Six Sigma}

Managerial System for Six Sigma includes those variables which are directly controlled under management but are not financial in nature. Variables such as Managerial Involvement \& Commitment, Corporate Culture, Communication and Goal Setting all fall into this category.

\section{Hypothesis 3}

a) Use of Managerial System for Six Sigma implementation increases Financial Performance.

b) Use of Managerial System for Six Sigma implementation decreases Defects per Million Opportunities.

c) Use of Managerial System for Six Sigma implementation increases Customer Satisfaction.

d) Use of Managerial System for Six Sigma implementation increases the Performance of Internal Work Processes.

e) Use of Managerial System for Six Sigma implementation increases Suppliers' Performance.

\section{Six Sigma Educational Underpinnings}

The Educational Underpinnings group includes those variables that require some formal training or experience to be used appropriately. Variables that fall into this category include Training; Project Management Skills; Project Prioritization, Selection, 
Review \& Tracking; Understand Six Sigma Methodology, Tools \& Techniques; and Statistical Tools.

\section{Hypothesis 4}

a) Use of Educational Underpinnings for Six Sigma implementation increases Financial Performance.

b) Use of Educational Underpinnings for Six Sigma implementation decreases Defects per Million Opportunities.

c) Use of Educational Underpinnings for Six Sigma implementation increases Customer Satisfaction.

d) Use of Educational Underpinnings for Six Sigma implementation increases the Performance of Internal Work Processes.

e) Use of Educational Underpinnings for Six Sigma implementation increases Suppliers' Performance.

\section{Moderated Relationship}

The moderated relationships in this study include those that are a combination of the above mentioned variables. The use of any set of variables mentioned above to affect the successful implementation of Six Sigma is addressed here.

a) Financing, Integration Strategy, Managerial System and Educational Underpinnings for Six Sigma implementation will all have different effects on increasing Financial Performance.

b) Financing, Integration Strategy, Managerial System and Educational Underpinnings for Six Sigma implementation will all have different effects on decreasing Defects per Million Opportunities.

c) Financing, Integration Strategy, Managerial System and Educational Underpinnings for Six Sigma implementation will all have different effects on increasing Customer Satisfaction.

d) Financing, Integration Strategy, Managerial System and Educational Underpinnings for Six Sigma implementation will all have different effects on increasing the Performance of Internal Work Processes.

e) Financing, Integration Strategy, Managerial System and Educational Underpinnings for Six Sigma implementation will all have different effects on increasing Suppliers' Performance. 


\subsection{Research Methodology}

The preliminary data collected focused on determining which key factors attribute to the successful implementation of Six Sigma. The data collected was based on the perceptions of Managers, Six Sigma Champions/Sponsors, Six Sigma Master Black Belts, Six Sigma Black Belts, Six Sigma Green Belts and team members across organizations. The study provides insight for Canadian organizations implementing or thinking about implementing Six Sigma.

In considering the design of this research, there were four main research design methods considered with each having their strengths and weaknesses over each other. These design methods include Field Studies, Surveys, Field Experiments and Laboratory Experiments. These four methods were categorized into Ex Post Facto Designs which included Field Studies and Surveys; and into Experimental Designs which included Field Experiments and Laboratory Experiments. A breakdown of these methods are outlined below in Table 4.0 .

\begin{tabular}{|l|l|l|l|l|}
\hline Design Type & \multicolumn{2}{|l|}{ Ex Post Facto Designs } & \multicolumn{2}{|l|}{ Experimental Designs } \\
\hline $\begin{array}{l}\text { Distinguishing } \\
\text { Factor }\end{array}$ & $\begin{array}{l}\text { No Manipulation of Independent } \\
\text { variable(s) }\end{array}$ & $\begin{array}{l}\text { Manipulation of independent } \\
\text { variable(s) }\end{array}$ \\
\hline $\begin{array}{l}\text { Primary Goal } \\
\text { of Study }\end{array}$ & Exploratory & Descriptive/predictive & & $\begin{array}{l}\text { Causal } \\
\text { (explanatory) }\end{array}$ \\
\hline $\begin{array}{l}\text { Degree of } \\
\text { Understanding }\end{array}$ & Low & \multicolumn{3}{|l|}{ High } \\
\hline Subtypes & Field Studies & Surveys & $\begin{array}{l}\text { Field } \\
\text { Experiments }\end{array}$ & $\begin{array}{l}\text { Laboratory } \\
\text { Experiments }\end{array}$ \\
\hline
\end{tabular}

Table 4.0 - A Comparison of the Major Types of Research Designs

Source: Davis, Duane (2000) Business Research for Decision Making, Fifth Edition, Duxbury Press. 
The nature of this research study did not require any manipulation of independent variables, as the variables themselves were not ranked as to which were considered most important. Therefore, an Ex Post Facto Design made the most sense. An exploratory secondary research was conducted which helped in determining which factors (independent variables) were included (presented above). However, more details and understanding was required, thus a survey method was deemed most feasible and reliable for this instance. After realizing that a survey was the best approach to this study, an assessment of the various different types of survey instruments were required in order to come up with a decision as to which one would fit this study best. Below is a table of the different types of survey instruments that were contemplated on to be used, with the advantages and disadvantages outlined for them summarized in Table 4.0.1. 


\begin{tabular}{|l|l|l|}
\hline Survey Types & Advantages & Disadvantages \\
\hline $\begin{array}{l}\text { Personal } \\
\text { Interviews }\end{array}$ & $\begin{array}{l}\text { - more elaborate answers } \\
\text { - can incorporate open ended } \\
\text { questions }\end{array}$ & $\begin{array}{l}\text { - interviewer should have some } \\
\text { experience } \\
\text { - intensive time requirement }\end{array}$ \\
\hline Telephone & $\begin{array}{l}\text { - flexible flow of questions } \\
\text { - changes can be incorporated on } \\
\text { the spot as required }\end{array}$ & $\begin{array}{l}\text { - many people don't like being } \\
\text { called/disturbed } \\
\text { - requires access to a list of number } \\
\text { for a proper sample }\end{array}$ \\
\hline Mail & $\begin{array}{l}\text { - people can answer it on their own } \\
\text { time } \\
\text { - there is more privacy }\end{array}$ & $\begin{array}{l}\text { - takes a long time to mail it and then } \\
\text { receive the responses back } \\
\text { - require access to a mailing list }\end{array}$ \\
\hline Computer & $\begin{array}{l}\text { - can setup to get respondents } \\
\text { a computer } \\
\text { - less chance for errors when info } \\
\text { is manually entered into a data } \\
\text { analysis tool }\end{array}$ & $\begin{array}{l}\text { - limited access to necessary } \\
\text { equipment } \\
\text { - programming knowledge for a } \\
\text { survey required }\end{array}$ \\
\hline Questionnaire & $\begin{array}{l}\text { - can easily design questions for } \\
\text { - standardized }\end{array}$ & $\begin{array}{l}\text { - won't get elaborate answers } \\
\text { - wording/design critical } \\
\text { - people may resist filling out a } \\
\text { survey }\end{array}$ \\
\hline
\end{tabular}

Table 4.0.1 - Advantages versus Disadvantages of Survey Types

Not only were there advantages and disadvantages for each survey method, there were also several differences between some characteristics that were deemed important during the collection and exploratory stage of this research. Some of these characteristics included rigidity of scheduling requirements, flexibility, interviewer control and accuracy on sensitive data. Provided in Table 4.0.2 is a summary of the different dimensions involved with the methods of Personal Interview, Telephone Interview, Mail Interview and Computerized Interview. 


\begin{tabular}{|l|l|l|l|l|}
\hline \multicolumn{5}{|c|}{ Method } \\
\hline Dimension & $\begin{array}{l}\text { Personal } \\
\text { Interview }\end{array}$ & $\begin{array}{l}\text { Telephone } \\
\text { Interview }\end{array}$ & Mail Interview & $\begin{array}{l}\text { Computerized } \\
\text { Interview }\end{array}$ \\
\hline $\begin{array}{l}\text { Respondent } \\
\text { Identification }\end{array}$ & Excellent & Good & Fair & Fair \\
\hline Flexibility & Excellent & Good & Fair & Good \\
\hline $\begin{array}{l}\text { Anonymity of } \\
\text { Respondent }\end{array}$ & Poor & Fair & Excellent & Good \\
\hline $\begin{array}{l}\text { Accuracy on } \\
\text { sensitive data }\end{array}$ & Fair & Fair & Good & Good \\
\hline $\begin{array}{l}\text { Control of } \\
\text { interviewer } \\
\text { effects }\end{array}$ & Poor & Fair & Excellent & Excellent \\
\hline $\begin{array}{l}\text { Rigidity of } \\
\text { scheduling } \\
\text { requirements }\end{array}$ & Poor & Fair & Excellent & Good \\
\hline Time required & Fair & Good & Fair & Very Good \\
\hline $\begin{array}{l}\text { Probable } \\
\text { response rate }\end{array}$ & Good & & Fair to Poor & Fair to Poor \\
\hline \begin{tabular}{l} 
Cost \\
\hline
\end{tabular} & Poor & Good & Good & Fair/Good \\
\hline
\end{tabular}

Table 4.0.2 - A Comparison of Data Collection Methods

Source: Davis, Duane (2000) Business Research for Decision Making, Fifth Edition, Duxbury Press.

\subsection{Survey Instrument}

Based on the information presented in the above section, it was concluded that the mail-in questionnaire method was the best technique to go with because the nature of the data required was not overly complex and specific details were minimal. A questionnaire that is properly worded and designed can gather the required data and have the potential to reach companies at a larger scale. By using the survey method the research was able to 
study many companies and, within those, even more individuals and teams. In each research initiative, the goal was to identify which managerial practices are definitively linked to positive Six Sigma outcomes and which were not.

The research objectives identified was fulfilled by the use of a survey instrument which was mailed to the appropriate organizations; please refer to Appendix V for the questionnaire.

The questionnaire itself begins with a brief introduction, which explains the survey instructions and gave the reader the purpose of the survey. The respondent was then asked to relate to their previous Six Sigma implementation experiences at their current organization. The questionnaire was divided up into different sections according to the investigative questions and the objectives of this research. The sections listed here represent the overall structure of the questionnaire:

I. Assess the firm's extent of involvement in Six Sigma.

II. Find the extent to which the firms use the factors to the successful implementation of Six Sigma.

III. Find the results of the measures of Six Sigma success by asking how well firms have done from pre to post Six Sigma implementation.

IV. Identify what the respondents' perceive as being the three most important and the three least important factors in a successful Six Sigma implementation.

Part I assessed the firm's extent of involvement in Six Sigma. This included questions that investigate how involved the company was with Six Sigma. This part collected data that found out what kind of company was being studied, how long the 
company has implemented Six Sigma, how many Master Black Belts/Black Belts they have and how many projects they have open/started/completed under Six Sigma. It investigated what Six Sigma methodologies and tools were being used and what other types of quality initiatives (ISO 9000, ISO 14000, TQM etc.) that the company has used in the past.

Part II measures the various factors to the successful implementation of Six Sigma. This section attempts to measure the extent of use of each of the factors from the perspective of the respondent to see which ones are apparent within their organization. The purpose of Part II is to reaffirm our factors to success and see how apparent these are in various Six Sigma companies. Each question that was asked in this section is specifically associated with the measurement of a factor to Six Sigma success. The table below depicts which questions are applicable to each factor.

\begin{tabular}{|c|c|}
\hline Questions & Factor Being Measured \\
\hline $\begin{array}{l}\text { My organization makes funding readily available for } \\
\text { our Six Sigma initiatives. } \\
\text { - There is a large financial budget at my organization } \\
\text { which is allocated to Six Sigma deployment (i.e. for } \\
\text { resources etc.). }\end{array}$ & Financial Support \\
\hline $\begin{array}{l}\text { My organization offers many rewards which are } \\
\text { directly related to our Six Sigma efforts. } \\
\text { - Six Sigma initiatives get full recognition by the } \\
\text { organization when a project is completed. }\end{array}$ & Rewards \\
\hline $\begin{array}{l}\text { - Six Sigma is integrated into our business such as into } \\
\text { our vision, into the way we do things, into our } \\
\text { strategy etc. } \\
\text { - Six Sigma is evident throughout all of our } \\
\text { departments / divisions all through the organization. }\end{array}$ & $\begin{array}{l}\text { Integrate Six Sigma } \\
\text { to Business }\end{array}$ \\
\hline
\end{tabular}




\begin{tabular}{|c|c|}
\hline $\begin{array}{l}\text { According to the way that our organization is set up, } \\
\text { our organizational infrastructure really supports Six } \\
\text { Sigma. } \\
\text { Within our Six Sigma initiatives, it can be easily seen } \\
\text { that there exists a hierarchy of the belt system, ie. } \\
\text { Green Belts, Black Belts, Master Black Belts etc. }\end{array}$ & $\begin{array}{l}\text { Organizational } \\
\text { Infrastructure }\end{array}$ \\
\hline $\begin{array}{l}\text { Six Sigma is fully integrated into our HR department } \\
\text { in that things that HR does is related directly or } \\
\text { indirectly to Six Sigma. } \\
\text { My organization's incentive systems, motivational } \\
\text { initiatives and hiring processes are optimized with } \\
\text { Six Sigma in mind. }\end{array}$ & $\begin{array}{l}\text { Integrate Six Sigma to } \\
\text { Human Resources }\end{array}$ \\
\hline $\begin{array}{l}\text { Our suppliers are fully aware of Six Sigma and are } \\
\text { trying to use, thinking about using or are using it } \\
\text { themselves. } \\
\text { Our Six Sigma efforts are coordinated with that of } \\
\text { our suppliers to get the full benefit of Six Sigma in } \\
\text { our organization. }\end{array}$ & $\begin{array}{l}\text { Integrate Six Sigma } \\
\text { to Suppliers }\end{array}$ \\
\hline $\begin{array}{l}\text { Our Six Sigma initiatives always start and end with } \\
\text { our customers. } \\
\text { We constantly get feedback from customers and we } \\
\text { tailor our Six Sigma efforts to address the customers' } \\
\text { concerns. }\end{array}$ & $\begin{array}{l}\text { Linking Six Sigma } \\
\text { to the Customer }\end{array}$ \\
\hline $\begin{array}{l}\text { There is a lot of upper management involvement \& } \\
\text { commitment for the Six Sigma initiatives at my } \\
\text { organization. } \\
\text { Upper management at my organization is } \\
\text { knowledgeable in Six Sigma tools and techniques, } \\
\text { and they follow it closely. }\end{array}$ & $\begin{array}{l}\text { Managerial Involvement \& } \\
\text { Commitment }\end{array}$ \\
\hline $\begin{array}{l}\text { In general, the corporate culture in our organization } \\
\text { supports using Six Sigma. } \\
\text { - Our organizational environment such as people's } \\
\text { perception and attitudes are in full support of Six } \\
\text { Sigma. }\end{array}$ & Corporate Culture \\
\hline $\begin{array}{l}\text { There is a lot of communication with respect to Six } \\
\text { Sigma in our organization as to how we are doing. } \\
\text { Both successes and failures are well communicated to } \\
\text { employees. } \\
\text { Management always talks about how our Six Sigma } \\
\text { initiatives are progressing. }\end{array}$ & Communication \\
\hline
\end{tabular}




\begin{tabular}{|c|c|c|}
\hline & $\begin{array}{l}\text { Our organization uses goal setting in initiating Six } \\
\text { Sigma projects in that goals are set ahead of time for } \\
\text { us to achieve. } \\
\text { The goals that are set before projects are initiated for } \\
\text { Six Sigma are often met when our projects are } \\
\text { completed. }\end{array}$ & Goal Setting \\
\hline & $\begin{array}{l}\text { There are many hours of training that are involved } \\
\text { before an employee can start on any Six Sigma effort. } \\
\text { The amount invested in training for Six Sigma is very } \\
\text { large as compared to other business units within our } \\
\text { organization. }\end{array}$ & Training \\
\hline$T$ & $\begin{array}{l}\text { My organization ensures that we use proper project } \\
\text { management skills as a part of our Six Sigma efforts. } \\
\text { Black Belts and Master Black Belts of my } \\
\text { organization have extensive experience in managing } \\
\text { projects. }\end{array}$ & $\begin{array}{c}\text { Project Management } \\
\text { Skills }\end{array}$ \\
\hline & $\begin{array}{l}\text { My organization believes that being able to prioritize, } \\
\text { select, review and track projects is very important for } \\
\text { using Six Sigma. } \\
\text { The projects that we select usually are those that we } \\
\text { know will be successful when completed. }\end{array}$ & $\begin{array}{l}\text { Project Prioritization, } \\
\text { Selection, Review } \\
\text { \& Tracking }\end{array}$ \\
\hline & $\begin{array}{l}\text { We fully understand the Six Sigma methodology, } \\
\text { tools and techniques that are used in our processes. } \\
\text { We always use the DMAIC (Define, Measure, } \\
\text { Analyze, Improve, Control) or DFSS (Design for Six } \\
\text { Sigma) methodologies for all of our Six Sigma } \\
\text { efforts. }\end{array}$ & $\begin{array}{l}\text { Understand Six Sigma } \\
\text { Methodology, Tools \& } \\
\text { Techniques }\end{array}$ \\
\hline & $\begin{array}{l}\text { In the Six Sigma efforts that we are involved in, we } \\
\text { use Statistical techniques to analyze data. } \\
\text { We are deeply knowledgeable in the statistical } \\
\text { techniques required for our Six Sigma efforts. }\end{array}$ & Statistical Tools \\
\hline
\end{tabular}

Table 4.0.3 - Association of Questions to Measures of Factors to Success

Part III found the results of the measures of Six Sigma success by asking how well firms have done from pre to post Six Sigma implementation. This section's sole purpose was to see how the companies have performed due to Six Sigma. The questions here were directed at the results that companies have achieved using the methodologies 
that they have used in the past. The variables listed under the measurement of success in

Six Sigma were used to gauge how well the firms did.

\begin{tabular}{|c|c|}
\hline Questions & Factor Being Measured \\
\hline $\begin{array}{l}\text { The overall costs related to our Six Sigma initiatives } \\
\text { have improved. Overall costs related to processes } \\
\text { from pre to post Six Sigma implementation have } \\
\text { decreased. } \\
\text { - After we have implemented Six Sigma to certain } \\
\text { processes within our organization, profits related to } \\
\text { these processes have improved. }\end{array}$ & Financial \\
\hline $\begin{array}{l}\text { - Defects per million opportunities (DPMO) have been } \\
\text { lowered because of our Six Sigma initiatives. } \\
\text { - Our "sigma levels" are closer to Six Sigma quality } \\
\text { since we have started to use the Six Sigma } \\
\text { methodologies. }\end{array}$ & $\begin{array}{l}\text { Defects Per Million } \\
\text { Opportunities }\end{array}$ \\
\hline $\begin{array}{l}\text { Overall, customer satisfaction levels have improved } \\
\text { due to Six Sigma. } \\
\text { Overall, the number of customer complaints has } \\
\text { decreased due to Six Sigma. }\end{array}$ & Customer Satisfaction \\
\hline $\begin{array}{l}\text { Our internal work processes (productivity) related to } \\
\text { Six Sigma projects have improved due to Six Sigma. } \\
\text { Overall, we have seen less employee turnover after } \\
\text { Six Sigma had been implemented. }\end{array}$ & $\begin{array}{l}\text { Performance of Internal } \\
\text { Work Processes }\end{array}$ \\
\hline $\begin{array}{l}\text { Our suppliers' order fulfillment accuracy has } \\
\text { improved because of our Six Sigma efforts. } \\
\text { Due to Six Sigma, the number of complaints our } \\
\text { organization has about our suppliers have decreased. }\end{array}$ & Suppliers' Performance \\
\hline
\end{tabular}

Table 4.0.4 - Association of Questions to Measures of Success

Part IV identified what the respondents perceive as being the three most important and the three least important factors in Six Sigma implementation. We asked the questions to see how the firms have been doing with respect to Six Sigma in terms of what they perceive to help the Six Sigma initiative, and also the results they have seen 
because of it. Our attempt with this section was to find out what the companies perceive to be the most important and the least important aspects in successful Six Sigma implementation, and see whether or not it is in congruence to what they are actually doing.

\subsection{Sample}

\subsubsection{Survey Population}

The survey population included all medium and large sized manufacturing firms who are located in Canada that have already started to implement Six Sigma. These firms include those that are listed on the iSixSigma website and those found by the researcher from the literature reviewed.

Medium and large size ${ }^{1}$ firms were chosen because smaller organizations are less likely to be implementing the Six Sigma methodologies (Dusharme, 2003). Large firms are also more likely to have established Six Sigma programs and more than likely will involve all the different components that were to be measured by this study. Spanyi and Wurtzel (2003) further stated that "Within large corporations, Six Sigma's popularity as a means of improving quality and reducing costs continues to increase. However, the same can't be said of small and medium-sized organizations, which, as a rule, have been less enthusiastic about adopting Six Sigma."

This is not to say that this same study couldn't have been done for SMEs (small to medium enterprises), but it was the purpose of this study to produce reliable data that would offer more knowledge to the field of Six Sigma, and it was believed that utilizing

\footnotetext{
${ }^{1}$ Medium size firms are those between the size of 75 to 500 full-time employees and large firms include more than 500 employees (Ainscough and Yazdani, 2000).
} 
medium to large size companies were the means to this end. As long as the primary business activity of the firm being studied was in manufacturing, and they are in the process of using Six Sigma, it was considered as part of the target sample in order to secure enough subjects for this research.

\subsubsection{Sample Frame and Sample Size}

The chosen sample selected was at both the organizational and individual level. At the organizational level the sample consisted of those companies that were selected as mentioned above, that were willing to participate, and that fell within the manufacturing industry in Canada. Manufacturing was used as the main industry to study because the area in which Six Sigma is most apparent is in this industry (Biolos, 2002). This is not to say that Six Sigma is not used for service related industries or that service industries do not use Six Sigma, as many of them do. Six Sigma is widely adopted in the service industry (Marash, 1999), but because this study focused on specifics, the manufacturing industry was the one concentrated on.

The sample selected at the individual level consisted of Managers, Champions, Sponsors, Master Black Belts, Black Belts and Green Belts of the company's Six Sigma initiative. It was important to get a variety of different levels of perspectives within the Six Sigma system in order to get a thorough analysis of the data collected. Each individual who was a part of this study inevitably was also a part of the Six Sigma system which involved them in Six Sigma projects and gave them the ability to answer the questionnaire supplied in the study. 


\subsubsection{Unit of Analysis}

The sample that was chosen had two levels, the individual and organizational levels as mentioned above. The selection at the organizational level was important because it was our unit of analysis. Instead of choosing to investigate the individuals within a Six Sigma organization, what we really wanted to know was how the organization as a whole faired with Six Sigma. The organizations involved were vast and many ranging in terms of size and profitability. Analyzing at the organizational level allowed us to provide better comparable data to draw conclusions from the measurements of success in Six Sigma which include Financial Measures, Defects per Million Opportunities, Customer Satisfaction, Performance of Internal Work Process and Suppliers' Performance.

\subsection{Measures}

Section 4.1 presented the different sections that are in the questionnaire. The following section is an outline of the different measures that were used for the questionnaire.

\section{Measure 1}

The first measure was an attempt to assess the type of company that was answering the questionnaire. This measure determined the characteristics of the company to see who they were, the number of employees in the company, the length of time the company have been using Six Sigma and how many Six Sigma Master Black Belts and Black Belts it employs. This measure also found out the attributes of the person filling out the questionnaire in terms of the position the person held in a Six Sigma context, the 
number of projects he/she had completed and which types of tools and methodologies he/she used to accomplish the projects. The reasoning for these measures was to have a means to draw conclusions for the different perceptions based on the characteristics of the organization and also based on the characteristics of the individual filling out the survey on Six Sigma implementation factors.

\section{Measure 2}

This second measure utilized questions which were related to the factors that could lead to successful Six Sigma implementation. In this measure, respondents were asked to answer the questions regarding the relevancy of the statements applying to their organization. There were thirty two statements in total. Within these thirty two statements there were two which were allocated to represent one of the sixteen factors leading to Six Sigma success as outlined in Section 3.3. Thirty two statements were used because we wanted each of the variables mentioned to be measured at least twice. This is done because it is possible that a factor may have more than one element. In other words we asked two questions per variable and the average response of those gave the value of that factor. Respondents were asked to answer whether or not they strongly agree (7) or if they strongly disagree (1) with the statements provided. This measure reflected the respondents' perception of their company in the different elements of Six Sigma implementation.

\section{Measure 3}

The third measure consisted of questions which were related to the measures of success involved with Six Sigma implementation. In this measure, respondents were asked to answer questions regarding the results they experienced as a direct result of Six 
Sigma implementation. In total, there were ten different questions for this measure. The questions consisted of one that directly related to one of the measures of success while also having additional questions which acted as a verification tool for a previous measure of success, similar to that of Measure 2. Respondents were asked to answer whether or not they strongly agree (7) or if they strongly disagree (1) with the statements provided. This measure reflected the respective company's Six Sigma performance.

\section{Measure 4}

Finally, in the fourth measure, the questions related to the respondents' perception as to what they think is the most and least important in Six Sigma implementation. In this measure, the respondents were asked to select the top three variables they felt are the most important to Six Sigma implementation and the three variables they felt are the least important to Six Sigma implementation. There were 16 variables to choose from which are representative of the ones mentioned above. This approach is similar to a study by Phillips (1981). The purpose of this measure was to assess what the respondent perceives to be the most important and the least important factors to successful Six Sigma implementation are. This way, this study can draw conclusions as to the discrepancy between what the individuals believe are important and to what the organization is currently expressing as the most important.

\subsection{Reliability and Validity Issues}

Like many other types of studies, there are some reliability and validity issues that we were aware of in this research. Presented below are important validity and reliability issues that were addressed for this research. Ways that this study tried to steer from these 
obstacles are also included. The discussion begins with the degree of confidence related to this study. This can also be interpreted as the internal validity of the study. Some of the variables which are applicable here include:

- History: The stressing of quality in the industry may affect the results of the study. Quality is now expected of individuals and of firms, and thus could have been interpreted differently from those wanting to answer with better responses.

- Testing: Some of the effects here could have been attributable to the fact that respondents were being tested, which could have essentially sensitized and biased a respondent's action. The fact that the respondents knew that this was a survey about how they've done with Six Sigma and how they felt about the methodologies may have made them answer untruthfully.

- Selection: The selection procedure could have had an artificial effect on the results of the study as well. The departments in organizations are different, and it is not known whether there were different responses to Six Sigma among different workers.

- Mortality: Respondents may have been lost from the study. Six Sigma is a quality initiative that involves reducing costs. These reduced costs might be a direct result of some employees being let go who were a part of the system before.

The following discussion involves the external validity issues. The results derived from this study are generalizable to other similar type industries but we will still look at some of the external validity issues that are apparent in this study:

- Testing Interaction: This is apparent because there are artificial effects that are created by testing respondents which makes conclusions not be reliably generalized to other situations. Respondents may have felt that they could not 
respond with complete honesty because they thought that they may have been watched by management.

- Selection Interaction: The effect that the type of respondents has on a study's results may limit its generalizability. This was made mainly apparent by our access to manufacturing firms in Canada. Manufacturing has many types and forms and because of this, the results may not be applicable to other industries.

The final type of validity issue has to do with the measurement scales that were used in the questionnaire. Because most of the measures have been derived from literature reviewed and from the researchers' educational experience, it is assumed that they were indeed measuring what they were supposed to. It was still, however, possible that the measures were subject to problems with content validity. Even though the literature had been exhaustively searched, the items to be included were still subjective to what the researcher found important to include.

In terms of dealing with construct validity, the issues of convergent validity were addressed. Measure 3 had built in questions that attempted to assess the degree of association between two different measurement scales that tried to measure the same thing. Also, in Measures 2 and 4, we tried to reaffirm the organization's role in utilizing what they thought is the best practices for Six Sigma to what they were currently doing. It was expected that these questions that correspond to the same measures were to be highly correlated. 
Finally, the discussion concludes with the consistency and stability issues of a measurement score. Consistency was tested by using the Cronbach Alpha for Measure 2, which uses a Likert scale. 


\subsection{Data Collection and Analysis}

\subsection{Data Collection}

In this research, Six Sigma was defined and firms were selected based on their involvement with Six Sigma. The company elected as being involved with Six Sigma was contacted by mail. It was hoped that the person contacted at the organization encouraged a Manager, Champion, Sponsor, Master Black Belt, Black Belt, Green Belt or anyone else in the organization who was involved with Six Sigma implementation to respond to the questionnaire.

The respondent at the organization was contacted by direct mail. The mailing was addressed directly to the targeted company to the "Quality Manager / Quality Practitioner" of the division. The Quality Manager / Quality Practitioner were the ones specifically approached to ensure that the study ended up with a person who had a higher likelihood of completing the survey. The respondent, who was involved in Six Sigma, was sent a self-administered questionnaire where they were asked to answer questions related to Six Sigma. The questionnaire was sent accompanied with a cover letter (see Appendix VI) which indicated the objectives of the research and importance of the respondent's contribution to the study. The cover letter also included the appropriate contacts for the respondent if needed and outlined in detail the rationale of the research. All questionnaires and cover letters that were sent to the respondents were accompanied with return envelopes which were prepaid.

The companies were approached in the month of May 2005, and the data were compiled within the months of August and September of 2005. Data collection ended by 
the end of September in order to ensure that there was enough time to analyze the data and discuss the conclusion of the research findings.

\subsection{Data Analysis}

There were obviously many different types of statistical techniques that were available for the analysis of this study. There were however, only a handful that were chosen to analyze the data collected. According to Antony and Banuelas (2002) doing a similar study on key factors to Six Sigma success, the Cronbach's Alpha Test was a good statistical technique to use in this type of study; it was used because it was considered to be most widely and commonly used in testing the internal reliability for a set of questions. Using the Cronbach's Alpha test, generally an alpha of 0.60 or higher is thought to indicate an acceptable level of internal consistency (Black and Porter, 1996).

There have also been similar studies which had chosen to use regression and correlation as methods of data analysis. Regression was appropriate in this study to test whether or not there was a relationship between the factors being measured and the measures of Six Sigma success. The Pearson correlation coefficient was used to examine the "strength of association" between the measures of success which was measured in terms of the factors to success.

Finally, descriptive statistics present the extent of use of the key factors for Six Sigma success and the perception of the respondent as to which key factors are deemed most important to their Six Sigma implementations. 


\subsection{Results}

This chapter examines the results of the study. The results are presented in the following sections: Section One discusses the demographic profile of the companies and of the respondents; Section Two talks about the quality characteristics of the Six Sigma organizations in the participating companies; Section Three reveals the emphasis of quality initiatives in the organizations being studied; Section Four discusses the most and least important factors of Six Sigma implementation; Section Five discusses the perceived approach of Canadian Manufacturing companies utilizing Six Sigma; Section Six discusses the successes organizations have seen in using Six Sigma; Section Seven will summarize the relationship of the factors in the successful implementation of Six Sigma to the various measures of success while also compare the findings of the study to the originally stated hypotheses.

It should be noted that the questionnaires were forwarded to 230 potential respondents at various Canadian manufacturing firms. From these 230 potential respondents, 35 responded which resulted in a response rate of $15.2 \%$. The respondent remained anonymous throughout the study. While the 230 potential respondents were approached, some may have been from the same company, but they all would have been at different divisions at a different geographic location.

\subsection{Demographic Profile}

The companies that participated in the study can be classified as medium to large sized based on the number of employees that were apparent. The average workforce size of the sample was 11,745 employees; the minimum workforce size was 70 and the 
maximum workforce size was over 300,000 as a whole. Table 6.1(a) presents a summary of the size of the respondent companies in the sample.

\begin{tabular}{|l|l|}
\hline \multicolumn{2}{|l|}{ Number of Employees: } \\
\hline Mean & 11,745 \\
\hline Minimum & 70 \\
\hline Maximum & 300,000 \\
\hline Less than 500 & 17 \\
\hline 500 or more & 18 \\
\hline Table 6.1 $(a)$ - Number of Employees $(N=35)$
\end{tabular}

The respondents of the questionnaire were people who were involved in Six Sigma implementation at their respective companies. A majority of the respondents included Green Belts, Black Belts, Master Black Belts and Champions / Sponsors. The majority of respondents were Black Belts within the Six Sigma system with $37.1 \%$ of all respondents. $20 \%$ of the respondents were Master Black Belts, $20 \%$ were Green Belts, $17.1 \%$ were Sponsors / Champions and $5.7 \%$ occupied another position as outlined in Table 6.1(b). 


\begin{tabular}{|l|l|}
\hline Six Sigma Position & $\begin{array}{l}\text { Percentage of } \\
\text { Respondents }\end{array}$ \\
\hline Green Belts & $20 \%$ \\
\hline Black Belts & $37.1 \%$ \\
\hline Master Black Belts & $20 \%$ \\
\hline $\begin{array}{l}\text { Sponsors / } \\
\text { Champions }\end{array}$ & $17.1 \%$ \\
\hline Other & $5.7 \%$ \\
\hline Total & $100 \%$ \\
\hline
\end{tabular}

All of the respondents of the survey have some Six Sigma project experience. A majority of the respondents $(74.1 \%)$ have completed between 0 to 20 projects using Six Sigma. Green Belts who answered this study have completed anywhere between 0 to 20 projects, whereas Black Belts have completed anywhere between 0 to 40 projects and Master Black Belts have completed anywhere between 11 to over 50 projects.

\subsection{Six Sigma Characteristics}

The extent of use and the characteristics of Six Sigma use differed from company to company. There were many which had just started implementing Six Sigma and thus had only basic Six Sigma characteristics, whereas there were also those who were deeply involved with implementing Six Sigma which showed in the things in which they did within their organization.

Of the companies studied, the most any one company had implemented Six Sigma for was 8 years, the minimum of which was only 1 year which resulted in a mean of 4.6 
years. Over 54.2\% of the respondents have had implemented Six Sigma for 5 years or more. Of these companies, it was concluded that the more employees an organization has, the more Black Belts and Master Black Belts they also have on staff as well. In general, with 16,000 or more employees in the company, it would also have more than 50 Master Black Belts and Black Belts.

$97.1 \%$ of the respondents use DMAIC as a methodology in implementing their Six Sigma efforts. This does not come as a surprise as DMAIC is the primary methodology when implementing and putting into place Six Sigma as described in the literature review. Of the respondents, only $48.6 \%$ of the respondents stated that they use the DFSS / DMADV methodologies in their Six Sigma implementation. This could be explained by the fact that these methodologies are not as dominant as DMAIC, and also because it is not as applicable to all situations in the Six Sigma world and instead are only applicable to a certain niche in Six Sigma deployment.

$80 \%$ of the respondents stated that they also use Pareto Diagrams when implementing their Six Sigma initiatives. This is not surprising again as Pareto Diagrams are an integral part of any good quality management system and is usually used to gauge quality in the case of Six Sigma.

EVOP (Evolutionary Operations), although a proven successful and useful methodology in the past, does not see many users in the world of Six Sigma organizations, in that $91.4 \%$ of respondents indicated that they do not use it, but about $57.1 \%$ of them did indicate that they used DOE (Design of Experiments).

In the world of Six Sigma, there are numerous tools in which practitioners can choose from in order to implement the initiative. Of the available tools, $65.7 \%$ of the 
respondents indicated that they use a Six Sigma Roadmap as a tool when implementing Six Sigma. This is not surprising given the roadmap allows for the company to see and visualize what the Six Sigma efforts entail and where it could take them.

Again, it is not a surprise that $94.3 \%$ of respondents indicated that they use Statistical Analysis as a tool for Six Sigma. This is the case because many parts of Six Sigma involves statistical analysis in some way, shape or form. Statistical analysis allows for the process to be compared to others, and also to see the progression as to where the company has gone or in some cases, not gone. Tying closely to statistical analysis is that of control charts, where $77.1 \%$ of respondents indicated that they use these.

On whether or not the Six Sigma Scorecard was used, fewer respondents replied that they had used this tool. It could possibly be because this concept as specifically related to Six Sigma is still quite novel, and thus it has not gained wide use as of yet. It was verified that not many Six Sigma organizations use this tool as only $48.6 \%$ of respondents indicated that they use it.

\subsection{Quality Initiatives}

As Six Sigma builds upon previous quality initiatives, the question was posed to the respondents to see what other quality initiatives they used. When asked whether or not the Six Sigma organizations that were approached used other quality initiatives in the past 10 years, there were a few common responses. ISO 9000 was seen as the most popular amongst the respondents with $71.4 \%$ of them which have implemented this. Lean was close behind with $65.7 \%$ that have used it. ISO 14000 , TQM and QS 9000 
were also used and they had $42.9 \%, 25.7 \%$ and $20.0 \%$ of respondents who had used them respectively.

\begin{tabular}{|l|l|}
\hline Initiative & \% Used \\
\hline ISO 9000 & $71.4 \%$ \\
\hline ISO 14000 & $42.9 \%$ \\
\hline TQM & $25.7 \%$ \\
\hline Lean & $65.7 \%$ \\
\hline QS 9000 & $20.0 \%$ \\
\hline Other & $17.1 \%$ \\
\hline
\end{tabular}

Table 6.3 - Quality Initiatives Used $(N=35)$

\subsection{Most and Least Important Factors in Six Sigma Success}

The straightforward question was posed to respondents asking them what they thought were the three most and least important factors in Six Sigma success based on their own personal experience. From the responses provided it turned out the top three most important factors in the successful implementation of Six Sigma were Integrating Six Sigma To Business, Training and Managerial Involvement and Commitment. Managerial Involvement and Commitment was the most supported variable in that $68.6 \%$ of respondents chose it as being one of the most important factors. This is reaffirmed as on the other end of the spectrum, no respondent chose this as a factor which is least important. Integrating Six Sigma to Business was voted as the second most important with 34.3\% of respondents electing it as being important in Six Sigma Success. Training 
at $31.4 \%$ of respondents rounded out the third most important factor for Six Sigma implementation as expressed by the individuals who responded.

The other side of the question was posed to respondents asking them what they thought were the three least important factors in Six Sigma success. From the responses provided it turned out the three least important factors in the successful implementation of Six Sigma were Rewards, Organizational Infrastructure and Integrating Six Sigma to $H R$. Integrating Six Sigma to $H R$ wound up to be the one in which most respondents elected as being the least important at $57.1 \%$. When asked for the top three most important factors that lead to Six Sigma success, only 5.7\% of respondents responded that this factor was important, which reaffirmed its position as being the least important one. Rewards with $48.6 \%$ of the respondents choosing it was the second least important factor while Organizational Infrastructure at $45.7 \%$ rounded out the third least important factors.

\subsection{Six Sigma Approach}

As discussed above, the key factors in the successful implementation of Six Sigma is measured using sixteen independent variables which were derived from the literature review. These variables include: Financial Support; Rewards; Integrating Six Sigma to the Business; Organizational Infrastructure; Integrating Six Sigma to Human Resources; Integrating Six Sigma to Suppliers; Linking Six Sigma to the Customer;

Managerial Involvement \& Commitment; Corporate Culture; Communication; Goal

Setting; Training; Project Management Skills; Project Prioritization, Selection, Review \& Tracking; Understanding Six Sigma Methodology, Tools \& Techniques; and Statistical 
Tools. Table 6.5(a) lists some descriptive statistics that were generated in the process of analyzing the data.

Descriptive Statistics

\begin{tabular}{|c|c|c|c|c|c|}
\hline & $N$ & Minimum & Maximum & Mean & Std. Deviation \\
\hline Financial Support & 35 & 1.50 & 7.00 & 4.7143 & 1.68159 \\
\hline Rewards & 35 & 1.00 & 7.00 & 4.3286 & 1.73605 \\
\hline $\begin{array}{l}\text { Integrating Six Sigma to } \\
\text { Business }\end{array}$ & 33 & 1.50 & 7.00 & 4.2273 & 1.75486 \\
\hline $\begin{array}{l}\text { Organizational } \\
\text { Infrastructure }\end{array}$ & 35 & 1.00 & 7.00 & 5.2286 & 1.64649 \\
\hline $\begin{array}{l}\text { Integrating Six Sigma to } \\
\text { Human Resources }\end{array}$ & 33 & 1.0 & 7.0 & 3.091 & 1.8769 \\
\hline $\begin{array}{l}\text { Integrating Six Sigma to } \\
\text { Suppliers }\end{array}$ & 35 & 1.00 & 7.00 & 3.1857 & 1.65869 \\
\hline $\begin{array}{l}\text { Linking Six Sigma to the } \\
\text { Customer }\end{array}$ & 33 & 1.00 & 7.00 & 4.3939 & 1.60934 \\
\hline $\begin{array}{l}\text { Managerial involvement } \\
\text { and Commitment }\end{array}$ & 35 & 1.00 & 7.00 & 4.3571 & 1.79694 \\
\hline Corporate Culture & 33 & 1.50 & 7.00 & 4.6212 & 1.56640 \\
\hline Communication & 35 & 1.00 & 7.00 & 3.9714 & 1.80254 \\
\hline Goal Setting & 34 & 2.00 & 7.00 & 4.8382 & 1.52614 \\
\hline Training & 35 & 1.00 & 7.00 & 5.0857 & 1.65158 \\
\hline $\begin{array}{l}\text { Project Management } \\
\text { Skills }\end{array}$ & 35 & 1.00 & 7.00 & 5.0286 & 1.50461 \\
\hline $\begin{array}{l}\text { Project Prioritization, } \\
\text { Selection, Review \& } \\
\text { Tracking }\end{array}$ & 35 & 2.00 & 7.00 & 5.4286 & 1.50070 \\
\hline $\begin{array}{l}\text { Understanding Six } \\
\text { Sigma Methodologies, } \\
\text { Tools \& Techniques }\end{array}$ & 35 & 1.00 & 7.00 & 5.3143 & 1.30094 \\
\hline Use of Statistical Tools & 35 & 2.00 & 7.00 & 5.2857 & 1.25021 \\
\hline Valid N (listwise) & 28 & & & & \\
\hline
\end{tabular}

Table 6.5(a) - Descriptive Statistics on Independent Variables

Each success factor stated above is measured by two variables. The study has ensured that the two variables are highly correlated as they are measuring the same factor. Once a good correlation is found, then the researcher took the average of the two variables for each factor. In some cases, if it turned out that two variables were not highly correlated; the researcher then attempted to look at the data for any outliers, and in 
a rare instance, had to discard one of the variables. By following the above method, the researcher was able to work with a maximum of 16 factors. With only 16 factors, factor analysis was not feasible as the sample size of 35 is still considered relatively small. Rather than working with 16 factors, we instead broke down the variables into four categories and found Cronbach's Alpha in each category. We stated earlier in this thesis that if Cronbach's Alpha comes out to be less than 0.6, then we'd have to revisit the data again. Generally speaking, an alpha of 0.60 or higher is thought to indicate an acceptable level of internal consistency (Black and Porter, 1996). Below is a table outlining the different categories used and the resulting Crobach's Alpha achieved.

\begin{tabular}{|l|l|}
\hline Groups & Cronbach's Alpha \\
\hline Financing Six Sigma & 0.8925 \\
\hline $\begin{array}{l}\text { Integration Strategy for } \\
\text { Six Sigma }\end{array}$ & 0.8940 \\
\hline $\begin{array}{l}\text { Managerial System for } \\
\text { Six Sigma }\end{array}$ & 0.8624 \\
\hline $\begin{array}{l}\text { Six Sigma Educational } \\
\text { Underpinnings }\end{array}$ & 0.7967 \\
\hline
\end{tabular}

According to the above alpha values achieved, it is confirmed that the groups will work collectively to explain the data. As mentioned earlier, according to Antony and Banuelas (2002) doing a similar study on key factors to Six Sigma success, the Cronbach's Alpha Test was a good statistical technique to use and it was used for their study because it was considered to be the most widely and commonly used in the internal 
reliability for a set of questions. Table 6.5(c) lists some descriptive statistics that were generated in the process of analyzing the grouped data.

Descriptive Statistics

\begin{tabular}{|l|r|r|r|r|r|r|r|}
\hline & \multicolumn{1}{|c|}{$\mathrm{N}$} & \multicolumn{1}{|c|}{ Range } & Minimum & Maximum & \multicolumn{1}{c|}{ Mean } & Std. Deviation & Variance \\
\hline Financing Six Sigma & 35 & 5.25 & 1.75 & 7.00 & 4.5214 & 1.62401 & 2.637 \\
Integration Strategy for & 35 & 4.90 & 1.50 & 6.40 & 4.0117 & 1.39558 & 1.948 \\
Six Sigma & & & & & & \\
Managerial System for & 35 & 5.21 & 1.67 & 6.88 & 4.4036 & 1.44619 & 2.091 \\
$\begin{array}{l}\text { Six Sigma } \\
\text { Six Sigma Educational }\end{array}$ & 35 & 5.20 & 1.80 & 7.00 & 5.2286 & 1.07610 & 1.158 \\
$\begin{array}{l}\text { Underpinnings } \\
\text { Valid N (listwise) }\end{array}$ & 35 & & & & & & \\
\hline
\end{tabular}

Table 6.5(c) - Descriptive Statistics on Grouped Variables

As described earlier in this study, the grouped data is a means to breakdown the data into four groups which explain Six Sigma well collectively. The four groupings include Financing Six Sigma, Integration Strategy for Six Sigma, Managerial System for Six Sigma and Six Sigma Educational Underpinnings. In analyzing the grouped data it is clear that there are some aspects to Six Sigma implementation that many of the medium to large sized Canadian Manufacturing companies puts into place time over time. Using the scales of the questionnaire where a scale of 1 to 7 was used where $1=$ Strongly Disagree, $7=$ Strongly Agree and $4=$ Neither Agree $/$ Disagree, any response which was answered with a 5, 6 or 7 response is considered to be in "agreement" with the statement.

$63.1 \%$ of the respondents agreed that their organization provided adequate Financing for Six Sigma. This is supported by both variables which made up this category in that Rewards had $60 \%$ of respondents agree whereas $60.1 \%$ of respondents agreed for Financial Support that their organization provided financial support for their Six Sigma initiatives. 
From an organization's Integration Strategy for Six Sigma standpoint, it was revealed that only $49.3 \%$ of respondents agreed that their organization provided strong support for this. Leading the way for this grouping was that $74.3 \%$ of respondents stated that Organizational Infrastructure at their organization was apparent and $57.6 \%$ of respondents agreed that Linking Six Sigma to the Customer were supported. However, only $45.6 \%, 33.5 \%$ and $28.6 \%$ stated that they agreed that their organization promoted Integrating Six Sigma to Business, Integrating Six Sigma to HR and Integrating Six Sigma to Suppliers respectively.

Respondents agreed that the management of their respective organizations provided good support with respect to Six Sigma implementation. $60.4 \%$ of respondents agreed that 'their organization's Managerial System for Six Sigma were supported. Of this, $67.7 \%$ agreed that Goal Setting was encouraged. $57.3 \%, 57.5 \%$ and $54.4 \%$ agreed that Managerial Involvement \& Commitment, Corporate Culture and Communication respectively were evident at their organization.

Very strong results were achieved when looking at the company's Six Sigma Educational Underpinnings in that $91.7 \%$ of the respondents agreed that their organization provided strong support for this element. Within this grouping, the percentage that agreed for each particular variable include: $62.9 \%$. Training, $82.9 \%$ Project Management Skills; 80\% Project Prioritization, Selection, Review \& Tracking, 80\% Understanding Six Sigma Methodology, Tools \& Techniques and 74.3\% Statistical Tools. 


\section{Six Sigma Approach by Organizations}

1. Project Management Skills - $82.9 \%$

2. Understanding Six Sigma Methodology, Tools \& Techniques - 80\%

3. Project Prioritization, Selection, Review \& Tracking - 80\%

4. Statistical Tools $-74.3 \%$

5. Organizational Infrastructure $-\mathbf{7 4 . 3 \%}$

6. Goal Setting $-67.7 \%$

7. Training $-62.9 \%$

8. Financial Support $-60.1 \%$

9. Rewards $-60 \%$

10. Linking Six Sigma to the Customer - $57.6 \%$

11. Corporate Culture $-57.5 \%$

12. Managerial Involvement \& Commitment - 57.3\%

13. Communication $-54.4 \%$

14. Integrating Six Sigma to Business - $45.6 \%$

15. Integrating Six Sigma to HR - 33.5\%

16. Integrating Six Sigma to Suppliers respectively $-28.6 \%$

Table 6.5(d) - Six Sigma Approach by Organizations 


\begin{tabular}{|l|c|c|c|c|}
\hline $\begin{array}{l}\text { Six Sigma Success } \\
\text { Measure }\end{array}$ & $\begin{array}{c}\text { Agreed } \\
\text { (Improved } \\
\text { w/ Six Sigma) }\end{array}$ & $\begin{array}{c}\text { Disagreed } \\
\text { (Did not improve } \\
\text { w/ Six Sigma) }\end{array}$ & $\begin{array}{c}\text { Neither } \\
\text { (No change } \\
\text { w/ Six Sigma) }\end{array}$ & Total \\
\hline Financing Six Sigma & $63.1 \%$ & $57.4 \%$ & $5.7 \%$ & $100 \%$ \\
\hline $\begin{array}{l}\text { Integration Strategy for } \\
\text { Six Sigma }\end{array}$ & $49.3 \%$ & $46.4 \%$ & $2.9 \%$ & $100 \%$ \\
\hline $\begin{array}{l}\text { Managerial System for } \\
\text { Six Sigma } \\
\text { I }\end{array}$ & $60.4 \%$ & $39.6 \%$ & $0.0 \%$ & $100 \%$ \\
\hline $\begin{array}{l}\text { Six Sigma Educational } \\
\text { Underpinnings }\end{array}$ & $91.7 \%$ & $8.3 \%$ & $0.0 \%$ & $100 \%$ \\
\hline
\end{tabular}

Table 6.5(e) - Factors with Six Sigma

As discovered in Section 6.4 above, the top three most important factors in the successful implementation of Six Sigma as answered by the individual respondents were Integrating Six Sigma To Business, Training and Managerial Involvement and Commitment while the three least important factors in the successful implementation of Six Sigma were Rewards, Organizational Infrastructure and Integrating Six Sigma to $H R$. As can be seen in Table 6.5(d) this same result is not reflective from what the respondents' organizations are currently practicing. According to the results obtained above, the three most practiced factors are: Project Management Skills, Understanding Six Sigma Methodology, Tools \& Techniques and Project Prioritization, Selection, Review \& Tracking. On the other end of the spectrum, the three least practiced factors are: Integrating Six Sigma to Business, Integrating Six Sigma to HR and Integrating Six Sigma to Suppliers respectively.

From these results, there are a couple of notables that stand out. One of which is the fact that Integrating Six Sigma To Business although selected by the individual 
respondents as an important factor, is not being practiced by the organizations as a whole. It is also interesting to note that the only variable that fell into the same category in both instances is that of Integrating Six Sigma to HR. It can be concluded that although the respondents have their own opinion on the variables that they think are important to Six Sigma success, none of the variables though, are being heavily introduced in practice at their respective organizations. Perhaps a way to get around the gap within the organizations is to ultimately have better communication within the companies. An ultimate goal for any organization is to have what the organization itself practice, and to what their representatives convey as important to Six Sigma success, to be the same.

\subsection{Successes of Six Sigma Implementation}

As previously elaborated upon, the measures of success for the implementation of Six Sigma are measured using five dependent variables which were derived from the literature review. These variables include: Financial Measures, Defects Per Million Opportunities.(DPMO), Customer Satisfaction, Performance of Internal Work Processes and Suppliers Performance. Table 6.6(a) lists some descriptive statistics that were generated in the process of analyzing the data.

\section{Descriptive Statistics}

\begin{tabular}{|l|r|r|r|r|r|}
\hline & \multicolumn{1}{|c|}{$\mathrm{N}$} & Minimum & Maximum & \multicolumn{1}{l|}{ Mean } & Std. Deviation \\
\hline Financial Measures & 33 & 2.00 & 7.00 & 5.6364 & 1.00989 \\
DPMO & 33 & 2.00 & 7.00 & 5.5303 & 1.09644 \\
Customer Satisfaction & 34 & 1.00 & 7.00 & 4.7647 & 1.31561 \\
Performance of Internal & 34 & 3.00 & 7.00 & 5.5588 & .92740 \\
Work Processes & 33 & 1.00 & 6.00 & 3.7273 & 1.54662 \\
Suppliers Performance & 31 & & & & \\
Valid N (listwise) & & & \\
\hline
\end{tabular}

Table 6.6(a) - Descriptive Statistics on Dependent Variables 
In reviewing the measures of Six Sigma success in the respondents, it is evident that there are many in which each Six Sigma organization has been successful in achieving, but it is also evident that there are certain components that the Canadian Manufacturing organizations need to improve upon before they can get closer to Six Sigma quality.

In Financial Measures, $94.0 \%$ of respondents agreed that their organization's financials have improved as a result of Six Sigma. Only $3.0 \%$ disagreed and said that their organization's financials did not improve while $3.0 \%$ stated that their organization's financials remained the same from pre to post Six Sigma implementation.

In the measure of success by using Defects Per Million Opportunities (DPMO) $90.8 \%$ of respondents stated that their organization's DPMO have improved as a result of Six Sigma. $6.1 \%$ thought that their organization's DPMO stayed the same while $3.1 \%$ disagreed that it improved at all.

In measuring the success of Customer Satisfaction, $58.9 \%$ of respondents concluded that their organization's improved after Six Sigma implementation, while $29.5 \%$ thought that there were no change from before in that customer satisfaction have remained the same from prior to Six Sigma implementation.

In what shouldn't be a surprise is the perceived success of the respondents of their own organization's Performance of Internal Work Processes in that Six Sigma in its purest elements is the continual improvement of processes. $91.2 \%$ of respondents concluded that their organization's Performance of Internal Work Processes have improved as a result of Six Sigma. Overall, only $2.9 \%$ of respondents thought that their 
organization's Performance of Internal Work Processes did not improve at all, while $5.9 \%$ thought that it stayed the same.

As it was stated earlier in this study, in order for an organization to fully realize Six Sigma levels of quality, it requires that all areas within its own organization and those connected to its organization to be at Six Sigma levels. However, as it was also stated, many of the Six Sigma organizations did not have its suppliers as one in which was practicing Six Sigma, therefore, it made sense that only $36.4 \%$ of respondents agreed that their organization's Suppliers' Performance have improved as a result of their own organization implementing Six Sigma. Overall, 30.3\% of respondents thought that their Suppliers' Performance stayed the same while $12.1 \%$ strongly disagreed that their Suppliers' Performance improved at all.

\begin{tabular}{|l|c|c|c|c|}
\hline $\begin{array}{l}\text { Six Sigma Success } \\
\text { Measure }\end{array}$ & $\begin{array}{c}\text { Agreed } \\
\text { (Improved } \\
\text { w/ Six Sigma) }\end{array}$ & $\begin{array}{c}\text { Disagreed } \\
\text { (Did not improve } \\
\text { w/ Six Sigma) }\end{array}$ & $\begin{array}{c}\text { Neither } \\
\text { (No change } \\
\text { w/ Six Sigma) }\end{array}$ & Total \\
\hline Financial Measures & $94.0 \%$ & $3.0 \%$ & $3.0 \%$ & $100 \%$ \\
\hline $\begin{array}{l}\text { Defects Per Million } \\
\text { Opportunities }\end{array}$ & $90.8 \%$ & $3.1 \%$ & $6.1 \%$ & $100 \%$ \\
\hline Customer Satisfaction & $58.9 \%$ & $11.6 \%$ & $29.5 \%$ & $100 \%$ \\
\hline $\begin{array}{l}\text { Performance of Internal } \\
\text { Work Processes }\end{array}$ & $91.2 \%$ & $2.9 \%$ & $5.9 \%$ & $100 \%$ \\
\hline Suppliers Performance & $36.4 \%$ & $33.3 \%$ & & $100 \%$ \\
\hline
\end{tabular}

Table 6.6(b) - Performance of Variables with Six Sigma 


\subsection{Impact of Key Factors to Six Sigma Success}

In Section 3.6.1, a list of hypotheses was developed based on a framework. The variables mentioned in the hypotheses are explained in detail in Sections 3.3 and Section 3.4. The hypotheses take into consideration all the information presented in this thesis and the literature review accompanying it. These were presented for means of being able to test them, and thus we are revisiting them to test the hypotheses developed. The Pearson correlation matrix between dependent variables and independent variables is shown in Table 6.7(a).

\begin{tabular}{|l|l|l|l|l|l|}
\hline & \multicolumn{5}{|c|}{ Dependent Variables } \\
\cline { 2 - 6 } $\begin{array}{l}\text { Independent } \\
\text { Variables }\end{array}$ & $\begin{array}{l}\text { Financial } \\
\text { Measures }\end{array}$ & $\mathrm{DPMO}$ & $\begin{array}{l}\text { Customer } \\
\text { Satisfaction }\end{array}$ & $\begin{array}{l}\text { Performance } \\
\text { of Int. Work } \\
\text { Processes }\end{array}$ & $\begin{array}{l}\text { Suppliers' } \\
\text { Performance }\end{array}$ \\
\hline $\begin{array}{l}\text { Financing Six } \\
\text { Sigma }\end{array}$ & $\begin{array}{l}\mathrm{R}=0.355 \\
\mathrm{p}=0.043\end{array}$ & $\begin{array}{l}\mathrm{R}=0.437 \\
\mathrm{p}=0.011\end{array}$ & $\begin{array}{l}\mathrm{R}=0.426 \\
\mathrm{p}=0.012\end{array}$ & $\begin{array}{l}\mathrm{R}=0.532 \\
\mathrm{p}=0.001\end{array}$ & $\begin{array}{l}\mathrm{R}=0.336 \\
\mathrm{p}=0.056\end{array}$ \\
\hline $\begin{array}{l}\text { Integration } \\
\text { Strategy for } \\
\text { Six Sigma }\end{array}$ & $\mathrm{R}=0.541$ & $\mathrm{p}=0.001$ & $\mathrm{R}=0.480$ & $\mathrm{R}=0.534$ & $\mathrm{R}=0.512$ \\
$\mathrm{p}=0.005$ & $\mathrm{p}=0.001$ & $\mathrm{R}=0.002$ & $\mathrm{p}=0.012$ \\
\hline $\begin{array}{l}\text { Managerial } \\
\text { System for Six } \\
\text { Sigma }\end{array}$ & $\mathrm{p}=0.544$ & $\mathrm{p}=0.001$ & $\mathrm{p}=0.023$ & $\mathrm{R}=0.448$ & $\mathrm{R}=0.582$ \\
\hline $\begin{array}{l}\text { Six Sigma } \\
\text { Educational } \\
\text { Underpinnings }\end{array}$ & $\mathrm{R}=0.008$ & $\mathrm{p}=0.000$ & $\mathrm{R}=0.286$ \\
$\mathrm{p}=0.005$ & $\mathrm{p}=0.107$ & \\
\hline
\end{tabular}

Table 6.7(a) - Descriptive Statistics on Dependent Variables

In order to come to a decision on how well the model fits the data and which of the analyzed variables have a specific influence on the success of Six Sigma, a stepwise multiple linear regression was performed. The stepwise multiple linear regression was 
performed since bivariate correlation analysis can only examine the separate association of each variable with one another without considering the effects from other variables. With the multiple linear regression technique, it can not only find out which of the analyzed variables contribute the greatest combined effects on Six Sigma success but also can assess how well the model fits the data. With the stepwise regression technique, the factors which have the most explanatory power enter the model sequentially, and only those variables having the greatest joint predictive power remain in the equation. This does not necessarily imply that the variables which do not enter the equation are not important. The implication for omitted variables is that they do not contribute any additional information over and above that already contributed by the variables already included in the model (Hosmer and Lemeshow, 1989).

The multiple regression equation takes the form:

$$
y=b_{1} x_{1}+b_{2} x_{2}+\ldots+b_{n} x_{n}+c
$$

The b's are the regression coefficients, representing the amount the dependent variable $y$ changes when the corresponding independent changes 1 unit. The $\mathrm{c}$ is the constant, where the regression line intercepts the $y$ axis, representing the amount the dependent $y$ will be when all the independent variables are 0 . The standardized versions of the $b$ coefficients are the beta weights, and the ratio of the beta coefficients is the ratio of the relative predictive power of the independent variables. Associated with multiple regression is $\mathbf{R}^{2}$, multiple correlation, which is the percent of variance in the dependent variable explained collectively by all of the independent variables.

Table 6.7(b) through Table 6.7(f) below comprises of those variables that have been selected with the Stepwise Multiple Regression method using the four different 
independent variables (groupings) described above. For each variable in the equation, the listed variables include: the regression coefficient (B); standard error of B; Beta coefficient; $t$-statistic and the significance level. The regression coefficient (B) is used to compute the regression equation whereas the standard error of $\mathbf{B}$ is a measure of how much the value of a test statistic varies from sample to sample. It is the standard deviation of the sampling distribution for a statistic. The Beta coefficients are the regression coefficients when all variables are expressed in standardized form. Transforming the independent variables to standardized form makes the coefficients more comparable since they are all in the same units of measure. The $t$-statistic is simply a statistic used to test the null hypothesis that there is no linear relationship between a dependent variable and an independent variable or, in other words, that a regression coefficient is equal to 0 . When the significance level is small (less than 0.10 ) the coefficient is considered significant. The significance level is the conditional probability that a relationship as strong as the one observed in the data would be present (the pvalue). Typically a value of less than 0.05 is considered significant.

\subsubsection{Financial}

As previously described, there are many different types of Financial Measures that can be used to reveal the success of Six Sigma besides profits and savings in dollars. Anything from ROI (Return on Investment), to ROE (Return on Equity) to EVA (Economic Value Added) can all be used to gauge Six Sigma's financial success. Below are the hypotheses which were all previously described and have an affect within the Six Sigma system to a company's Financial Performance within Six Sigma. 


\section{Hypotheses}

a) Using more Financing for Six Sigma implementation increases Financial Performance.

b) Use of Integration Strategy for Six Sigma implementation increases Financial Performance.

c) Use of Managerial System for Six Sigma implementation increases Financial Performance.

d) Use of Educational Underpinnings for Six Sigma implementation increases Financial Performance.

As seen from Table 6.7(a), the findings support these hypotheses associated with Financial Performance in that all independent variables affected Financial Performance positively in a Six Sigma setting. Financing Six Sigma is significantly correlated with Financial Measures $(\mathrm{R}=0.355, \mathrm{p}<0.05)$, Integration Strategy for Six Sigma is significantly correlated with Financial Measures $(\mathrm{R}=0.541, \mathrm{p}<0.005)$, Managerial System for Six Sigma is significantly correlated with Financial Measures $(\mathrm{R}=0.544, \mathrm{p}<$ 0.005) and Educational Underpinnings for Six Sigma is significantly correlated with Financial Measures $(\mathrm{R}=0.479, \mathrm{p}<0.05)$. As all the measures here had a strong significance level and all $\mathrm{R}$ values are positive, it is confirmed that all of the independent variables positively affects the Financial measure of success.

In running a stepwise multiple linear regression analysis, the below output was generated. The results here allows for us to see which variable best explains the Six Sigma success measure of Financial. 


\section{Coefficients}

\begin{tabular}{|c|c|c|c|c|c|c|}
\hline \multirow{2}{*}{\multicolumn{2}{|c|}{ Model }} & \multicolumn{2}{|c|}{$\begin{array}{c}\text { Unstandardized } \\
\text { Coefficients }\end{array}$} & \multirow{2}{*}{$\begin{array}{c}\begin{array}{c}\text { Standardized } \\
\text { Coefficients }\end{array} \\
\text { Beta } \\
\end{array}$} & \multirow[b]{2}{*}{$t$} & \multirow[b]{2}{*}{ Sig. } \\
\hline & & B & Std. Error & & & \\
\hline 1 & (Constant) & 3.949 & .491 & & 8.051 & .000 \\
\hline & $\begin{array}{l}\text { Managerial System } \\
\text { for Six Sigma }\end{array}$ & .378 & .105 & .544 & 3.612 & .001 \\
\hline
\end{tabular}

a. Dependent Variable: Financial Measures

Table 6.7(b) - Financial Success

In generating all independent variables to that of Financial Measures, the independent variable that best describes this measure of Six Sigma success is Managerial System for Six Sigma. The significance level indicates that the independent variable is significant at the significance level of $p<0.005$ with a Beta of 0.544 . This is a strong association and does not vary from our regular thought pattern in Six Sigma success as all factors within this grouping of Managerial System for Six Sigma are upper management controlled, which makes sense when, in most cases, upper management are mostly concerned about the bottom line, which is usually why a Six Sigma implementation is initiated in the first place.

\subsubsection{Defects Per Million Opportunities (DPMO)}

Defects Per Million Opportunities (DPMO) has been a common measure of Six Sigma success. DPMO indicates how many defects would arise if there were one million opportunities (Pande et al., 2000). Generally speaking, the lower the DPMO, the better is the process. Associated directly with DPMO is the obvious measure of sigma levels that a system is operating at. Below are the set of hypotheses that we established earlier on in the formation of this study to test the effects of the various factors in Six Sigma implementation to this measure of Six Sigma success. 


\section{Hypotheses}

a) Using more Financing for Six Sigma implementation decreases Defects per Million Opportunities.

b) Use of Integration Strategy for Six Sigma implementation decreases Defects per Million Opportunities.

c) Use of Managerial System for Six Sigma implementation decreases Defects per Million Opportunities.

d) Use of Educational Underpinnings for Six Sigma implementation decreases Defects per Million Opportunities.

Referring to Table 6.7(a), the findings support these hypotheses associated with Defects per Million Opportunities (DPMO) in that all independent variables affected DPMO positively within a Six Sigma system. Financing Six Sigma is significantly correlated with DPMO $(\mathrm{R}=0.437, \mathrm{p}<0.05)$, Integration Strategy for Six Sigma is significantly correlated with DPMO $(\mathrm{R}=0.480, \mathrm{p}<0.05)$, Managerial System for Six Sigma is significantly correlated with DPMO $(\mathrm{R}=0.396, \mathrm{p}<0.05)$ and Educational Underpinnings for Six Sigma is significantly correlated with DPMO $(\mathrm{R}=0.412, \mathrm{p}<$ 0.05). The results support these in that all of the independent variables affected the measure of success in DPMO in an assenting way.

After a stepwise multiple linear regression analysis the below was yielded. The results here allows us to see which variable best explains the Six Sigma success measure of Defects per Million Opportunities.

\section{Coefficients $^{\mathrm{a}}$}

\begin{tabular}{|c|c|c|c|c|c|c|}
\hline \multirow{2}{*}{\multicolumn{2}{|c|}{ Model }} & \multicolumn{2}{|c|}{$\begin{array}{c}\text { Unstandardized } \\
\text { Coefficients }\end{array}$} & \multirow{2}{*}{$\begin{array}{c}\text { Standardized } \\
\text { Coefficients } \\
\text { Beta }\end{array}$} & \multirow[b]{2}{*}{$\mathrm{t}$} & \multirow[b]{2}{*}{ Sig. } \\
\hline & & B & Std. Error & & & \\
\hline & (Constant) & 3.961 & .543 & & 7.297 & .000 \\
\hline & $\begin{array}{l}\text { Integration Strategy } \\
\text { for Six Sigma }\end{array}$ & .382 & .125 & .480 & 3.045 & .005 \\
\hline
\end{tabular}

a. Dependent Variable: DPMO

Table 6.7(c) - DPMO Success 
In using our stepwise multiple linear regression analysis and using all independent variables to that of $D P M O$, the independent variable that best describes this measure of Six Sigma success is Integration Strategy for Six Sigma. The significance level indicates that the independent variable is significant at the significance level of $p<0.05$ with a Beta of 0.480. Integration Strategy for Six Sigma's main purpose is to improve processes within a Six Sigma organization, and when processes are improved, it would inevitably improve an organization's internal defects, which is what $D P M O$ is set to measure.

\subsubsection{Customer Satisfaction}

Customer Satisfaction is our third measure of Six Sigma success as described earlier. By measuring performance against customer requirements would allow an organization to see exactly how they are doing in the customer's eyes with respect to their Six Sigma initiatives. The hypotheses below were earlier generated which are meant to test the effects of the independent variables to that of Customer Satisfaction within Six Sigma.

\section{Hypotheses}

a) Using more Financing for Six Sigma implementation increases Customer Satisfaction.

b) Use of Integration Strategy for Six Sigma implementation increases Customer Satisfaction.

c) Use of Managerial System for Six Sigma implementation increases Customer Satisfaction.

d) Use of Educational Underpinnings for Six Sigma implementation increases Customer Satisfaction.

Again, if we refer to Table 6.7(a), the findings support these hypotheses associated with Customer Satisfaction as well in that all independent variables affected Customer Satisfaction firmly within a Six Sigma system. Financing Six Sigma is 
significantly correlated with Customer Satisfaction $(\mathrm{R}=0.426, \mathrm{p}<0.005)$, Integration Strategy for Six Sigma is significantly correlated with Customer Satisfaction $(\mathrm{R}=0.534$, $\mathrm{p}<0.005)$, Managerial System for Six Sigma is significantly correlated with Customer Satisfaction $(\mathrm{R}=0.448, \mathrm{p}<0.05)$ and Educational Underpinnings for Six Sigma is significantly correlated with Customer Satisfaction $(\mathrm{R}=0.403, \mathrm{p}<0.05)$,

In calculating the multiple linear regression analysis the below output was produced. The results here allows us to see which variable best explains the Six Sigma success measure of Customer Satisfaction.

\section{Coefficients $^{\mathrm{a}}$}

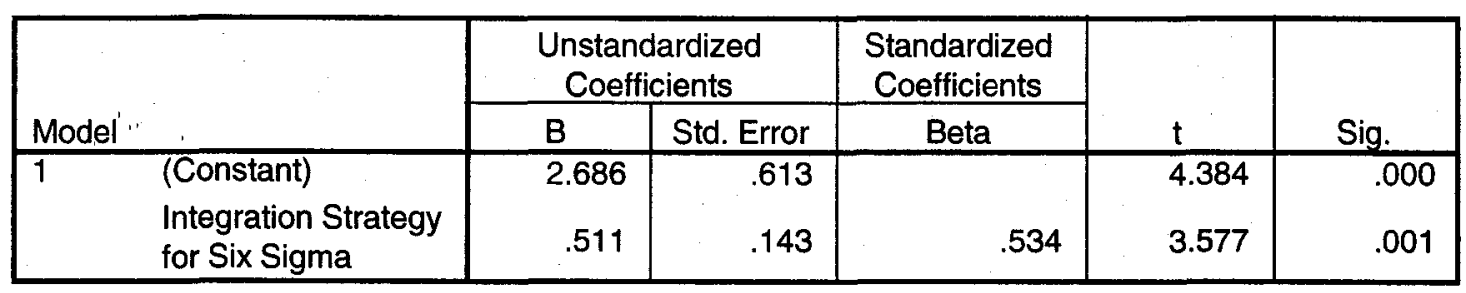

a. Dependent Variable: Customer Satisfaction

Table 6.7(d) - Customer Satisfaction Success

In using our stepwise multiple linear regression analysis and using all independent variables to that of Customer Satisfaction, the independent variable that best describes this measure of Six Sigma success is Integration Strategy for Six Sigma. The significance level indicates that the independent variable is significant at the significance level of $p<0.005$ with a Beta of 0.534 . The key part of this is similar to the above where Integration Strategy for Six Sigma was also very vital to the success of DPMO. This is further supported when looking at the variables which form this group for success. The variable Linking Six Sigma to the Customer as a part of the factor to success of 
Integration Strategy for Six Sigma, and the supporting variables are all areas in which an organization's customers would immediately see as a result of their improvement.

\subsubsection{Performance of Internal Work Processes}

The Performance of Internal Work Processes were also considered to be an important measure as to the success of Six Sigma. Things such as cycle times and product and service quality are all measures of an organization's internal processes. These following hypotheses were developed to confirm their effects to the Performance of internal Work Processes.

\section{Hypotheses}

a) Using more Financing for Six Sigma implementation increases the Performance of Internal Work Processes.

b) Use of Integration Strategy for Six Sigma implementation increases the Performance of Internal Work Processes.

c) Use of Managerial System for Six Sigma implementation increases the Performance of Internal Work Processes.

d) Use of Educational Underpinnings for Six Sigma implementation increases the Performance of Internal Work Processes.

Table 6.7(a) provides us with information that affirms the testing of the hypotheses mentioned above. The findings support these hypotheses associated with the Performance of Internal Work Processes in that all independent variables affected the Performance of Internal Work Processes positively within a Six Sigma system. Financing Six Sigma is significantly correlated with Performance of Internal Work Processes $(\mathrm{R}=0.532, \mathrm{p}<0.005)$, Integration Strategy for Six Sigma is significantly correlated with Performance of Internal Work Processes $(\mathrm{R}=0.512, \mathrm{p}<0.005)$, Managerial System for Six Sigma is significantly correlated with Performance of Internal Work Processes $(\mathrm{R}=0.582, \mathrm{p}<0.0005)$ and Educational Underpinnings for Six Sigma is 
significantly correlated with Performance of Internal Work Processes $(\mathrm{R}=0.465, \mathrm{p}<$ $0.05)$.

In calculating the multiple linear regression analysis, the below output was produced. The results here allows us to see which variable best explains the Six Sigma success measure of the Performance of Internal Work Processes.

\section{Coefficients ${ }^{\mathrm{a}}$}

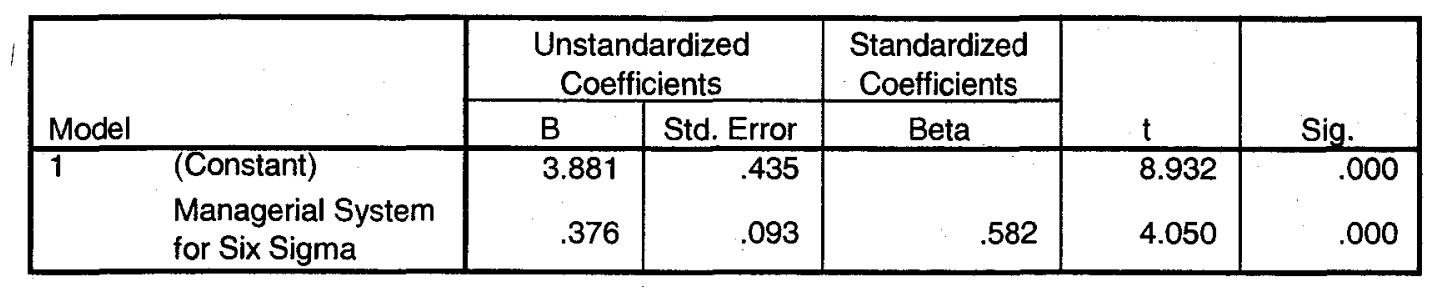

a. Dependent Variable: Performance of Internal Work Processes

Table 6.7(e)-Performance of Internal Work Processes Success

In using our stepwise multiple linear regression analysis and using all independent variables to that of the Performance of Internal Work Processes, the independent variable that best describes this measure of Six Sigma success is Managerial System for Six Sigma. The significance level indicates that the independent variable is significant at the significance level of $p<0.0005$ with a Beta of 0.582 . The main component of this is the fact that the Performance of Internal Work Processes is a product of effective management and specifically the Managerial System for Six Sigma. The implications of this result provides for the reason that effectively paying attention to Managerial Involvement \& Commitment, Corporate Culture, Communication and Goal Setting have a significant positive effect on the Performance of Internal Work Processes. 


\subsubsection{Suppliers' Performance}

A company's Suppliers' Performance is the final measure of Six Sigma success that we have discussed above. The performance of a supplier's against an organization's own requirements is a good indication of Six Sigma success. The improvement of your suppliers over the course of your Six Sigma implementation will have a major say as to the success of your Six Sigma initiative (Goldstein, 2001). The below hypotheses were developed to test how they all affect this measure of Six Sigma success.

\section{Hypotheses}

a) Using more Financing for Six Sigma implementation increases Suppliers' Performance.

b) Use of Integration Strategy for Six Sigma implementation increases Suppliers' Performance.

c) Use of Managerial System for Six Sigma implementation increases Suppliers' Performance.

d) Use of Educational Underpinnings for Six Sigma implementation increases Suppliers' Performance.

Again, by referring to Table 6.7(a), the findings support these hypotheses associated with the Suppliers' Performance in that all independent variables affected the measure of success on a company's Suppliers' Performance positively within a Six Sigma system. However, it should be noted that the significance levels and relative affect of Suppliers' Performance is quite a bit weaker than the above results, but nonetheless, is still a positive effect. Financing Six Sigma is not significantly correlated with Suppliers' Performance $(\mathrm{R}=0.336, \mathrm{p}<0.5)$, Integration Strategy for Six Sigma is significantly correlated with Suppliers' Performance $(\mathrm{R}=0.430, \mathrm{p}<0.05)$, Managerial System for Six Sigma is not significantly correlated with Suppliers' Performance $(\mathrm{R}=0.286, \mathrm{p}<0.5)$ 
and Educational Underpinnings for Six Sigma is not significantly correlated with Suppliers' Performance $(\mathrm{R}=0.090, \mathrm{p}=0.618)$.

As described, the effects overall by the various independent variables on the measure of Suppliers' Performance in this instance is a lot weaker than the previous measures of successes. More notable are the independent variables of Educational Underpinnings for Six Sigma, Financing Six Sigma and Managerial System for Six Sigma. It is thought that the reason for the weak effect to Suppliers' Performance is that this measure of success for Six Sigma is external and thus is harder for Six Sigma organizations to garner. Goldstein (2001) stated that the improvement of your suppliers over the course of your Six Sigma implementation will have a major say as to the success of your Six Sigma initiative. Suppliers' Performance is also harder to gauge as well, because again it is an external measure and is not readily measurable by Six Sigma organizations. However, Badri (1995) is a firm believer that a good supplier quality management system is said to be a large factor as to whether or not an organization truly achieves Six Sigma levels of success.

In calculating the multiple linear regression analysis the below output was produced. The results here allows us to see which variable best explains the Six Sigma success measure of the Suppliers' Performance.

Coefficients $^{\mathrm{a}}$

\begin{tabular}{|c|c|c|c|c|c|c|}
\hline \multirow[b]{2}{*}{ Mode } & & \multicolumn{2}{|c|}{$\begin{array}{c}\text { Unstandardized } \\
\text { Coefficients }\end{array}$} & \multirow{2}{*}{$\begin{array}{c}\begin{array}{c}\text { Standardized } \\
\text { Coefficients }\end{array} \\
\text { Beta }\end{array}$} & \multirow[b]{2}{*}{$t$} & \multirow[b]{2}{*}{ Sig. } \\
\hline & & $\mathrm{B}$ & Std. Error & & & \\
\hline 1 & (Constant) & 1.867 & .743 & & 2.511 & .017 \\
\hline & $\begin{array}{l}\text { Integration Strategy } \\
\text { for Six Sigma }\end{array}$ & .469 & .177 & .430 & 2.653 & .012 \\
\hline
\end{tabular}

a. Dependent Variable: Suppliers Performance

Table 6.7(f) - Suppliers' Performance Success 
In using our stepwise multiple linear regression analysis and using all independent variables to that of the Suppliers' Performance, the independent variable that best describes this measure of Six Sigma success is Integration Strategy for Six Sigma. The significance level indicates that the independent variable is significant at the significance level of $p<0.05$ with a Beta of 0.430. The key part of this is where Integration Strategy for Six Sigma was also very vital to the success of DPMO and Customer Satisfaction. This is further supported when looking at the variables which form this group for success. The variable Linking Six Sigma to Suppliers as a part of the factor to success of Integration Strategy for Six Sigma, and the supporting variables are all areas in which an organization's suppliers would immediately see as a result of their improvement.

\subsubsection{Moderated Relationships}

The moderated relationships in this study include those that are a combination of the above mentioned hypotheses. The use of any set of variables mentioned above to affect the successful implementation of Six Sigma is addressed here.

\section{Moderated Relationship Hypotheses}

a) Financing, Integration Strategy, Managerial System and Educational Underpinnings for Six Sigma implementation will all have different effects on increasing Financial Performance.

b) Financing, Integration Strategy, Managerial System and Educational Underpinnings for Six Sigma implementation will all have different effects on decreasing Defects per Million Opportunities.

c) Financing, Integration Strategy, Managerial System and Educational Underpinnings for Six Sigma implementation will all have different effects on increasing Customer Satisfaction.

d) Financing, Integration Strategy, Managerial System and Educational Underpinnings for Six Sigma implementation will all have different effects on increasing the Performance of Internal Work Processes.

e) Financing, Integration Strategy, Managerial System and Educational Underpinnings for Six Sigma implementation will all have different effects on increasing Suppliers' Performance. 
As evident in reviewing and confirming the above hypotheses, all the factors to the successful implementation of Six Sigma have varying effects on the different measures of success. All of the factors to success, however, do have the commonality in that they all contribute positively to the success of Six Sigma, but all of which to differing extents. It is noted that depending on the measure of success that we are looking at, they individually affect each measure of success differently. 


\subsection{Benefits and Limitations}

\subsection{Discussion of Results}

Based on the results of the hypothesis testing, the study documents that all the factors to the successful implementation of Six Sigma positively affects all the various measures of success for Six Sigma. Albeit, some had more of an impact than others, nonetheless, all had positive effects as confirmed by the hypothesis tests. Various numbers of medium to large sized Canadian manufacturing organizations were involved with this study providing for a good batch of data in which to analyze.

The average workforce size of the sample was 11,745 employees; the minimum workforce size was 70 and the maximum workforce size was over 300,000 as a whole. The majority of respondents were Black Belts within the Six Sigma system but also included a number of Master Black Belts, Green Belts, and Sponsors / Champions. Over $54.2 \%$ of the respondents have had implemented Six Sigma for 5 years or more. Almost all of the respondents use DMAIC as a methodology in implementing their Six Sigma efforts. There were a number of respondents who have implemented other quality initiatives. ISO 9000 was seen as the most popular amongst the respondents with $71.4 \%$ of them which have implemented this. Lean was close behind with $65.7 \%$ that have used it. ISO 14000, TQM and QS 9000 were also used and they had 42.9\%, 25.7\% and $20.0 \%$ of respondents who had used them respectively.

One of the main questions asked on the study was to form the three most and the three least important factors based on the respondents' perspective. From the responses provided, it turned out the top three most important factors in the successful implementation of Six Sigma were Integrating Six Sigma To Business, Training and 
Managerial Involvement and Commitment. While it turned out that from the responses provided, the three least important factors to the successful implementation of Six Sigma were Rewards, Organizational Infrastructure and Integrating Six Sigma to HR.

Based on the results of the stepwise multiple linear regression analysis of the data retrieved by the researcher, this study documents that the factors in the successful implementation of Six Sigma plays crucial roles in achieving Six Sigma success in Canadian Manufacturing companies. Both Integration Strategy for Six Sigma and Managerial System for Six Sigma were essential in strongly affecting the various measures of Six Sigma success. However, Financing Six Sigma and Six Sigma Educational Underpinnings did not have as much of an effect.

In summary, the interaction between Integration Strategy for Six Sigma and Managerial System for Six Sigma are the areas to concentrate when Six Sigma success is the goal of an organization. These factors will facilitate the Six Sigma process and contribute to their ultimate successes.

\subsection{Benefits}

This research provides for the manager or Six Sigma practitioners further understanding for the factors to Six Sigma implementation. The study provides both academia and the corporate world important knowledge to the successful implementation of Six Sigma. By breaking down the factors to Six Sigma success, each addressing a different area of the Six Sigma system, the results obtained from this study gives direction to the variables involved to successfully implement Six Sigma. This is unique to most of the literature that exists already on Six Sigma in that very few have looked at 
this combination of variables and not many have researched the factors to Six Sigma success.

This study also took into consideration a company's current Six Sigma performance looking at their current use of the variables mentioned, their current performance using Six Sigma and also the respondents' perception as to the variables they think should be most important in Six Sigma implementations. Six Sigma is the current wave of the quality movement, assessing the impact of such a phenomenon will help the further understanding of the quality movement of the business world.

Another benefit of this research is its contribution as a foundation for detailed future research using these factors. It also serves to account for the reasoning behind why a firm is successful with Six Sigma while others are not and would allow those who are thinking about implementing Six Sigma to know what they should be aware of and which areas they should concentrate on in order to avoid pitfalls in the future.

\subsection{Limitations}

Perhaps one of the greatest obstacles that was expected when collecting the data was identifying the appropriate respondent for the questionnaire. Since it is important that the respondent be knowledgeable of the Six Sigma system, only select few was targeted. Another aspect considered was the fact that people do not necessarily have the time nor patience to fill out a survey. Finding respondents who were willing to sacrifice their time to answer the questionnaire may have been a constraint as Six Sigma itself stresses quality, filling out a questionnaire may not have necessarily improved the 
company's quality levels by any means. If any of these obstacles were present, then the results achieved may be hindered.

There are obviously limitations to this study which are beyond the scope of this questionnaire. The simple fact that this survey was geared towards the manufacturing sector will exclude many potential candidates who practice Six Sigma. As a result, the findings of this study may be limited to only this sector. The same also applies to the fact that this survey was initiated in Canada, which may have excluded many different companies around the world from participating in it.

There are also time limitations in that the student doing this research was not able to perform a long term study on the subject. It might be appropriate to see whether or not firms, after being made aware of the factors to Six Sigma success, might change their perspectives and approach after the initial survey.

Based on the simple fact that it is a student who was conducting this research, there are resource limitations due to the student's limited financial support. This was somewhat alleviated by the help of the Eric Sprott School of Business at Carleton University, but nonetheless was still a limitation to the student's abilities to conduct a completely thorough analysis.

Limitations were also related to the sample size and inability to consider many other validity and reliability attempts to make the study more significant and generalizable. The samples simply may not have been distributed randomly enough which means that our sampling frame may lead to bias. 


\subsection{Implications for Future Studies}

This thesis study on Factors in the Successful Implementation of Six Sigma in Canadian Manufacturing Firms was put together without many past research being done on the same topic nor to the same extent, thus there are many areas in which the researcher or any future researchers can do in order to take this study to the next level and further the knowledge of Six Sigma success. Below lists a few areas in which the researcher felt could be done somewhat differently in order to develop an extension to the already developed models above.

As the main component of this thesis is the use of the stepwise multiple linear regression technique, it should be noted that in the theory testing stage for future research, the researcher should base choice of the variables and their order on theory, not necessarily on a computer algorithm. Menard (1995) writes, "there appears to be general agreement that the use of computer-controlled stepwise procedures to select variables is inappropriate for theory testing because it capitalizes on random variations in the data and produces results that tend to be idosyncratic and difficult to replicate in any sample other than the sample in which they were originally obtained." It should also be noted that the 0.05 significance level used at each step in a stepwise regression is subject to inflation, such that the real significance level by the last step may be much worse, even below 0.50 , dramatically increasing the chances of Type I errors (Garson, 2005).

Future research to further the one at hand can quantify the measures of success to be able to calculate pre to post Six Sigma implementation success. From time to time, the responses given could have only been the Six Sigma professional's own opinion, but if future research is able to give quantifiable data, then it may make future studies more 
reliable in terms of being able to put forth and give "how much" success was achieved which may better rationalize what a company has potentially spent on Six Sigma, versus what it gets back.

Because the factors that lead to Six Sigma success in this study had the least impact on the measure of success of Suppliers' Performance, this in itself could be a good foundation for future research. In the Suppliers' Performance measure of success, a good question may be to ask whether or not the Six Sigma organization has a supplier quality management system in place, and see if those who do have better results in terms of Suppliers' Performance success. There may be untapped avenues of the factors leading to "Six Sigma Suppliers' Success" which would make for good future research on this topic, because as a good supplier quality management system is said to be a large factor as to whether or not an organization truly achieves Six Sigma levels of success (Badri, 1995) 


\section{References}

Ainscough, M. and Yazdani, B., (2000), "Concurrent Engineering Within British Industry", Concurrent Engineering: Research and Applications, Vol. 8 No. 1, pp. $2-11$.

Antony, J. and Coronado, R. B., (2001), "Six Sigma: A Strategy for Survival", Manufacturing Engineer, Vol. 80 No. 3, pp. 119-121.

Antony, J., (2002), "Design for six sigma: a breakthrough business improvement strategy for achieving competitive advantage", Work Study, Vol. 51 No. 1, pp 6-8.

Antony, J. and Banuelas, R. (2001), “A strategy for survival”, Manufacturing Engineer, Vol. 80 No. 3 , pp. 119-121.

Antony, J. and Banuelas, R., (2002), "Key Ingredients for the Effective Implementation of Six Sigma Program”, Measuring Business Excellence, Vol. 6 No. 4, pp. 20-27.

Badri, M. A. et al., (1995) "A study of measuring the critical factors of quality management”, International Journal of Quality, Vol. 12 No. 2, pp. 36-53.

Behara, R. S., (1995), "Customer Satisfaction Measurement and Analysis using Six Sigma", International Journal of Quality \& Reliability Management, Vol. 12 No. 3 , pp 9-18.

Berte, L. M. and Nevalainen, D.E. (1997), "Quality Pays - in Every Business!", Transfusion Science, Vol. 18 No. 4, pp. 589-596.

Biolos, J., (2002), "Six Sigma Meets the Service Economy: This quality improvement method may have been invented for manufacturing processes, but it also has a lot to offer service functions", Harvard Management Update, Vol. 7 No. 11, pp. 3-5.

Black, S. A. and Porter, L. J., (1996), "Identification of the critical factors of TQM", Decision Science, Vol. 27 No. 1, pp. 1-21.

Bolze, S., (1998), “A Six Sigma Approach to Competitiveness”, Transmission \& Distribution World, Vol. 50 No. 8, pp. 18.

Brown, A. et al., (1998), "Smaller enterprises' experiences with ISO 9000", International Journal of Quality \& Reliability Management, Vol. 15 No. 3, pp. 273-285.

Burrington-Brown, J., (2002), "Six Sigma Makes Sense as Quality Initiative", Journal of AHIMA, Vol. 73 No. 5, pp. 56-57.

Carnell, M., (2000), "Understanding Six Sigma Deployment Failures”, iSixSigma, Available at: http://www.isixsigma.com/library/content/c020916a.asp. 
Carr, L. P., (1995), "How Xerox Sustains the Cost of Quality", Management Accounting, August, pp. 26-32.

Casadesus, M. and Gimenez, G., (2000), "The benefits of the implementation of the ISO 9000 standard: empirical research in 288 Spanish companies", The TQM Magazine, Vol. 12 No. 6, pp. 432-441.

Caulcutt, R., (2001), "Why is Six Sigma so successful?", Journal of Applied Statistics, Vol. 28 No $3 \& 4$, pp. 301-306.

Chang, T., (2003), "Six Sigma Success Factors", Process Quality Associates Inc., Available at: http://www.pqa.net/sixsigma/W06002005.html.

Conlin, M., (1998), “Revealed at last: The Secret of Jack Welch's success”, Forbes, Vol. 161 No. 2.

Coronado, R. B. and Antony, J., (2002), "Critical Success Factors for the Successful Implementation of Six Sigma Projects in Organisations", The TQM Magazine, Vol. 14 No. 2, pp 92-99.

Crosby, P. B., (1979), Quality is Free, The Art of Making Quality Certain, McGraw-Hill, New York, NY.

Crosby, P. B., (1984), Quality Without Tears: The Art of Hassle-Free Management, McGraw-Hill, New York, NY.

Dale, B. (2000), “Marginalisation of quality: Is There a Case to Answer?", The TQM Magazine, Vol. 12 No. 4, pp. 266-74.

Davis, D., (2000), Business Research for Decision Making - Fifth Edition, Duxbury Press, Pacific Grove, CA.

De Feo, J. A. et al., (2002), “The Joy of Six: A multilayered application suite designed to optimize quality, innovation and design functionality", European Quality, Vol. 9 No. 1, pp. 56-61.

Dusharme, D., (2003), "Six Sigma Survey: Big success... but what about the other 98 percent?", Quality Digest, Available at: http://www.qualitydigest.com/feb03/ articles/01_article.shtml

Eckes, G., (2000), The Six Sigma Revolution, John Wiley and Sons, New York, NY.

Feigenbaum, A. V., (1991), Totally Quality Control - Third Edition, McGraw-Hill, New York, NY.

Feigenbaum, A. V., (1997), "No Pain, No Gain”, Chief Executive, No. 121, pp. 36-38. 
Garson, D. A., (2005), “Multiple Regression", Available at: http://www2.chass.ncsu.edu/ garson/pa765/regress.htm.

Goldstein, M. D., (2001), "Six Sigma Program Success Factors”, Six Sigma Forum Magazine, Vol. 1 No. 1, pp. 36-45.

Grant, E. L. and Leavenworth, R., (1988), Statistical Quality Control - $6^{\text {th }}$ Edition, McGraw-Hill, New York, NY.

Grazier, P., (1998), "Team Motivation", The Team Building Supersite, Available at: http://www.teambuildinginc.com/article_teammotivation.htm.

Gross, J. M., (2001), “A Road Map to Six Sigma Quality”, Quality Progress, Vol. 34 No. 11 , pp. 24-30.

Gryna, F. M., (2001), Quality Planning \& Analysis: From Product Development Through Use - Fourth Edition, McGraw-Hill, New York, NY.

Gupta, M. and Campbell, V. S., (1995), "The Cost of Quality", Production and Inventory Management Journal, Vol. 36 No. 3, pp. 43-50.

Gupta, P., (2004), Six Sigma Business Scorecard: Ensuring Performance for Profit, McGraw-Hill Professional, New York, NY.

Halliday, S., (2001), "So What Exactly is Six Sigma?", Works Management, Vol. 54 No. 1, p. 15.

Harnett, D. L. and Murphy, J. L., (1993), Statistical Analysis: For Business and Economics - First Canadian Edition, Addison-Wesley Publishers, Cary, N.C.

Harry, M. J., (1998), “Six Sigma: A Breakthrough Strategy for Profitability”, Quality Progress, Vol. 31 No. 5, pp. 60-64.

Harry, M. J. and Schroeder, R., (2000), Six Sigma: The Breakthrough Management Strategy Revolutionizing the World's Top Corporations, Doubleday, NY.

Henderson, K. M. and Evans, J. R., (2000), "Successful Implementation of Six Sigma: Benchmarking General Electric Company", Benchmarking: An International Journal, Vol. 7 No. 4, pp. 260-81.

Hendricks, C. A. and Kelbaugh, R., (1998), "Implementing Six Sigma at GE", The Journal for Quality and Participation, Vol. 21 No. 4, pp. 48-53. 
Hockman, K., (2001), "Why is a Design for Six Sigma Methodology Necessary?", ASQ Six Sigma Forum, Available at: http://www.sixsigmaforum.com/protected/articles/ds_dfss.shtml

Hoerl, R. W., (1998), "Six Sigma and the future of the quality profession", IEEE Engineering Management Review, Fall, pp. 87-94.

Hosmer, D.G. and S. Lemeshow, (1989), "Applied Logistic Regression", John Wiley \& Sons, New York.

Ittner, C. D. and Larcker, D. F., (2003), "Coming up Short on Non-Financial Performance Measurement", Harvard Business Review, Vol. 81 No. 11, pp. 8895.

Juran, J. M. and Gryna, F. M., (1988), Juran's quality control handbook - Fourth Edition, McGraw-Hill, New York, NY.

Kaplan, R. S. and Norton, D. P., (1992), "The Balanced Scorecard - Measures That Drive Performance", Harvard Business Review, Vol. 70 No. 1, pp. 71-79.

Kaplan, R. S. and Norton, D. P., (1996), "Using the Balanced Scorecard as A Strategic Management System", Harvard Business Review, Vol. 74 No. 1, pp. 75-85.

Lee, T. Y. et al., (1997), The Hong Kong Quality Journey - Report on a consultancy study on the effect and impact of ISO 9000 certification on companies and organizations in Hong Kong, Industry Department, the Government of the Hong Kong SAR.

Lee, T. Y. et al., (1999), "Improving quality management on the basis of ISO 9000", The TQM Magazine, Vol. 11 No. 2, pp. 88-94.

Lexa, R., (2003), "Flying High With Six Sigma Quality", Manufacturing Engineering, Vol. 130 No. 2, pp 69-73.

Lim, C., (1998), "A system model for ISO 9000 standards", Managing Service Quality, Vol. 8 No. 1, pp. 64-67.

Linderman et al., (2002), "Six Sigma: A Goal-Theoretic Perspective", Journal of Operations Management, Vol. 21 No. 2, pp. 193-203.

Locke, E. A., (1967), "Relationship of Success and Expectation to Affect on GoalSeeking Tasks", Journal of Personality and Social Psychology, Vol. 7 No. 2, pp. 125-134.

Locke, E. A. and Latham, G. P., (1990), A Theory of Goal Setting and Task Performance, Prentice-Hall, Englewood, NJ. 
Lucas, J. M., (2002), “The Essential Six Sigma: How successful Six Sigma implementation can improve the bottom line", Quality Progress, Vol. 35 No. 1, pp. 27-32.

Main, J., (1994), Quality Wars: The Triumphs and Defeats of American Business, New York: The Free Press, New York, NY.

Maleyeff, J. and Kaminsky, F. C., (2002), "Six sigma and introductory statistics education", Education + Training, Vol. 44 No. 2, pp. 82-89.

Mallak et al., (1997), "A cultural study of ISO 9000 certification", International Journal of Quality \& Reliability Management, Vol. 14 No. 4, pp. 328-348.

Mann, R. and Kehoe, D., (1995), "Factors affecting the implementation and success of TQM", International Journal of Quality, Vol. 12 No. 1, pp. 11-23.

Marash, S. A., (1999), “A New Look at Six Sigma: Is Six Sigma a passing fad or a sign of things to come?", Quality Digest, Available at: http://www.qualitydigest.com/ mar99/ html/columnists.html.

Menard, Scott (1995). "Applied logistic regression analysis", Quantitative Applications in the Social Sciences, No. 106.

Murphy, T., (1998), “Close Enough to Perfect”, Ward's Auto World, Vol. 34 No. 8, pp. 50.

Niles, K., (2000), “What Makes Six Sigma Work?”, iSixSigma, Available at: http://www. isixsigma.com/library/content/c010723a.asp.

Olexa, R., (2003), "Driving Quality with Six Sigma”, Manufacturing Engineering, Vol. 130 No. 2, pp 61-68.

Pande et al., (2000), The Six Sigma Way: How GE, Motorola and Other Top Companies are Honing their Performance, McGraw-Hill Professional, New York, NY.

Pande et al., (2002), The Six Sigma Way Team Fieldbook: An Implementation Guide for Process Improvement Teams, McGraw-Hill Professional, New York, NY.

Paul, R., (1996), "Evaluating Ideas and Concepts for New Business-to-Business Products", In Rosenau, M., Griffin, A., Castellion, G., \& Anschuetz, N., eds., The PDMA Handbook of New Product Development, John Wiley \& Sons, New York, NY.

Paul, L., (1999), "Practice makes perfect”, CIO Enterprise, Vol. 12 No. 7, Section 2. 
Pavletic, D. and Sokovic, M., (2002), "Six Sigma: A Complex Quality Initiative", Journal of Mechanical Engineering, Vol. 48 No. 3, pp. 158-168.

Phillips, L. W., (1981), "Assessing Measurement Error in Key Informant Reports: A Methodological Note on Organizational Analysis in Marketing", Journal of Marketing Research, Vol. XVIII, pp. 395-415.

Prewitt, E., (2003), "Six Sigma Comes to IT: Once Confined to Manufacturing Groups, the Quality Improvement Program called Six Sigma is now being used to Clean Up IT's Act", $C I O$, Vol. 16 No. 21, pp. 87-92.

Pyzdek, T., (2001), "Why Six Sigma is not TQM", Pyzdek Consulting, Available at: http://www.pyzdek.com/six_sigma_vs_tqm.htm.

Pyzdek, T., (2003), "Microsoft Accelerates Six Sigma: Point-and-click your way to Six Sigma success", Quality Digest, April 2003 Issue.

Pyzdek, T., (2003), The Six Sigma Handbook: A Complete Guide for Green Belts, Black Belts, and Managers at All Levels, McGraw-Hill, New York, NY.

Quazi, H. A. and Padibjo, S. R., (1998), "A journey towards total quality management through ISO 9000 certification. A study on small and medium sized enterprises in Singapore", International Journal of Quality \& Reliability Management, Vol. 15 No. 5, pp. 364-371.

ReVelle, J. B. et al., (1998), The QFD Handbook, John Wiley \& Sons, New York, NY.

Rucker, R., (2000), "Citibank Increases Customer Loyalty with Defect-Free Processes", Journal for Quality and Participation, Vol. 23 No. 4, pp 32-36.

Sandhold, L. and Sorqvist, L., (2002), "12 Requirements For Six Sigma Success", Six Sigma Forum Magazine, Vol. 12 No. 1, pp. 17-22.

Schroder, R. G., (2000), "Six Sigma Quality Improvement: What is Six Sigma and what are the Important implications?", In: Proceeding of the Fourth Annual International POMS Conference, Seville, Spain, August 27-September 1.

Simmerman, S. J., (1993), “Achieving Service Quality Improvements", Quality Progress, Vol. 26 No. 11, pp 47.

Simon, K., (2000), "DMAIC vs. DMADV”, iSixSigma, Available at: http://www. isixsigma.com/library/content/c001211a.asp.

Smith, K., (2003), "Six Sigma at Ford Revisited", Quality Digest, Vol. 23 No. 6, pp. 2832. 
Spanyi, A. and Wurtzel, M., (2003), "Six Sigma for the Rest of Us: It's possible to tailor this popular methodology to fit your organization's size and finances.", Quality Digest Magazine, Available at: http://www.qualitydigest.com/july03/articles 101_article.shtml.

Suh, N., (1990), The Principle of Design, Oxford University Press, New York, NY.

Swinney, Z., (2003), "1.5 Sigma Process Shift Explanation", iSixSigma, Available at: http://www.isixsigma.com/library/content/c010701a.asp

Tonner, C., (2003), "Six Sigma", iSixSigma, Available at: http://www.isixsigma. com/dictionary/Six_Sigma-85.htm.

Tsiotras, G. and Gotzamani, K., (1996), "ISO 9000 as an entry key to TQM: the case of Greek industry", International Journal of Quality and Reliability Management, Vol. 13 No. 4, pp. 64-76.

White, F. M. and Locke, E. A., (1981), "Perceived Determinants of High and Low Productivity in Three Occupational Groups: A Critical Incident Study", Journal of Management Studies, Vol. 18 No. 4, pp. 375-387.

Wortman, B. et al., (2001), The Certified Six Sigma Black Belt Primer - First Edition, Quality Council of Indiana, West Terre Haute, IN. 


\section{Appendices}

\section{Appendix I - Capability Indices}

(All the processes, procedures and information here is from Gryna, 2001)

There is an increase use of capability indexes. This has led to the failure to understand and verify some important assumptions that are required for statistical validity. There are five key assumptions for this:

1. Process Stability: Statistical validity requires a state of statistical control with no drift or oscillation.

2. Normality of the Characteristic being Measured: Normality is required in order to draw up statistical conclusions.

3. Sufficient Data: Enough data is needed to minimize the sampling error for the capability indexes.

4. Representativeness of Samples: These must be random samples.

5. Independence of Measurements: Consecutive measurements cannot be correlated.

When using $C p k$, we must recognize that $C p k$ is an abbreviation of two parameters - the average and the standard deviation. This means that if we want to increase the value of $C p k$, it may require a change in the process average, the process standard deviation or both. For certain processes, increasing the value of $C p k$ by changing the average value may be easier than doing so by reducing the standard deviation.

When implementing any new or old processes, there is usually an element of inspection accuracy. Inspection accuracy simply refers to the precision of the process 
being looked at. Inspection accuracy depends on: (1) the completeness of the inspection planning, (2) the bias and precision of the instruments and (3) the level of human error. When using any type of a measuring instrument, even when it is correctly used, it still may not give a true reading of a characteristic. Gryna states that there are generally five sources to this variation:

1. Bias: This is the difference between the observed value and the reference value.

2. Repeatability: This is the variation in measurements obtained with an instrument when used more than once by an inspector while measuring the identical characteristic on the same part.

3. Reproducibility: This is the variation apparent when different appraisers using the same equipment, measuring the identical characteristic on the same part.

4. Stability: This is the variation that is seen (or not) when appraisers use the same measurement system on the same part when measuring a single characteristic over a long time horizon.

5. Linearity: This is the difference in the bias values through the expected operating range. 


\section{Appendix II - Types of Tests on Theories Developed}

\begin{tabular}{|l|l|}
\hline TYPE OF TEST & DESCRIPTION \\
\hline Flow Diagram & $\begin{array}{l}\text { Helps in understanding the progression of steps in a } \\
\text { process. }\end{array}$ \\
\hline Process Capability Analysis & $\begin{array}{l}\text { Measurements from the process must be used and } \\
\text { analyzed to assess the amount of variability in the process. }\end{array}$ \\
\hline $\begin{array}{l}\text { Product and Process } \\
\text { Dissection }\end{array}$ & $\begin{array}{l}\text { Create measurements at intermediate steps in the process } \\
\text { in order to discover at which step the defect appears. } \\
\text { Discoveries made from this test can drastically reduce the } \\
\text { effort needed in testing theories. }\end{array}$ \\
\hline Stream to Stream Analysis & $\begin{array}{l}\text { The streams referred to here can take the form of different } \\
\text { machines, the machine operators, call centre operator } \\
\text { shifts, suppliers etc. This analysis requires the recording } \\
\text { and examination of data separately for each stream. }\end{array}$ \\
\hline Time to Time Analysis & $\begin{array}{l}\text { This includes a simple plot of data on a time scale, } \\
\text { analysis of the time between abnormalities or problems. }\end{array}$ \\
\hline Simultaneous Dissection & $\begin{array}{l}\text { The multivari chart is a tool for analyzing such a variation. } \\
\text { In this chart, a vertical line portrays the range of variation } \\
\text { within a single piece of product. }\end{array}$ \\
\hline $\begin{array}{l}\text { Defect Concentration } \\
\text { Analysis }\end{array}$ & $\begin{array}{l}\text { This is used for attributes types of defects. The purpose of } \\
\text { this is to see whether or not defects are within the same } \\
\text { physical area. }\end{array}$ \\
\hline Association Searches & $\begin{array}{l}\text { Using data to create some theory of causation, pinpointing } \\
\text { the process, piece of equipment, employee(s) or other } \\
\text { factor(s). The different relationships can be looked at by } \\
\text { using things like correlation and ranking. }\end{array}$ \\
\hline
\end{tabular}

(Gryna, 2001) 


\section{Appendix III - Types of Statistical Analysis in Six Sigma}

\begin{tabular}{|l|l|}
\hline SAMPLE STATISTICS & DISCUSSION \\
\hline Measures of Location: & \\
\hline Population Mean & The center of gravity or centroid of the distribution. \\
\hline Sample Mean & $\begin{array}{l}\text { The center of gravity or centroid of a sample from a } \\
\text { distribution. }\end{array}$ \\
\hline Median & $\begin{array}{l}\text { The } 50 \% / 50 \% \text { split point. Precisely half of the data set } \\
\text { will be above the median, and half below it. }\end{array}$ \\
\hline Mode & $\begin{array}{l}\text { The value that occurs most often. If the data are grouped, } \\
\text { the mode is the group with the highest frequency. }\end{array}$ \\
\hline Measures of Dispersion: & The distance between the sample extreme values. \\
\hline Range & $\begin{array}{l}\text { A measure of the variation around the mean; units are the } \\
\text { square of the units used for the original data. }\end{array}$ \\
\hline Population Variance & $\begin{array}{l}\text { A measure of the variation around the mean, in the same } \\
\text { units as the original data. }\end{array}$ \\
\hline $\begin{array}{l}\text { Population standard } \\
\text { deviation }\end{array}$ & $\begin{array}{l}\text { A measure of the variation around the mean; units are the } \\
\text { square of the units used for the original data. }\end{array}$ \\
\hline Sample Variance & $\begin{array}{l}\text { A measure of the variation around the mean, in the same } \\
\text { units as the original data. }\end{array}$ \\
\hline Sample Standard Deviation & $\begin{array}{l}\text { A measure of asymmetry. Zero indicates perfect } \\
\text { symmetry; the normal distribution has a skewness of zero. } \\
\text { Positive skewness indicates that the "tail" of the } \\
\text { distribution is more stretched on the side above the mean. } \\
\text { distribution is more stretched on the side below the mean. }\end{array}$ \\
\hline Measures of Shape: & $\begin{array}{l}\text { Kurtosis is a measure of flatness of the distribution. } \\
\text { Heavier tailed distributions have larger kurtosis measures. } \\
\text { The normal distribution has a kurtosis of 3. }\end{array}$ \\
\hline Skewness & \\
\hline
\end{tabular}

Table from Pzydek (2003) 


\section{Appendix IV - Types of Charts used in Six Sigma}

\begin{tabular}{|c|c|}
\hline TYPE & DESCRIPTION \\
\hline \multicolumn{2}{|l|}{ Variable Charts: } \\
\hline $\begin{array}{l}\text { Averages and ranges control } \\
\text { charts }\end{array}$ & $\begin{array}{l}\text { Used to evaluate the central tendency of a process over } \\
\text { time and to evaluate the dispersion of a process over time. }\end{array}$ \\
\hline $\begin{array}{l}\text { Averages and standard } \\
\text { deviation (sigma) control } \\
\text { charts }\end{array}$ & $\begin{array}{l}\text { Conceptually identical to averages and ranges control } \\
\text { charts. But the subgroup standard deviation is used to } \\
\text { measure dispersion. }\end{array}$ \\
\hline $\begin{array}{l}\text { Control charts for individual } \\
\text { measurements ( } \mathrm{X} \text { charts) }\end{array}$ & $\begin{array}{l}\text { Used to evaluate the central tendency of a process over } \\
\text { time. Used when it is not feasible to use averages for } \\
\text { process control. Often used to monitor batch process. }\end{array}$ \\
\hline \multicolumn{2}{|l|}{ Attribute Charts: } \\
\hline $\begin{array}{l}\text { Control charts for } \\
\text { proportion defective } \\
(p \text { charts })\end{array}$ & $\begin{array}{l}\text { Used to evaluate the proportion defective, or proportion } \\
\text { non-conforming, produced by the process. Can be applied } \\
\text { to any variable where the appropriate performance } \\
\text { measure is a unit count. }\end{array}$ \\
\hline $\begin{array}{l}\text { Control charts for count of } \\
\text { defectives ( } n p \text { charts) }\end{array}$ & $\begin{array}{l}\text { Used to evaluate the count of defectives, or count of items } \\
\text { non-conforming, produced by a process. Can be applied } \\
\text { to any variable where the appropriate performance } \\
\text { measure is a unit count and the subgroup size is held } \\
\text { constant. }\end{array}$ \\
\hline $\begin{array}{l}\text { Control charts for average } \\
\text { occurrences-per-unit } \\
(u \text { charts })\end{array}$ & $\begin{array}{l}\text { Used to evaluate the average number of occurrences-per- } \\
\text { unit produced by a process. Can be applied to any } \\
\text { variable where the appropriate performance measure is a } \\
\text { count of how often a particular event occurs. }\end{array}$ \\
\hline $\begin{array}{l}\text { Control charts for counts of } \\
\text { occurrences-per-unit } \\
(c \text { charts })\end{array}$ & $\begin{array}{l}\text { Used to evaluate the number of occurrences-per-unit } \\
\text { produced by a process. Can be applied to any variable } \\
\text { where the appropriate performance measure is a count of } \\
\text { how often a particular event occurs and samples of } \\
\text { constant size are used. }\end{array}$ \\
\hline
\end{tabular}

Information obtained from Pyzdek (2003) 
Appendix V - Questionnaire

Factors in the Successful Implementation of Six Sigma - Questionnaire

\section{Section I}

The first section of this questionnaire asks for characteristics about your organization and about yourself. Please answer them as best as you can.

1. Approximately how many employees are employed at your organization?

2. Approximately how many years has it been since your organization initiated Six Sigma?

3. In total, how many Black Belts $\boldsymbol{A N D}$ Master Black Belts are currently employed at your organization? (Please circle one)

0 to 10

11 to 20

21 to 30

31 to 40

41 to 50

More than 50

4. Which position do you currently hold in your organization with respect to Six Sigma? (Please circle one)

Green Belt

Black Belt

Master Black Belt

Sponsor/Champion

Other (Please Specify):

5. How many projects (from start to finish) have you been a part of when utilizing the Six Sigma methodologies? (Please circle one)

0 to 10

31 to 40
11 to 20

41 to 50
21 to 30

More than 50

6. Which methodologies do you often use for Six Sigma implementation at your organization? (Please check all that apply)
$\square$ DMAIC
DFSS/DMADV
口 Pareto Diagrams
$\square$ EVOP
DOE
Other

7. Which tools do you often use for Six Sigma implementation at your organization? (Please check all that apply)
[ Six Sigma Roadmap
Statistical Analysis
Control Charts
¿ Six Sigma Scorecard
Other: 
8. What other quality initiatives (other than Six Sigma) has your organization implemented or tried to implement in the past 10 years? (Please check all that apply)
[ ISO 9000
ISO 14000
$\square$ TQM
$\square$ Lean
QS 9000
$\square$ Other:

\section{Section II}

This section and its subsequent questions relate to your perceptions of your organization with respect to Six Sigma initiatives.

9. Please read the statements below and answer whether you strongly agree (7) or if you strongly disagree (1) with the statements.

\begin{tabular}{|l|l|l|l|l|l|l|l|}
\hline \multicolumn{2}{|l|}{ Str. Disagree } \\
\hline $\begin{array}{l}\text { My organization makes funding readily available for our Six Sigma } \\
\text { initiatives. }\end{array}$ & 1 & 2 & 3 & 4 & 5 & 6 & 7 \\
\hline $\begin{array}{l}\text { There is a large financial budget at my organization which is allocated } \\
\text { to Six Sigma deployment (i.e. for resources etc.). }\end{array}$ & 1 & 2 & 3 & 4 & 5 & 6 & 7 \\
\hline $\begin{array}{l}\text { My organization offers many rewards which are directly related to our } \\
\text { Six Sigma efforts. }\end{array}$ & 1 & 2 & 3 & 4 & 5 & 6 & 7 \\
\hline $\begin{array}{l}\text { Six Sigma initiatives get full recognition by the organization when a } \\
\text { project is completed. }\end{array}$ & 1 & 2 & 3 & 4 & 5 & 6 & 7 \\
\hline $\begin{array}{l}\text { Six Sigma is integrated into our business such as into our vision, into } \\
\text { the way we do things, into our strategy etc. }\end{array}$ & 1 & 2 & 3 & 4 & 5 & 6 & 7 \\
\hline $\begin{array}{l}\text { Six Sigma is evident throughout all of our departments / divisions all } \\
\text { through the organization. }\end{array}$ & 1 & 2 & 3 & 4 & 5 & 6 & 7 \\
\hline $\begin{array}{l}\text { According to the way that our organization is set up, our } \\
\text { organizational infrastructure really supports Six Sigma. }\end{array}$ & 1 & 2 & 3 & 4 & 5 & 6 & 7 \\
\hline $\begin{array}{l}\text { Within our Six Sigma initiatives, it can be easily seen that there exists } \\
\text { a hierarchy of the belt system, ie. Green Belts, Black Belts, Master } \\
\text { Black Belts etc. }\end{array}$ & 1 & 2 & 3 & 4 & 5 & 6 & 7 \\
\hline $\begin{array}{l}\text { Six Sigma is fully integrated into our HR department in that things that } \\
\text { HR does is related directly or indirectly to Six Sigma. }\end{array}$ & 1 & 2 & 3 & 4 & 5 & 6 & 7 \\
\hline $\begin{array}{l}\text { My organization's incentive systems, motivational initiatives and } \\
\text { hiring processes are optimized with Six Sigma in mind. }\end{array}$ & 2 & 3 & 4 & 5 & 6 & 7 \\
\hline
\end{tabular}




\begin{tabular}{|c|c|c|c|c|c|c|c|}
\hline & & Dise & & & & tir. $A$ & \\
\hline $\begin{array}{l}\text { Our suppliers are fully aware of Six Sigma and are trying to use, } \\
\text { thinking about using or are using it themselves. }\end{array}$ & 1 & 2 & 3 & 4 & 5 & 6 & 7 \\
\hline $\begin{array}{l}\text { Our Six Sigma efforts are coordinated with that of our suppliers to get } \\
\text { the full benefit of Six Sigma in our organization. }\end{array}$ & 1 & 2 & 3 & 4 & 5 & 6 & 7 \\
\hline Our Six Sigma initiatives always start and end with our customers. & 1 & 2 & 3 & 4 & 5 & 6 & 7 \\
\hline $\begin{array}{l}\text { We constantly get feedback from customers and we tailor our Six } \\
\text { Sigma efforts to address the customers' concerns. }\end{array}$ & 1 & 2 & 3 & 4 & 5 & 6 & 7 \\
\hline $\begin{array}{l}\text { There is a lot of upper management involvement \& commitment for } \\
\text { the Six Sigma initiatives at my organization. }\end{array}$ & 1 & 2 & 3 & 4 & 5 & 6 & 7 \\
\hline $\begin{array}{l}\text { Upper management at my organization is knowledgeable in Six Sigma } \\
\text { tools and techniques, and they follow it closely. }\end{array}$ & 1 & 2 & 3 & 4 & 5 & 6 & 7 \\
\hline $\begin{array}{l}\text { In general, the corporate culture in our organization supports using Six } \\
\text { Sigma. }\end{array}$ & 1 & 2 & 3 & 4 & 5 & 6 & 7 \\
\hline $\begin{array}{l}\text { Our organizational environment such as people's perception and } \\
\text { attitudes are in full support of Six Sigma. }\end{array}$ & 1 & 2 & 3 & 4 & 5 & 6 & 7 \\
\hline $\begin{array}{l}\text { There is a lot of communication with respect to Six Sigma in our } \\
\text { organization as to how we are doing. Both successes and failures are } \\
\text { well communicated to employees. }\end{array}$ & 1 & 2 & 3 & 4 & 5 & 6 & 7 \\
\hline $\begin{array}{l}\text { Management always talks about how our Six Sigma initiatives are } \\
\text { progressing. }\end{array}$ & 1 & 2 & 3 & 4 & 5 & 6 & 7 \\
\hline $\begin{array}{l}\text { Our organization uses goal setting in initiating Six Sigma projects in } \\
\text { that goals are set ahead of time for us to achieve. }\end{array}$ & 1 & 2 & 3 & 4 & 5 & 6 & 7 \\
\hline $\begin{array}{l}\text { The goals that are set before projects are initiated for Six Sigma are } \\
\text { often met when our projects are completed. }\end{array}$ & 1 & 2 & 3 & 4 & 5 & 6 & 7 \\
\hline $\begin{array}{l}\text { There are many hours of training that are involved before an employee } \\
\text { can start on any Six Sigma effort. }\end{array}$ & 1 & 2 & 3 & 4 & 5 & 6 & 7 \\
\hline $\begin{array}{l}\text { The amount invested in training for Six Sigma is very large as } \\
\text { compared to other business units within our organization. }\end{array}$ & 1 & 2 & 3 & 4 & 5 & 6 & 7 \\
\hline $\begin{array}{l}\text { My organization ensures that we use proper project management skills } \\
\text { as a part of our Six Sigma efforts. }\end{array}$ & 1 & 2 & 3 & 4 & 5 & 6 & 7 \\
\hline $\begin{array}{l}\text { Black Belts and Master Black Belts of my organization have extensive } \\
\text { experience in managing projects. }\end{array}$ & 1 & 2 & 3 & 4 & 5 & 6 & 7 \\
\hline
\end{tabular}




\begin{tabular}{|l|l|l|l|l|l|l|l|}
\hline & \multicolumn{3}{|l|}{ Str. Disagree } \\
\hline $\begin{array}{l}\text { My organization believes that being able to prioritize, select, review } \\
\text { and track projects is very important for using Six Sigma. }\end{array}$ & 1 & 2 & 3 & 4 & 5 & 6 & 7 \\
\hline $\begin{array}{l}\text { The projects that we select usually are those that we know will be } \\
\text { successful when completed. }\end{array}$ & 1 & 2 & 3 & 4 & 5 & 6 & 7 \\
\hline $\begin{array}{l}\text { We fully understand the Six Sigma methodology, tools and techniques } \\
\text { that are used in our processes. }\end{array}$ & 1 & 2 & 3 & 4 & 5 & 6 & 7 \\
\hline $\begin{array}{l}\text { We always use the DMAIC (Define, Measure, Analyze, Improve, } \\
\text { Control) or DFSS (Design for Six Sigma) methodologies for all of our } \\
\text { Six Sigma efforts. }\end{array}$ & 1 & 2 & 3 & 4 & 5 & 6 & 7 \\
\hline $\begin{array}{l}\text { In the Six Sigma efforts that we are involved in, we use Statistical } \\
\text { techniques to analyze data. }\end{array}$ & 1 & 2 & 3 & 4 & 5 & 6 & 7 \\
\hline $\begin{array}{l}\text { We are deeply knowledgeable in the statistical techniques required for } \\
\text { our Six Sigma efforts. }\end{array}$ & 1 & 2 & 3 & 4 & 5 & 6 & 7 \\
\hline
\end{tabular}

\section{Section III}

The following questions relate to the results that you have seen as a consequence of Six Sigma initiatives at your organization.

10. Answer whether you strongly agree (7) or if you strongly disagree (1) with the Statements, where a response of four (4) represents that you have not seen any changes.

\begin{tabular}{|c|c|c|c|c|c|c|c|}
\hline & & gree & & $\begin{array}{l}\text { Staye } \\
\text { Same }\end{array}$ & & & ree \\
\hline $\begin{array}{l}\text { The overall costs related to our Six Sigma initiatives have improved. } \\
\text { Overall costs related to processes from pre to post Six Sigma } \\
\text { implementation have decreased. }\end{array}$ & 1 & 2 & 3 & 4 & 5 & 6 & 7 \\
\hline $\begin{array}{l}\text { After we have implemented Six Sigma to certain processes within our } \\
\text { organization, profits related to these processes have improved. }\end{array}$ & 1 & 2 & 3 & 4 & 5 & 6 & 7 \\
\hline $\begin{array}{l}\text { Defects per million opportunities (DPMO) have been lowered because } \\
\text { of our Six Sigma initiatives. }\end{array}$ & 1 & 2 & 3 & 4 & 5 & 6 & 7 \\
\hline $\begin{array}{l}\text { Our "sigma levels" are closer to Six Sigma quality since we have } \\
\text { started to use the Six Sigma methodologies. }\end{array}$ & 1 & 2 & 3 & 4 & 5 & 6 & 7 \\
\hline Overall, customer satisfaction levels have improved due to Six Sigma. & 1 & 2 & 3 & 4 & 5 & 6 & 7 \\
\hline $\begin{array}{l}\text { Overall, the number of customer complaints has decreased due to Six } \\
\text { Sigma. }\end{array}$ & 1 & 2 & 3 & 4 & 5 & 6 & 7 \\
\hline
\end{tabular}




\begin{tabular}{|l|l|l|l|l|l|l|l|}
\hline & \multicolumn{3}{|c|}{ Disagree } & \multicolumn{3}{|c|}{ Stayed } \\
\hline $\begin{array}{l}\text { Our internal work processes (productivity) related to Six Sigma } \\
\text { projects have improved due to Six Sigma. }\end{array}$ & 1 & 2 & 3 & 4 & 5 & 6 & 7 \\
\hline $\begin{array}{l}\text { Overall, we have seen less employee turnover after Six Sigma had } \\
\text { been implemented. }\end{array}$ & 1 & 2 & 3 & 4 & 5 & 6 & 7 \\
\hline $\begin{array}{l}\text { Our suppliers' order fulfillment accuracy has improved because of our } \\
\text { Six Sigma efforts. }\end{array}$ & 1 & 2 & 3 & 4 & 5 & 6 & 7 \\
\hline $\begin{array}{l}\text { Due to Six Sigma, the number of complaints our organization has } \\
\text { about our suppliers have decreased. }\end{array}$ & 1 & 2 & 3 & 4 & 5 & 6 & 7 \\
\hline
\end{tabular}

\section{$\underline{\text { Section IV }}$}

This section relates to what you believe are the most important aspects in a Six Sigma initiative to ensure that it is successful.

11. Please select the factors that you consider are the three (3) MOST important ones for implementing Six Sigma with an "X".

\begin{tabular}{|l|l|}
\hline & Financial Support \\
\hline & Rewards \\
\hline & Integrating Six Sigma to Business \\
\hline & Organizational Infrastructure \\
\hline & Integrating Six Sigma to Human Resources \\
\hline & Integrating Six Sigma to Suppliers \\
\hline & Linking Six Sigma to the Customer \\
\hline & Managerial Involvement and Commitment \\
\hline & Corporate Culture \\
\hline & Communication \\
\hline & Goal Setting \\
\hline & Training \\
\hline & Project Management Skills \\
\hline & Project Prioritization, Selection, Review \& Tracking \\
\hline & Understanding Six Sigma Methodology, Tools \& Techniques \\
\hline & Use of Statistical Tools \\
\hline
\end{tabular}


12. Please select the factors that you consider are the three (3) $L E A S T$ important ones for implementing Six Sigma with an "X".

\begin{tabular}{|l|l|}
\hline & Financial Support \\
\hline & Rewards \\
\hline & Integrating Six Sigma to Business \\
\hline & Organizational Infrastructure \\
\hline & Integrating Six Sigma to Human Resources \\
\hline & Integrating Six Sigma to Suppliers \\
\hline & Linking Six Sigma to the Customer \\
\hline & Managerial Involvement and Commitment \\
\hline & Corporate Culture \\
\hline & Communication \\
\hline & Goal Setting \\
\hline & Training \\
\hline & Project Management Skills \\
\hline & Project Prioritization, Selection, Review \& Tracking \\
\hline & Understanding Six Sigma Methodology, Tools \& Techniques \\
\hline & Use of Statistical Tools \\
\hline
\end{tabular}

13. In the space below, you can make any suggestions or comments regarding this questionnaire or the study itself.

\section{THANK YOU KINDLY FOR YOUR TIME AND EFFORTS IN COMPLETING THIS QUESTIONNAIRE. YOUR HELP AND COOPERATION IS VERY MUCH APPRECIATED.}




\section{Appendix VI - Cover Letter}

\section{COVER LETTER}

Date

Principal Researcher: David Tran, MBA Student, Eric Sprott School of Business, Carleton University

Phone: $416-423-7934$

Email:

Supervisor: Vinod Kumar

Phone: 613-520-2379

Email: vinod_kumar@carleton.ca

Title of research project: Factors in the Successful Implementation of Six Sigma

Dear Sir or Madame,

I am conducting research on the implementation of Six Sigma by Canadian manufacturing organizations as part of my MBA studies at Carleton University in Ottawa. The study will help organizations in quality intensive industries better understand what makes Six Sigma successful. This study will help organizations better understand what makes Six Sigma a successful quality management methodology and will provide for further studies into Six Sigma methodologies in the future.

Successful implementation of Six Sigma is measured in terms of Financial Performance, Defects per Million Opportunities, Customer Satisfaction, Performance of Internal Work Processes and Suppliers' Performance, all of which will be examined in this study.

In order to help me with this research I am kindly asking you to complete the enclosed questionnaire by answering the questions to the best of your knowledge. It will take approximately 20 minutes to complete. You are requested to return the questionnaire in the self-addressed and stamped envelop provided in this package. I would appreciate the return of the questionnaire before May $13^{\text {th }}, 2005$.

There are no foreseen risks to you or your company for participating in this research. The questionnaire is anonymous. I am not asking you to identify yourself or your company. You will not be identified in the final report and all results of the research will appear in aggregate form. 
Your participation is voluntary. You are not obligated to answer questions that make you uncomfortable and you are free to contact me or my supervisor with any questions about the project.

Only I will have access to the raw data. The data will be kept in a locked filing cabinet in my home office. At the end of the study the data will be destroyed by August $30^{\text {th }}, 2005$.

This project has been approved by the Carleton University Research Ethics Committee. If you have concerns or questions about the ethical content or conduct pertaining to this project you may contact the committee chair.

Prof. Antonio Gualtieri, Chair,

Carleton University Research Ethics Committee

Office of Research Services

Carleton University

1125 Colonel By Drive

Ottawa, Ontario K1S 5B6

Phone: $613-520-2517$ fax: 613-520-2521

email: ethics@carleton.ca

Thank you for your time and effort in this project; it is greatly appreciated.

Sincerely,

David Tran 